

\section{REPRODUCED FAOM \\ BEST: $\cdots \cdots \cdots \cdot \cdots$}

NOTICE

This report was prepared as an account of work sponsored by the United States Government. Neither the United States nor the United States Department of Energy, nor any of their employees, nor any of their contractors, subcontractors, or their employees, makes any warranty, express or implied, or assumer any legal liablitity or respongibility for the accuracy, completeness or usefulress of any information, apparatus, product or process disclosed, or represents that its use would not intringe privately owned rights.

Printed in the Unlted States of America

Avallable from:

National Technical Information Service

U.S. Dopartuent of Comerce 5285 Port Royal Road

Springteld, Virginia 22161

Price Pxinted Copy $\$ \ldots \ldots$; Microfiche $\$ 4.50$

\begin{tabular}{lr} 
tPages & selling \\
\cline { 2 - 2 } $1-25$ & $\$ 7.00$ \\
$25-50$ & $\$ 8.50$ \\
$51-75$ & $\$ 10.00$ \\
$76-100$ & $\$ 11.50$ \\
$101-125$ & $\$ 13.00$ \\
$126-150$ & $\$ 14.50$ \\
$151-175$ & $\$ 16.00$ \\
$176-200$ & $\$ 17.50$ \\
$201-225$ & $\$ 19.00$ \\
$226-250$ & $\$ 20.50$ \\
$251-275$ & $\$ 22.00$ \\
$276-300$ & $\$ 23.50$ \\
$301-325$ & $\$ 25.00$ \\
$326-350$ & $\$ 26.50$ \\
$351-375$ & $\$ 28.00$ \\
$376-400$ & $\$ 29.50$ \\
$401-425$ & $\$ 31.00$ \\
$426-450$ & $\$ 32.50$ \\
$451=475$ & $\$ 34.00$ \\
$476-500$ & $\$ 35.50$ \\
$500-525$ & $\$ 37.00$ \\
$526-550$ & $\$ 38.50$ \\
$551-575$ & $\$ 40.00$ \\
$567-600$ & $\$ 41.50$
\end{tabular}

For documents over 600

pages, add $\$ 1.50$ for each additional 25-page increnent. 
PPPL- -2496

DE88 009356

\title{
Safety Assessment Document (SAD) \\ for the \\ Princeton Beta Experiment Modification \\ (PBX-M)
}

\author{
Princeton Plasma Physics Laboratory \\ Princeton, NJ 08544
}

J.R. Stencel

R.F. Parsells

(Editors) 


\section{SAEETY ASSESSMENT DOCUMENT}

\section{PRINCETON BETA EYPERIMENT \\ MODIFICATION}

PBX.M

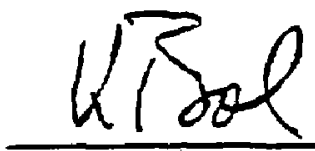

K. BOL, Manager

Experimental Projects

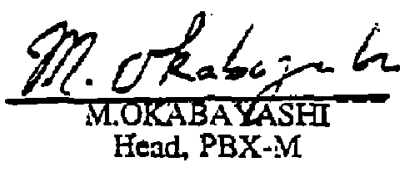

APPROVALS

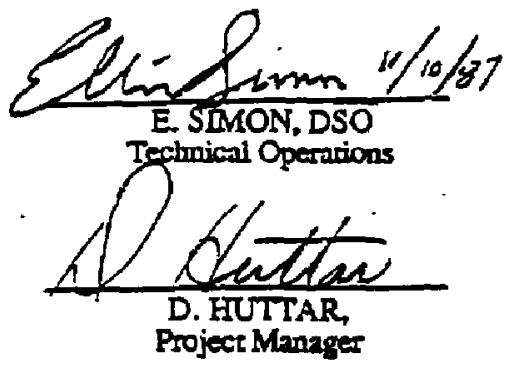

D. FUTTAR,

Project Manager

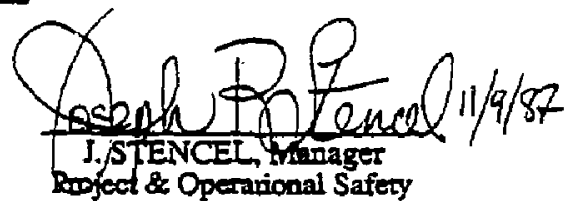
Roject \& Operavional Safery

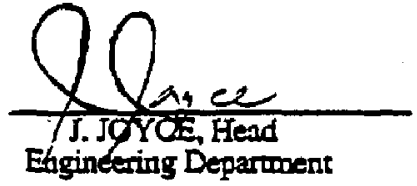

ISSUE DATE: NOVEMBER 1987 Revision 0 
1.1 Introduction

1.2 Scope of Modifleation

1.3 Goals and objectives

1.4 Participants

1.5 Sumary of Signiflcant Items

2.0 SUYARY SAFETY AHALYSIS

2. 1 Hazards 5

2.2 Fire Safety 7

2.3 Property Damage 8

2.4 Explosion and High Pressure Safety 8

2.5 Natural Phenomena 9

2.5.1 Earthquake 9

2.5.2 Tornadoes, Extreme Hind 9

2.5.3 Floods

2.6 Noise 9

$3.0 \mathrm{SITE} \quad 9$

4.0 FACILITY AND PROCESS DESCRIPTION 11

4.1 Experimental Area 11

4.2 Power Suppiles 16

4.2.1 PBX-M Electrical Power System 16

4.2.2 AC Power Distribution 24

4.3 PBX-M Device 27

4.3.1 Coll System.

$\begin{array}{lll}4.3 .2 & \text { Vacuum Systen } & 3.4\end{array}$

4.3.3 Vacuum Pumping Systen $\quad 3.4$

4.4 PBX-H Operating Controls

4.4.1 Control System Architecture 35

4.4.2 Hardwired Personnel Safety System 39

4.4.3 Remote Control and Monitoring of Power Supplies 42

4.4.4 Machire Protection Functions 48

4.4.5 Fallure Mode and Effect Analysis 50

4.5 Radiation 50

4.5.1 Ionizing Radiation 50

4.5.2 Non-Ionizing Radiation 51

4.6 Eire Protection \& Emergency Services 52

4.6.1 Fire Protection System 52

4.6.2 Fire Fighting Personnel \& Equipment 53 
5.1 High Consequence Accidents to Equipment 54

5.2 Failure Mode and Effects Analysis 58

5.3 Table, Vacuum Vessel Assembly Failure Modes and
Effects Analysis

5.4 Table, Neutral Beam Injection System Failure Modes
and Efrects Analysis

5.5 Table, Vacuum Pumping Systems Failure Modes and
Effects Analysis

5.6 Table, Nitrogen Supply System Failure Modes and

5.7 Table, Poloidal Field Coll and Neutral Beam Power

5.8 Tabie, Auxiliary System Power Distribution Failure
Modes and Effects Analys is

5.9 Table, Toroidal Field Pulsed Energy Conversion System (MG
Sets) Failure Modes and Effects Analysis

5.10 Table, Ohmic Heating Pulsed Energy Conversion System
Failure Modes and Effects Analysis

5.11 Table, Equilibrium Field Pulsed Energy Conversion System
Failure Modes and Effects Analysis

5.12 Table, NBPSS Faflure Modes and Effects Analysis 81

5.13 Table, Diesel Generator System Failure Modes and

5.14 PBX-M Control System Protective Functions 85

$\begin{array}{ll}6.0 \text { QUNLITY ASSURANE } & 87\end{array}$

$\begin{array}{ll}7.0 \text { conduct of OPERatious } & 87\end{array}$

8.0 acrionlemegris 89



$\begin{array}{ll}10.0 \text { APPEDIX A } & 92\end{array}$

PBX Modification Plan of Conformance

$\begin{array}{ll}11.0 \text { APPaDIX B } & 105\end{array}$

PBX-M Design Review Procedure

\subsection{Appendix $c$}

Coil Manufacturing Procedures 
13.0 APPEIDIX D

Review Committee Assessment and Project Besponse 


\subsection{INTRODUCTION AND GENERAL DESCRIPTION (K.BOL)}

\subsection{Introduction}

The Princeton Beta Experiment-Modification (PBX-M) is an experimental device of the tokamak type. A tokamak is characterized by a strong toroidal magnetic field composed of an externally driven conponent parallel to the torus centerline modified by the field produced by a transformer-driven current $(\mathrm{OH})$ in the confined plasma. A second magnetic field parallel to the major toroidal axis is added to provide radial equilibrium for the plasma. As an advanced tokamak, PBX-M will have additional magnetic fields to reshape the plasma cross section from a cirele into a kidney bean shape; it w1ll also be equipped with 6M or more of auxiliary heating power provided by four neutral beam injectors, with RE systems, and with an extensive set of diagnostics. Potential hazards assoclated with PBX-M, which are analyzed in this report, result from energy stored in the magnetic fields, high voltages necessary for the operation of some of the equipment and diagnostics, neutron radiation when the neutral beams are run with deuterium and $\mathrm{x}$-rays, especially those emitted as a result of plasma-wall interaction. This report satisfles the requirements set forth in the PPPL Health and Safety Directives, specifically HSD-5003, and in DOE Order 5481.1B and its Chicago operations supplement (DOE86, DOEB2).

\subsection{Scope of Modification}

PBX-M is a modification of PBX, which in turn was a modification of the Pololdal Divertor Experiment (PDX). A Safety Assessment Document for PBX was issued February 9, 1984. The PDX to PBX rodification, in terms of device operation, involved minimal changes. Controls, interlocks, power supplies, radiation and electrical hazards all remained the same.

The current modification is much more extengive. It entails a totally new control system, the addition of six new power supplies, a new polarity-reversing panel, five new coils inside the vacuum vessel, extensive new bus work both inside and outside the vacuum vessel, and considerable revision of the personnel-protective interlock system. However, much remains the same. The basic machine and the Toroidal Field (TF) and Omic Heating (OH) coil systems are unchanged. For the Equilibrlue Field (EF) only a minor relocation of a coll pair was made plus the addition of a set of existing coils (CF-10). The TF and EF power sources are untouched; but the operating wode of the Otmic Heating Supply (OHS) will be somewhat changed. These three are the highest power system; the biggest new supply, the Indentation Field Supply (IFS), has about $20 \%$ the MVA rating of the smallest of the old, the $E F$. 
Two other machine changes have a major impact on the physics but virtually none on the safety aspect. These are (1) an increase in plasma major radius from 145 to $165 \mathrm{~cm}$, and (2) the addition of a set of aluminum plates shaped to form a conducting shell that hugs the plasma over most of its surface. Inspection of Figure 1-1 indicates the changes from PBX to PBX-M.

\subsection{Goals and Objectives}

The :Iltimate goal of the PBX/PBX-M progran is to achieve by the use of highly shaped plasmas much higher values of beta, the ratio of plasma to magnetic fleld pressure, than are achlevable in standard tokamaks. The PBX-M design is a refinement of PBX; it will rely on the conducting shell to stabllize the mode which was found to be most limiting of beta in PBX. The larger major radius of PBX-M allows for a more deeply indented plasma and provides room for divertor chambers near the bean lobes. The additional power supplies and highly articulated coil system will allow the degree of control over the plasma shape that the close fitting conducting shell necessitates. The initial objectives of the PBX-M program will be the verification of these desig' goals.

1.4 Participants in PBX-M Design, Construction, and Operation

The primary participants in the design, development, construction, installation, and operation of PBX-M are the U.S. Department of Energy (DOE) and the Plasma Physics Laboratory of Princeton University (PPPL).

a. DOE within its office of Fusion Energy has the responsibility for the development of the fusion power program.

b. PPPL has the responsibflity for overall planning, scoping, and monitoring within the guidelines provided by DOE Directives. Ultimate responsibility for the operation rests with PPPL. This includes the operational and environmental health and safety of the operating personnel and the general public. The relationship of PPPL (Princeton University) and DOE is governed by U.S. DOE Contract DE-ACO2-76-CHO-3073.

\subsection{Sumary of Signifleant Items}

Design, developwent, manufacture, fabrication, construction, installation, tests, operation, maintenance, and subsequent modifications are and will be accomplished in accurdance with safety provisions of the DOE Environwental Safety and Health (ES\&H) Orders and the generally applicable environmental guidelines of the Environmental Protection Agency (EPA). In particular, the applicable criteria for routine and accidental occupational exposure to radiation are in accord with DOE 5480.1A, Chapter XI (DOEB1) requirements. Applicable sections of the DOE orders have been interpreted and established as design requirements on detailed site-related characteristics. Buildings, facilities, and systems have been designed and buflt to assure safe operation. 


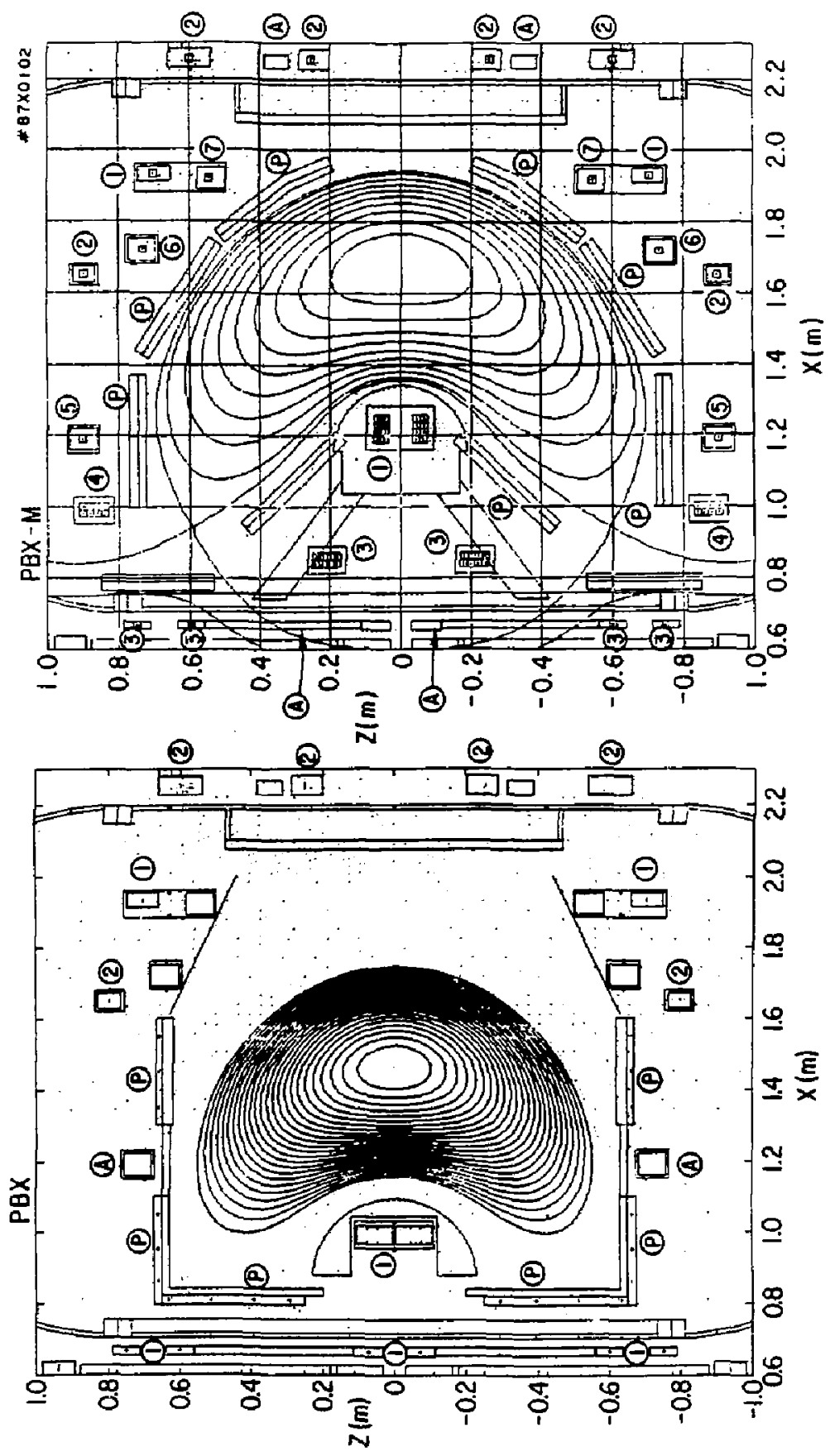

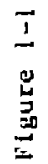


A summary tabulation of the principal hazards evaluated and the safety provisions incorporated is presented in Table $1-1$.

$$
\text { Table 1-i }
$$

HAZARD EVALUATION AND DESIGN PROVISIONS

\section{Consideration}

Hydrogen

High Voltage

Radiation

Coils and

Mechanical Equipment

Fire Enclosure

Power Supplies

\section{Provision}

Installation per established safety codes.

Air $/ \mathrm{H}_{2}$ mixture concentrations safe for afl failure modes.

Interlocks, locks, fences, ground provisions, insillation, marking, controls.

All interlocks identified in operations procedure and verifled prior to facility operation, tested periodically.

$x$-rays and neutrons are potential radiation problems; safety office issues authorization for safe operation. Health Physics monitors, surveys, and issues radiation work permits as needed.

Continued monitoring as experiment progresses.

Design margins adequate for stress and deflections. Detailed calculations performed.

Device is within a bullding protected by automatic halon system.

Building materials and construction are in accordance with fire codes.

Installed per fire protection codes and N.E.C. 


\subsection{SUMARY SAFETY ANALYSIS (J.R. Stencel)}

\subsection{Hazards}

The operation of this experiment will not generate effluents of any kind which wight contribute to the pollution of air or water. Any hazards that accidents cause are localized, contained, and controlled within the confines of the protective envelope that surrounds the PBX-M device and Its electrical connections to external power sources.

Specific hazards analyzed were:

A. Materials

1. Toxic or carcinogenic materials are not, in general, employed in this operation. PCBs are still present in some capacitors and transformers.

2. Fire and explosion hazards

Hydrogen/deuterium is used to fuel the tokamak, a palladium leak serves to purify the gas. The flow into the machine is limited to about 200 torr-liter/second by piezo electric valves which is about $1 / 4$ liter per second at S.T.P. In practice this rate is never maintained for more than a second.

Everything evacuated from the vacuum vessel by pump is exhausted outside the building. The gas itself is comercial grade and is delivered in 5000 liter S.T.P. bottles at 1750 psi pressure. Since the test cell volume is over 350,000 cu. ft., release of a full bottle would result in an average volune concentration of $0.05 \%$, far below the lower explosive mixture limit of $4 \%$ (assuming full nixing).

B. Electrical Hazards

Large power supplies dominate the operation of the device. Their installation and interlock protection meets all PPPL requirewents of HSD 5008, section 2 (HSD2a, HSD2b).

c. Mechanical Hazards

Full use of a finite element code to analyze the PBX-M vacuum vessel for mechanical stress and to support the design of new coil supports guarantees safe operation under even the worst case electrcanechan cal and gravitational loads. 
Rotating equipment and heavy objects are potential sources of mechanical hazards to personnel.

1. Vacuum pumps - Conventional mechanical vacuum pumps and turbomolecular yacuum pumps are used.

2. Heavy Objects - The risks associated with handling heavy objects will be minimized by following the procedures outlined in the PPPL HSD 5008, Health and Safety Manual (Section 9.8). The Laboratory has a Lift Committee to review other than ordinary lifts.

3. Pressurized Systems - Pressurizec: systems which present hazards due to the possible creation of projectiles are the following: air receivers, the gas delivery system, and the fire protection systems (Halon 1301).

These systems have been installed as standard acceptable risk systems. The probability of failure is considered to be low and acceptable.

4. Miscellaneous - Portable and non-portable power-driven tools such as electric drills and band saws, will be sources of hazard to personnel because of the possibility of improper use of defective equipment.

D. Radiation Hazards

1. Ionizing

Radiation from PBX-M is expected to be limited to $X$ radiation (bremsstrahlung) and neutrons, with minimal activation. Monitoring for radiation levels will take a conservative approach as is customary at the start-up of all new devices at PPPL. Thermoimminescent dosimeters (TLD) will be placed on the vessel and the surrounding area to indicate potential exposure dose levels and patterns. Real time high sensitivity monitors are in place in areas requiring occupancy during initial operations. When new operating parameters are introduced, appropriate surrounding occupied areas will be evacuated until adequate radiation data are collected.

Authorization for operation of new operating parameters of PBX-M will not be granted until Health Physics certifies that there is no radiation hazard. 


\section{Non-Ionizing}

The PBX-M will use some lasers for diagnostics. These devices are regulated by HSD 5008, Section 3 (HSD3). Personnel operating these lasers come under the medical surveillance articles of HSD 5008, which follows ANSI 2136,1-1986 (ANSI 86). Because these lasers are interlocked during operations, the potential hazards are related to individuals involved in standard alignment and calibration procedures. These individuals according to Laboratory policy must be knowledgeable in the use of lasers, and, where deemed appropriate, they will take part in laser training programs.

\subsection{Fire Safety}

A. Combustible Materials

The Hazards Analysis of the PBX-M Project identified the following combustible waterials.

1. Hydrogen

This gas, needed to fuel the discharge, is only used in leak-tight, metal systems.

2. Plastic conduits

Plastic conduit is used in limited amounts where electrical noise reduction is required. Plastic condult is installed in open areas to increase the probability that any fire would be detected quickly by the fire detection system.

3. Insulating oil

There are no oil-filled capacitors in the machine area, but capacitor banks are used in connection with the $O H$ system, scone RF systems which w1ll be attached to PBX-M, and with. both the diagnostic neutral beam and the heating beams. These have all been in existence for at least seven years (some for weh longer) and were constructed in accordance with the best practice of the time. It is laboratory policy in accordance with. EPA policy to replace obsolete banks with PCB-free material but to allow continued use of existing PCB type capacitors. There is a total of five gallons of oil in the MG filter capacitors which are located in an enclosure in the $\mathrm{MG}$ area. A metal strip was installed around the perimeter of the enclosure to contain any oll that spills, and a swoke detector that is tied into the PPPL fire alarm system was. also installed. 
4. Hood

Fire retardant treated wood covered with a fire retarda: $t$ paint and fire retardant treated masonite is the principal construction material of the platform. There is adequate fire protection in this area.

5. Other Materials

The most signiflcant quantities of combustible materials are the insulation on cables and bus bars.

6. Contributory Causes

The Accident Analysis Identified the contributory causes for starting fire to be primarily electrical faults. Historically the most dangerous fault is failure of a high current bus joint, with consequent formation of an are and ignition of fires by blobs of molten metal as well as by the are itself of nearby insulation. Regular checking of all high current joints, especially where aluminum is used, is the only preventive.

B. Fire Detection Systems

The control room and experimental areas both have ionization smoke detection. In additior, the experimental area has flame detection.

C. Fire Suppression Systems

Both the control room and the experimental area are protected by a Halon 1301 total flooding system.

\subsection{Property Damage}

Fire damage is the principal property damage risk. Fire alarm boxes and annunciator alarms are connected through the fire alarm system to the fire and security offices, which are manned at all times. A trained Emergency Services Unit (ESU) will respond to alarms with backup support provided by Plainsboro Township.

\subsection{Explosion and High Pressure Safety}

A. Capacitor Explosion - Indoor capacitor banks are surrounded by expanded metal mesh or by solid walls to help contain any explosion. Circult protection is installed to prevent excessive energy dissipation inside a capacitor thereby reducing the probability of a violent event.

B. High Pressure Airline. - A compressed airline enters the area. Pipes are conservatively designed and installation recessed to minimize damaging effects. A protective device cuts off the air on sudden drop in pressure. 
c. High Pressure Waterline. - Cooling water is part of the area facilities, Conservative design and sudden pressure drop protection minimizes the damage.

D. Pressurized Gas Bottles. - Working gases for PBX-M experiments are contained in standard pressurized gas cylinders. Explosion hazard is minimized by the conservative design of the bottles, by secure anchoring of the bottles, and by keeping the absolute minimum of bottles in the area.

\subsection{Natural Phenomena}

\subsubsection{Earthquakes}

The area is in a low probability earthquake region. All equipment is designed to "most probable" earthquake standards.

\subsubsection{Tornados, Extreme Wind}

The building was built over 20 years ago. No adverse effect was evident during the most violent winds during this period.

\subsubsection{Floods}

The area is not in a floodplain and there have not been any floods in its 20 years existence.

\subsection{Noise}

There are no significant nolse sources associated with the PBX-M - device or its equipment.

\subsection{SITE}

\section{Location}

The experimental area for the PBX-M is the high bay area in the CS Building (Fig. 3-1), C-Site James Forrestal Campus, of the Princeton University Plasma Physles Laboratory. 


\section{CED SITES}

D STE

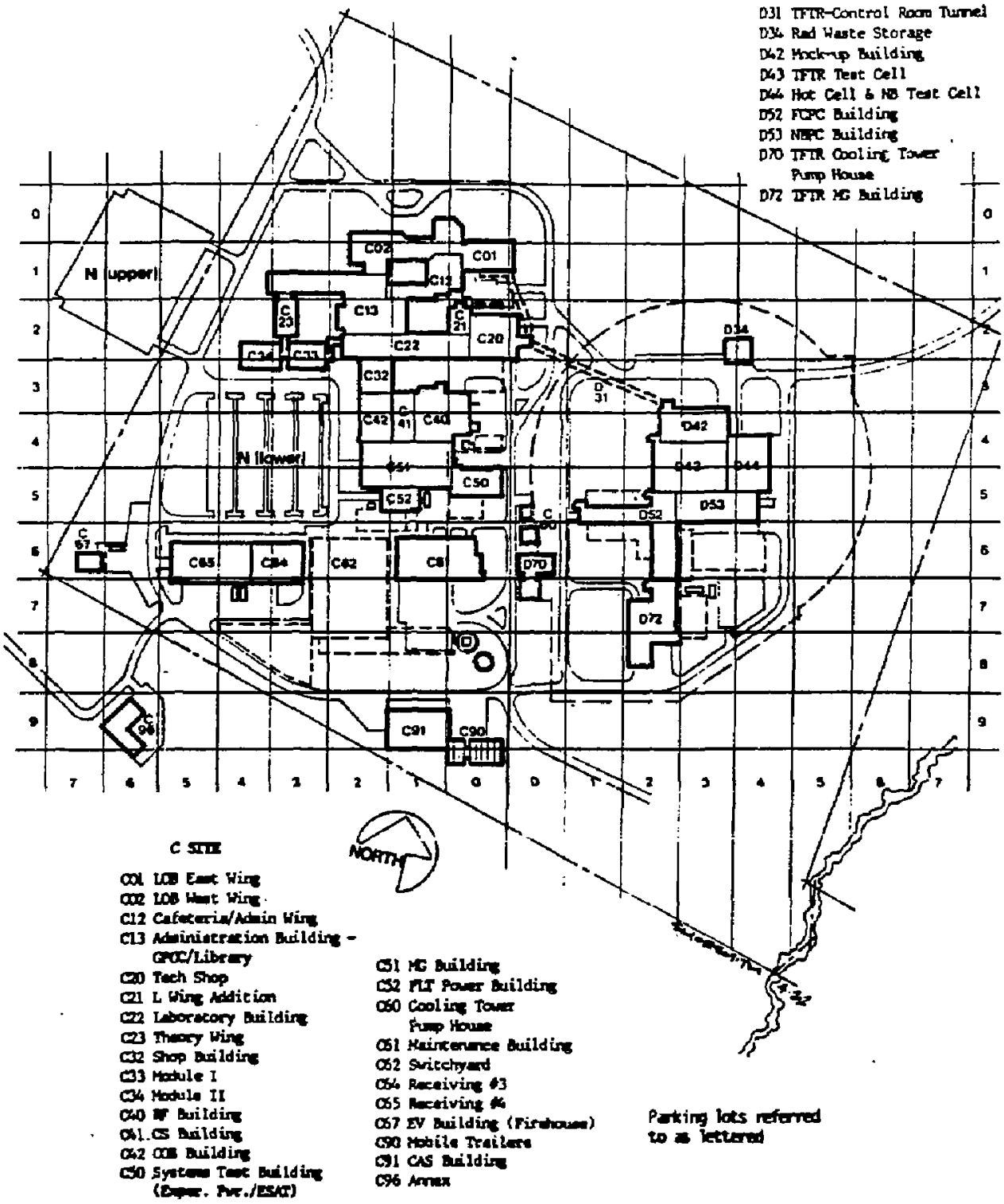

Figure 3-1 


\subsection{EACILITY AND PROCESS DESCRIPTION}

\section{1 Experimental Area (S. Hand)}

PBX-M experimental area is located in the northwest corner of the CStellarator (CS) building (Figures 4,1-1 and 4,i-2). It consists of three adjacent but separate areas: the machine area, two control rooms, and two general purpose rooms.

The machine area is defined by a 32 " thick radiation shielding wall extending approxtmately $75^{\prime}$ from columns $2 K$ to $3 K$ and from this colum line, for approximately 52' toward the south. The wall extends from the first floor (elevation 98'-6") to elevation 121'-0" (Figures 4.1-3 and 4.1-4). Access to the machine is at two levels: the first floor and the platform (elevation 104"-6"). The machine supports are at the first floor level as well as the 16" deionized cooling water mins, power buses, T.F. coil hydraulic system, safety breaks and various ancillary components. The main access to the machine is at the platform level, where most of the diagnostics are located. A third level, the balcony, is at elevation $117^{\prime}-43 / 4^{\prime \prime}$ and extends frow the north, west, and south radiation walls approximately 5'. More diagnostic components are located on this level. The mac..ine area at the platform level is accessible to the 5 ton and 30 ton rail cranes. In addition to the high current DC power, there is $110 / 220 / 480$ VAC power avallable in the machine area.

The main operation-control room is located adjacent to the west radiation wall and extends westward 30 feet. It extends approx 1mately 40 feet in the north, south direction. The floor is at elevation 111"-2". The neutral beam control room is located adjacent to the north radiation wall and extends northward 12 feet. It extends approximately 71 feet in the east, west direction. The floor is at elevation $112^{\prime}-4^{\prime \prime}$. Both control rooms have $110 \mathrm{~V}$ electrical service.

The two general purpose rooms are located under the operations control room at the first floor level. One room (C103) is used as a light assembly and technleian ready-room, and the other (C104) is used for a diagnostic laser.

The experimental area is fire protected by a central halon system, Nozzles are located at varfous levels starting at the first floor and extending to the high bay. In addition, hand-held fire extinguishers are strategically placed throughout the area.

All machine area access doors are interlocked and have kick-out panels. During machine operation the area is monitored by closed cfrcuit IV. 


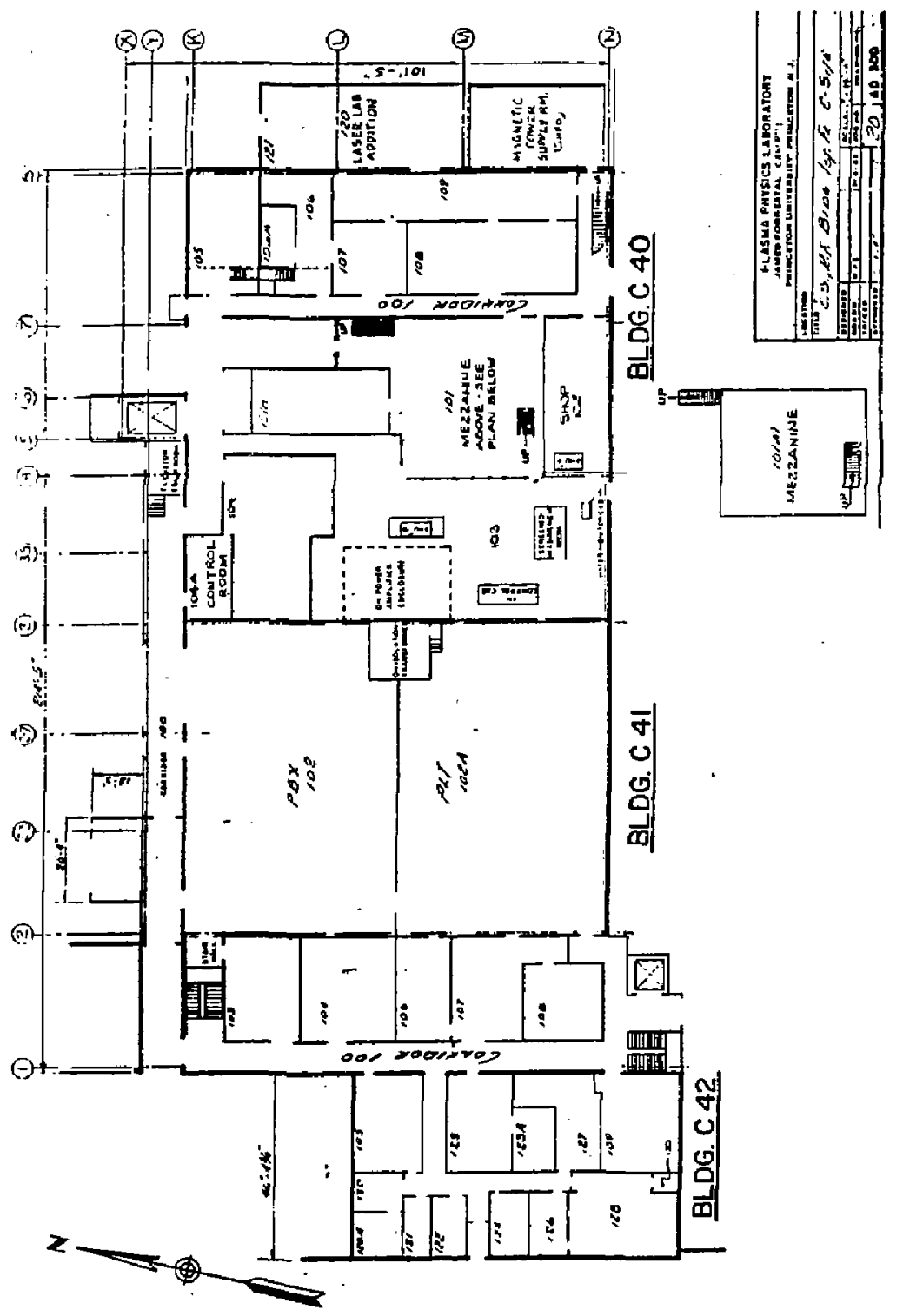

Flgure 4.1-1 


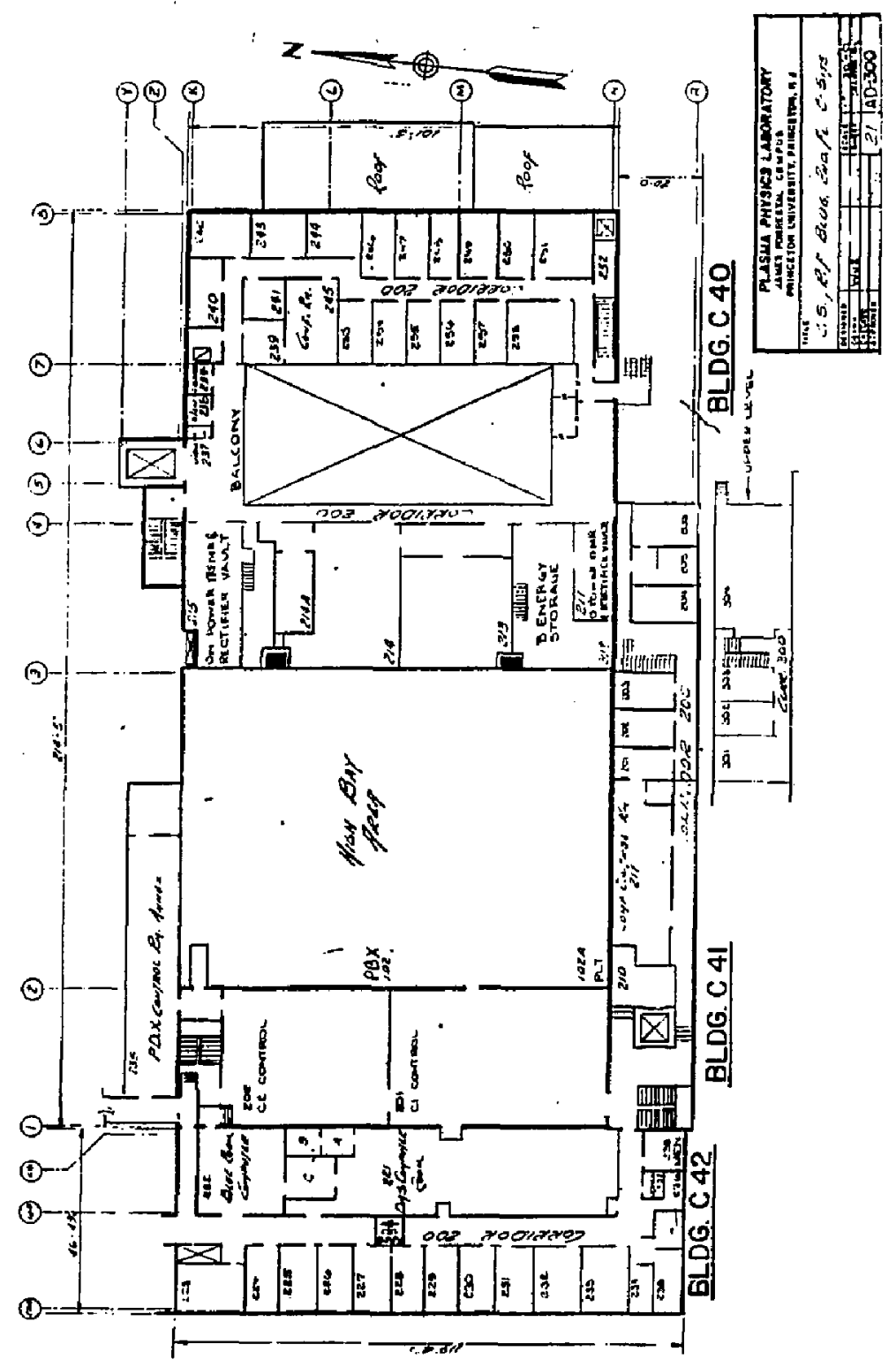

Flgure $4.1-2$ 


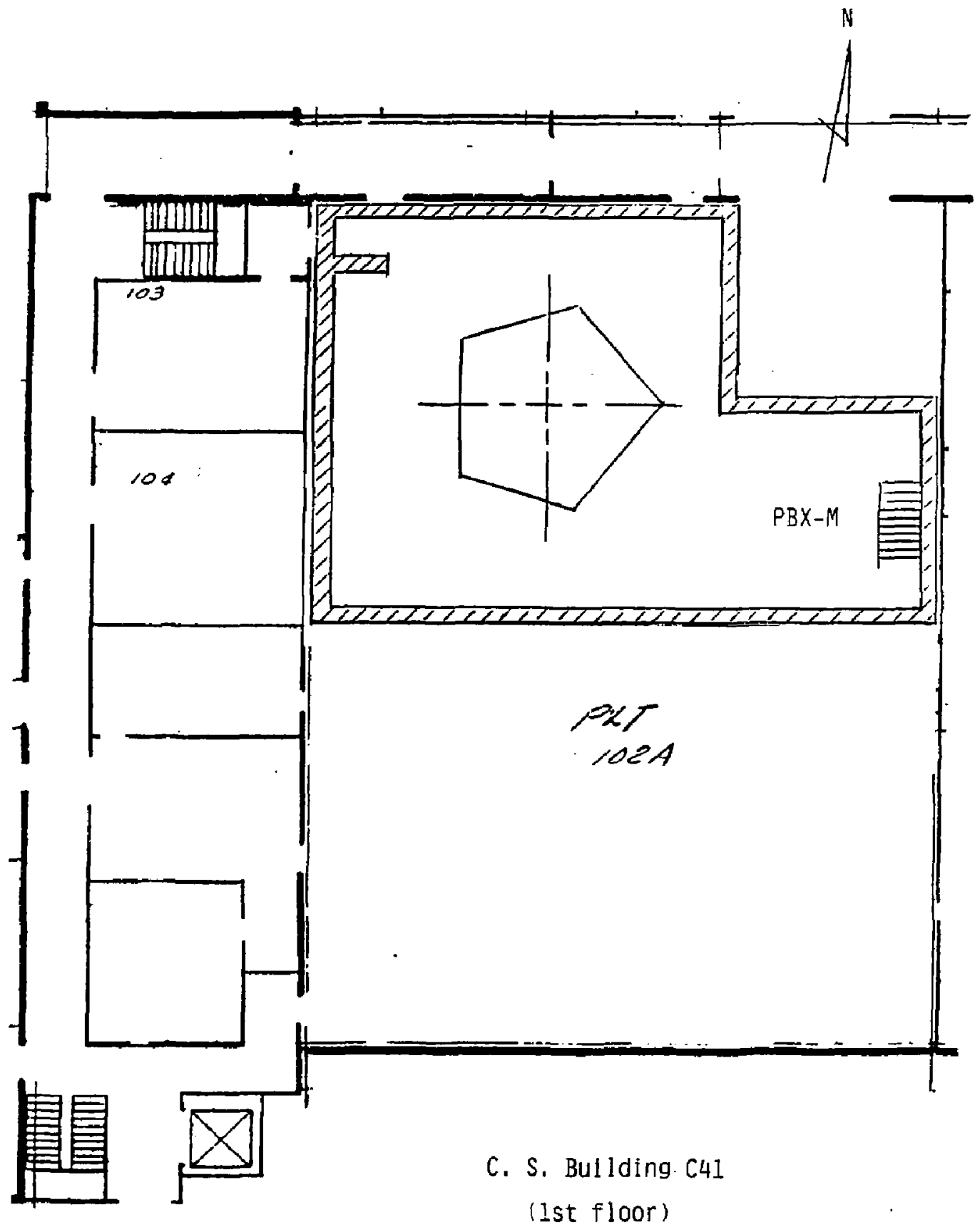

Figure 4.1-3 




Flgure 4.1-4 


\subsection{Power Supplies (D. Ashcroft)}

\subsubsection{PBX-M Electrical Power Systems}

This section presents a safety assessment of the electrical power systems to be used on the PBX-M machine. The equipment covered herein includes the OH Coil Pawer Supply, the EF Coil Power Supply, the TF Coll Power Supply, the Radial Field Coil Power Supply, the shaping Field Coil(s) Power Supplies, and the AC Power Distribution System.

\subsubsection{OH Coil Power Supply}

The power supply that will be used to power the PBX $-\mathrm{H} O \mathrm{OH}$ coil is the same power supply that has been in operation for the past 10 years, initially to supply power to the PLT OH coils and subsequently to the PDX and PBX $\mathrm{OH}$ coils. The performance of this equipment with respect to both equipment safety and personnel safety has been demonstrated during many years of successful operation.

The design of the equipment and the associated safety features are commensurate with that expected in a research facility and at the power levels used. The equipment meets the requirements of PPPL Health and Safety Directives (HSD $2 a$, HSD $2 b$ ).

Safety features associated with this equipment include the following:

A. All high power equipment is completely guarded by sturdy wire mesh fencing to a height of eight feet. This fencing is well separated from all operating equipment and all gates are locked with serialized Kirk key locks.

B. All local control and monitoring equipment is located outside the perimeter of the safety fencing. All controls and monitoring equipment which interface with thigh energy or high voltage sources are isolated by either two independent insulating gaps or optically isolated electronics. 
C. All equipment located outside the perimeter of the safety fencing containing 480 VAC or higher has its conductors shielded by protective barriers which must be mechanically unfastened using tools in order to be accessed, or the cabinet is fitted with a Kirk key lock. Such shielded compartments are labelled with high voltage warning signs.

D. Capacitor banks are provided with Kirk key interlocked shorting and grounding switches, mechanically operated from a safe location isolated from the capacitor banks. These capacitor banks are located outside the rectifler building and are completely surrounded by safety fencing. This fencedin area cannot be entered without a key released at the switch when in the safe grounded position. In addition, this capacitor area may not be entered without a second key (a padlock key) obtainable only from cognizant operations personnel and released only to listed personnel who are qualified by tralning to have access to the area.

E. All equipment enclosures (high and low voltage) are solidly grounded to building ground.

F. The safe control areas are limited access areas, meaning that card keys having authorized magnetic code are required for entry.

G. Fire extinguishers suitable for electrical type fires are strategically located throughout the area. The rectifier room is protected by an automatic sprinkler system which is connected to operate the emergency stop in the event of water flow. The room also has a sooke detection- system.

$H$. Whenever a high voltage area is entered, even though it is safe, there must be at least two qualifled persons present so as to have a safety watch in sight at all times in the event of an emergency. (See also $\mathrm{K}$ below.) 
I. An electromechanical fast acting heavy duty crowbar assembly is located at the output of the power supply. Upon sensing a power supply or system fault, the crowbar is activated. Additionally, nower suppiy firing pulses are blocked, commutating bank energy is discharged, and the power supply output is shorted, thereby dissipating energy in the load. The power supply $A C$ breaker will be tripped if clirrent remains higher than the predetermined trip set point.

J. Lower voltage (legs than 208 VAC, 125 VDC) control and monitor wiring are not interwixed with high voltage wiring.

K. In the event that high voltage areas must be entered for inspection, service or maintenance, a safety procedure must be followed. This procedure includes the following sequential steps:

(1) Notification of on-duty cognizant operating personnel that the area is going to be entered.

(2) Orderly and safe shutdown of equipment.

(3) Orderiy and safe-shutdown of incoming power.

(4) Obtaining of Kirk keys and padlock keys from operating consoles and personnel required to unlock the appropriate area.

(5) Initiate the use of "yellow tags" by personnel entering the high voltage area. These tags will. be securely attached to protective devices (e.g., a racked out circult breaker) and removed only by these same people after they have left the high voltage area. (This procedure complies with Section 2 of HSD-5008.) 
(6) Upon entering the high voltage area all energy storage devices (e.g., capacitors) are shorted and grounded using appropriate grounding sticks, and personnel protective equipment - (insulating gloves, goggles) following a rehearsed (written) procedure.

(7) Visual "hands off" inspection of the area is made to establish the safe status of equipment prior to any work being done.

(8) Only authorized trained personnel are permitted within high voltage areas.

The modification made to the OH power supply for PBY-H consists almost entirely of changes in power circuit electrical configuration. None of the foregoing statements is changed by this reconfiguration. The modification has been subject to Conceptual. Preliminary, and Einal Design Reyiews, in which the Project and Operational Safety office specifically, and ocher reviewers in general, have assured that the requirements of codes, standards, and regulations have been net. The equipment will be operated in PBX-M within electrical ratings and other operating constraints established by years of experience in using the same components in PLT, $\mathrm{PDX}$, and $\mathrm{PBX}$.

\subsubsection{EF Coil Power Supply}

The power suppiy that will be used to power the PBX-M EE coils is the same power supply that has been in operation for PLT/PDX/PBX. The performance of this equipwent with respect to both equipeent safety and personnel safety has been deonstrated during wany years of successful operation.

This equipoent was purchased, installed, and tested at the same time as the $\mathrm{OH}$ Coil Power Supply and is located in the same general area. Because of its location and functional similarity to the OH equipwent, the same safety assessment couments apply as made above for the $\mathrm{OH}$ equipment. 
Several years ago, during the operation of PDX, the EF supply was upgraded to provide a higher intrinsic current capability (15kA). It is this upgrade EF rectifier that will be used to supply the PBX-M EF. Since the supply will not be required to operate beyond 10KA for $\mathrm{PBX}-\mathrm{M}$, and since it has demonstrated this capability in PBX use, one may conclude that it comprises equipment which has an established safety record.

\subsubsection{TE Coil Power Supply}

The power supply that will be used to power the PBX-M TF coils is the same power supply that has been in operation for the past 23 years for all wachines at C-Site, inftially for the $c$ Stellarator and more recently for PBX. The safety features of this equipment have been demonstrated over this time.

This power supply comprises eight large dc generators plus associated rotating generator field exciters, drive motors, liquid rheostats for motor control, power buswork, disconnect switches, circuit breakers, control transfer switches, control circuits, and control and monitoring consoles.

Safety features associated with this equipment include the following:

A. The generators, exiters, drive motors, rheostats, circuit breakers, and control transfer switches are all totally enclosed such that covers must be unbolted or doors unlocked to gain access to hazardous circuits.

B. Buswork and disconnect switches are completely guarded by sturdy wire mest fencing to a height of eight feet. All Bates to this fenced-in area are locked with serialized Kirk key locks. Furthermore, the disconnect switches located within this fenced-in area are enclosed by plexiglass covers and the disconneat switches themselves are keyed with Kirk key locks.

c. Control and monitoring circuits are located in separate cabinets whose doors are locked with keys obtainable only from cognizant personnel. 
D. All equipment enclosures (high and low voltage) are solidly grounded to building ground.

E. Emergency shutdown pushbuttons are prominently located throughout the area, providing for the rapid and safe shutdown of all equipment in the event of an emergency. Periodic testing of this system is performed routinely.

F. Fire extinguishers sultable for electrical type fires are strategicaliy located throughout the area. The motor generator sets are protected by a $\mathrm{CO}_{2}$ fire protection system. The MG control room and the dc board enclosures have halon systems. Critical areas of the $M G$ building are provided with thermal and smoke detection systems.

G. Fast acting heavy duty circuit breakers are located at the output of the generators arranged to open and ground the outputs and dissipate energy stored in the load inductance. Upon the detection of a fault, in addition to the opening of the circuit breakers, the electrical power to the generator fields is interrupted, thus interrupting the electrical output of the generators and maintaining the stored energy in the flywheel as purely mechanical kinetic energy.

H. The generators and power control devices are fully instrumented to monitor performance, providing continuous displays of system status as well as audible annunciation of fault conditions.

1. Low voltage control and monitor wiring are run separately from high voltage wiring.

J. All monitoring devices located within hazardous areas are insulated by two independent insulating gaps. 
K. In the event that a high voltage area mușt be entered for inspection, service, or maintenance, safety procedures very similar to those described above for the $\mathrm{OH}$ power supply are followed. Entry to the unsafe experimental machine areas can be gained oniy after a Safety Isolation Switch (a Kirk key multiple contact switch) has been removed to the SAFE position, disabling all power supplies. This securely opens all MG disconnect switches, and grounds and shorts the respective loads.

L. The entire area in whicis the generators and associated control devices are located is a limited access area requiring controlled identification card entry.

For PBX-M there are no equipment modifications required for the TF Coil Power Supply.

4.2.1.4 Radial Field Coil Power Supply

The power supply that will be used to power the $P 9 X-M$ radial field is the same power supply that has been used for years on PDX and PBX. As with other power supplies used on PDX, the safety features have been demonstrated to be effective over the years of use. This power supply conprises a self-contained transistorized power amplifier controlled from the PBX-M Control Room.

Safety features of this equiprent include the following:

A. The power amplifier is completely guarded by sturdy wire mesh fencing to a height of eight feet. This fencing is well separated from all power connections and its single gate is locked with a serialized kirk key lock.

B. All control an!: monitoring lines are Isolated via optically isolated links and electronics. 480 VAC power is isolated by $30 k V$ isolation transformers.

C. The power amplifier enclosure is solidly grounded to bullding ground. 
D. A fast acting overcurrent trip circuit as well as a ground fault detector circuit are used to protect the equipment and provide for an emergency shutdown.

E. In order to enter the power amplifier area, the Kirk key for the gate must be obtained from the control room which automatically shuts down the power system.

The supply will be operated exactly as it has been operated for PBX, hence its established safety record can be inferred to apply to $P B X-M$ operation.

\subsubsection{Shaping Field Coll(s) Power Supplies}

A major feature of the PBX-M, as compared to PBX, is the provision of considerably greater flexibility in shaping the plasma cross section. This provision, in part, comprises the utilization of six power supplies for reconfigured poloidal field coils. These supplies (coils) have been designated $I F, D F, T 1, T 2, T 3$, and T4. Except that the IF furnishes $20 \mathrm{kA}$ at 500 VDC, the DF 10KA at 200 VDC, and T1-4 5kA at 300 VDC, they are built in exactly the same configuration. Thus all have the same safety features. In general, each of the Shaping Field Supplies was designed and manufactured to provide the same time-proven safety measures provided in the $\mathrm{EF}$ and $\mathrm{OH}$ coll power supplies.

Safety features of the Shaping Field Coil Power Supplies Include:

A. All high power equipment is completely guarded by sturdy wire mesh fencing to a height of eight feet. This fencing is well separated from all operating equipment.

B. All controls and monitoring equipment which interface with high energy or high voltage sources are isolated by either two independent insulating gaps or optically isolated electronics.

C. All equipment enclosures (high and low voltage) are solidly grounded to building ground. 
D. The safe control areas are limited access areas, meaning that card keys having authorized magnetic code are required for entry.

E. Fire extinguishers suitable for electrical type fires ire strategically located throughout the area. The rectifier room is protected by an automatic sprinkler system which is connected to operate the emergency stop in the event of water flow. The room also has a smoke detection system.

F. Whenever a high voltage area is entered, even though it is safe, there must be at least two qualified persons present so as to have a safety watch in sight at all times in the event of an emergency (ref. HSD 2a).

G. The design of these supplies has been subject to Conceptual, Preliminary, and Final Design Reviews, in which the Project and Operational Safety office specifically, and other reviewers in general, have assured that the requirements of PPPL Health and Safety Directives have been met.

\subsubsection{AC Power Distribution}

The AC power distribution that will be used to provide AC power to the various PBX-M power supplies is substantially the same distribution system used to power equipment for PBX. The safety of this equipment has been demonstrated during years of successful operation.

This equipment comprises $138 \mathrm{kV} / 4.16 \mathrm{kV}$ three-phase power transformers, circult breakers, series reactors and/or capacitors, shunt reactors and/or capacitors where required, and distribution transformers for lower voltage levels for various equipment. All of this equipment is monitored and protected by current transformers, potential transformers, spark gaps, lightning arrestors, appropriate grounding and remote controls, monitors, and annunciators. The level of monitoring and protection is conmensurate with that required by industry standards for a distribution system of this type.

In addition to the above ancillary protective equipment are the following safety features: 
A. All high power equipment is located in a outside fenced area, with gates padlocked for extra security. The keys to these locks bey betained only from the cognizant power dispatcher, who has the authority and responsibility to limit the distribution of these keys until satisfied that only authorized and knowledgeable personnel will enter the hazardous area under safe conditions. In addition to the padlock key, a controlled identiflcation card key is required to gain entry to this area.

B. All controls and monitoring equipment which interface with high energy or high voltage sources are isolated by at least two independent insulating gaps.

C. All equipment enclosures are solidly grounded to earth ground.

To provide power for the PBX-M Shaping Field Coil power supplies, additional $5 \mathrm{kV}$ class cabling, metal-clad swicchgear, current-limiting reactors, and ancillary protective equipment have been installed. These additions were made to be in all ways similar and compatible with the established PBX distribution system. That is, the system as augmented remains at a levei of monitoring and protection commensurate with that required by industry standards for a distribution system of this type.

\subsubsection{Power Distribution}

The DC power distribution scheme that will be used to provide DC power to the various machine coils is the same as used for $P B X$, in the case of the $T F, O H, E F$, and Radial Field Coils. This distribution system has demonstrated years of safe operation. The shaping field coils, IF, DF and $\mathrm{T} 1-\mathrm{T} 4$, added for PBX-M, are supplied through a network of cable and buswork that is designed to be electrically similar to the remainder of the system. It may be inferred, then, that the additional portions of the distribution system are as conservatively (safety) designed as those portions which have served well.

A. The shaping fields are supplied by DC cables made up of multiple $2 \mathrm{kV}$ class, $750 \mathrm{kCM}$ single conductor cables in parallel. These cableg are run, in numbers as required by the National Electrical Code, in laddertype cable tray, between the power-supply planking and the DC disconnect/ grounding switches.

B. Planking interconnections interlocked by links of various physical dimensians are provided to control dispateh of the DC power from the power supply ends of the transinission lines. 
C. Fully rated DC disconnect/grounding switches, interlocked in the same manner as $O H, E F$, etc., are provided to assure positively safe machine access.

D. Transmission lines are terminated with semiconductor voltage transient limiters.

E. Power passes from DC disconnect switches to planting interconnections interlocked by physical dimensions and thence to coil feed buswork. These latter features are described further under "Coil system," below. 


\subsection{PQX-M DEVICE (J. Alton/D. Knutson)}

4.3.1 Coil System

\subsubsection{Poloidal Field Coils (PF)}

The primary functions of the Poloidal Field system are to stabilize, heat, and shape the plasma.

The upgrade PEX-M poloidal coil system includes five (5) new internal (in-vessel) coils and the establishment of nine (9) separately powered coil groups (see Eig. 4.3.1-1).

A) Divertor Fleld (DE)

B) Indentation Field (IF)

C) Equilibrium Field (EF)

D) Active-Feedback (AF)

E) Trim Systems 1 thru 4. (T-1 thru 4)

F) Onmic Heating (OH)

All of the PF coils are water-cooled copper conductor wound coils of conventional design. The coils located inside the vacuum vessel are encased in stainless steel to eliminate outgassing from their insulating materials and to reinforce them mechanically.

All of the coils use a primary insulation of half-lapped layers of my lar insulating tape ( 6.5 $\mathrm{kV}$ per mil-dielectric strength). The internal canned coils then use a combination of dry glass insulation, epoxy impregnated to complete their dielectric/mechanical bundle. The external coils use a B-stage epoxy-glass insulation scheme to complete their electrical/mechanical bundle.

The poloidal coil parameters are listed in Table 4.3.1-1.

\subsubsection{Passive Coils}

The Passive Coil system was Installed to carry currents induced by vertical motion of the plasma, which helps in slowing or damping these vertical motlons. 


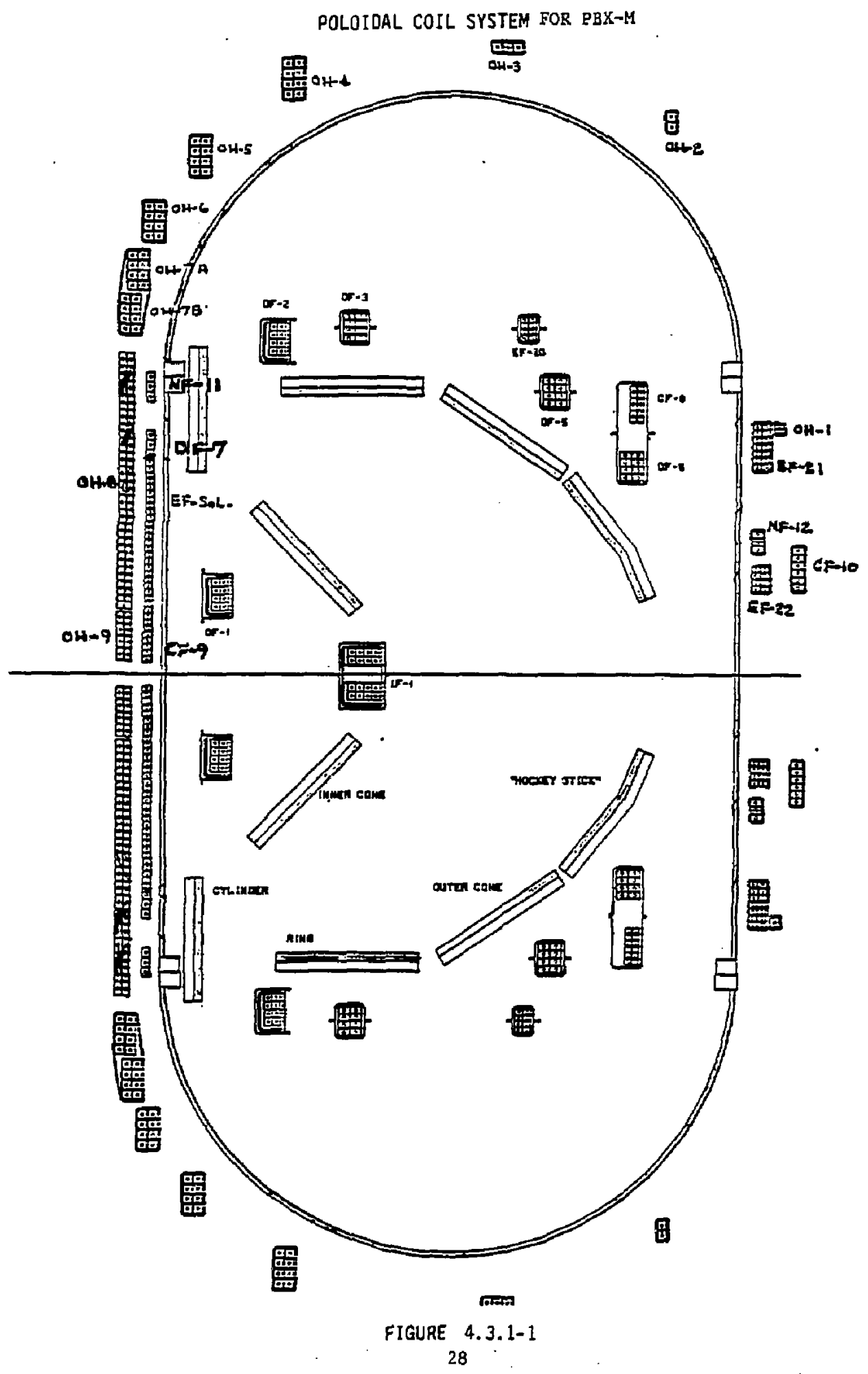


PBX - M COIL DATA SHEET

POLOIDAL COILS

\begin{tabular}{|c|c|c|c|c|c|c|c|c|c|c|}
\hline \multirow{2}{*}{$\begin{array}{c}\text { SYSTEH } \\
\text { ID }\end{array}$} & \multirow{2}{*}{$\begin{array}{c}\text { coll } \\
10\end{array}$} & \multirow{2}{*}{$\begin{array}{c}\text { HEAH COIL } \\
\text { RAD, } \\
\text { (In.) }\end{array}$} & \multirow{2}{*}{$\begin{array}{l}\text { Ho. } \\
\text { TuRHS }\end{array}$} & \multicolumn{3}{|c|}{ CONDUcton } & \multirow{2}{*}{$\begin{array}{c}\text { COPPER } \\
\operatorname{AnE}_{A} \\
\left(1 \mathrm{n}^{2}\right)\end{array}$} & \multirow{2}{*}{$\begin{array}{c}\text { COPPER } \\
\text { IENGTI } \\
\text { per coll } \\
\text { (rt.) }\end{array}$} & \multirow{2}{*}{$\begin{array}{l}\text { COIL } \\
\text { WEIGHT } \\
(1 \mathrm{bS})\end{array}$} & \multirow{2}{*}{$\begin{array}{c}\text { COIL } \\
\text { RESISTAHCE } \\
\text { (olims) }\end{array}$} \\
\hline & & & & $\begin{array}{l}\text { WIDTI } \\
\text { (In.) }\end{array}$ & $\begin{array}{l}\text { (In.) } \\
\text { (IDIT }\end{array}$ & $\begin{array}{l}\text { HOLE } \\
\text { DIA. } \\
\text { (In.) }\end{array}$ & & & & \\
\hline $\begin{array}{l}\text { Equilibrlum } \\
\text { Fleid }\end{array}$ & $\begin{array}{l}C F-10 \\
G F-20 \\
E F-21 \\
E F-22\end{array}$ & $\begin{array}{l}92.638 \\
64.961 \\
88.767 \\
88.767\end{array}$ & $\begin{array}{r}6 \\
7 \\
13 \\
8\end{array}$ & $\begin{array}{l}1.110 \\
0.734 \\
0.734 \\
0.734\end{array}$ & $\begin{array}{l}0.625 \\
0.500 \\
0.500 \\
0.500\end{array}$ & $\begin{array}{l}0.313 \\
0.250 \\
0.250 \\
0.250\end{array}$ & $\begin{array}{l}0.609 \\
0.310 \\
0.310 \\
0.310\end{array}$ & $\begin{array}{l}291.0 \\
283 \div 1 \\
604.2 \\
371.8\end{array}$ & $\begin{array}{l}687.2 \\
286: 4 \\
726.8 \\
447.2\end{array}$ & $\begin{array}{l}0.0039 \\
0.0062 \\
0.0158 \\
0.0097\end{array}$ \\
\hline $\begin{array}{l}\text { Shaping } \\
\text { Fleld }\end{array}$ & $\begin{array}{l}C E-\theta \\
I F-1\end{array}$ & $\begin{array}{l}75.076 \\
48.110\end{array}$ & $\begin{array}{r}6 \\
16\end{array}$ & $\begin{array}{l}0.625 \\
0.775\end{array}$ & $\begin{array}{l}1.110 \\
0.775\end{array}$ & $\begin{array}{l}0.313 \\
0.250\end{array}$ & $\begin{array}{l}0.609 \\
0.552\end{array}$ & $\begin{array}{l}239.0 \\
402.2\end{array}$ & $\begin{array}{l}560.8 \\
848.0\end{array}$ & $\begin{array}{l}0.0032 \\
0.006\end{array}$ \\
\hline $\begin{array}{l}\text { Dlvertor } \\
\text { Fleld }\end{array}$ & $\begin{array}{l}D F-1 \\
D E-7 \\
H F-11\end{array}$ & $\begin{array}{l}33.460 \\
26.260 \\
26.260\end{array}$ & $\begin{array}{l}8 \\
3 \\
3\end{array}$ & $\begin{array}{l}0.775 \\
0: 724 \\
0.724\end{array}$ & $\begin{array}{l}0.775 \\
0: 847 \\
0.847\end{array}$ & $\begin{array}{l}0.250 \\
0.250 \\
0.250\end{array}$ & $\begin{array}{l}0.552 \\
0.557 \\
0.557\end{array}$ & $\begin{array}{r}134.9 \\
41.2 \\
41.2\end{array}$ & $\begin{array}{r}285.0 \\
89: 0 \\
89.0\end{array}$ & $\begin{array}{l}0.002 \\
0.0006 \\
0.0006\end{array}$ \\
\hline TrIa No. 1 & $D F-2$ & 39.020 & 8 & 0.775 & 0.775 & 0.250 & 0.552 & 163.4 & 345.0 & 0.0024 \\
\hline Trsin Ho. 2 & $D F-3$ & 46.850 & 8 & 1.110 & 0.625 & 0.313 & 0.609 & 196.2 & 463.4 & 0.0026 \\
\hline Trim No. 3 & DF -5 & 67.717 & 8 & 1.110 & 0.625 & 0.313 & 0.609 & 283.7 & 669.8 & 0.0038 \\
\hline Trim Ho. 4 & $D F-6$ & 75.591 & 8 & 1.110 & 0.625 & 0.313 & 0.609 & 316.6 & 747.7 & 0.0042 \\
\hline $\begin{array}{l}\text { Aotlve - } \\
\text { Feedback }\end{array}$ & $\begin{array}{l}\text { HF-12 } \\
\text { EF-SOL- }\end{array}$ & $\begin{array}{l}88.490 \\
26.260\end{array}$ & $\begin{array}{r}3 \\
28\end{array}$ & $\begin{array}{l}1.110 \\
0.734\end{array}$ & $\begin{array}{l}0.625 \\
0.500\end{array}$ & $\begin{array}{l}0.313 \\
0.250\end{array}$ & $\begin{array}{l}0.609 \\
0.310\end{array}$ & $\begin{array}{l}139.0 \\
385.0\end{array}$ & $\begin{array}{l}328.3 \\
463: 1\end{array}$ & $\begin{array}{l}0.0019 \\
0.0101\end{array}$ \\
\hline $\begin{array}{l}\text { Ohato } \\
\text { lleat Ing }\end{array}$ & $\begin{array}{l}011-1 \\
011-2 \\
011-3 \\
0 H-4 \\
011-5 \\
011-6 \\
011-71 \\
011-78 \\
011-8 \\
011-9\end{array}$ & $\begin{array}{l}90.553 \\
79.370 \\
62.630 \\
40.433 \\
31.102 \\
24.173 \\
24.942 \\
24: 217 \\
23.909 \\
23.909\end{array}$ & $\begin{array}{r}1 \\
2 \\
3 \\
8 \\
8 \\
8 \\
8 \\
8 \\
36 \\
8\end{array}$ & $\begin{array}{l}0.875 \\
0.875 \\
0.875 \\
0.875 \\
0.875 \\
0.875 \\
0.875 \\
0.875 \\
0.625 \\
0.625\end{array}$ & $\begin{array}{l}0.875 \\
0.875 \\
0.875 \\
0.875 \\
0.875 \\
0.875 \\
0.875 \\
0.875 \\
1.320 \\
1.050\end{array}$ & $\begin{array}{l}0.250 \\
0.250 \\
0.250 \\
0.250 \\
0.250 \\
0.250 \\
0.250 \\
0.250 \\
0.313 \\
0.313\end{array}$ & $\begin{array}{l}0.709 \\
0.709 \\
0.709 \\
0.709 \\
0.709 \\
0.709 \\
0.709 \\
0.709 \\
0.740 \\
0.572\end{array}$ & $\begin{array}{c}47.4 \\
83.1 \\
98.4 \\
169.4 \\
130.3 \\
111.2 \\
104.5 \\
101.4 \\
100.15 \\
450.673\end{array}$ & $\begin{array}{c}130.3 \\
228: 4 \\
270.4 \\
165: 4 \\
358.0 \\
305.6 \\
287.2 \\
278.7 \\
1295 \\
222\end{array}$ & $\begin{array}{l}0.0005 \\
0.0010 \\
0.0011 \\
0.0019 \\
0.0015 \\
0.00128 \\
0.0012 \\
0.00116 \\
0.004602 \\
0.001296\end{array}$ \\
\hline
\end{tabular}

Table 4.3.1-1 
PBX-H COIL COOLIHG DATA SUIEET

POLOIDAI. COILS

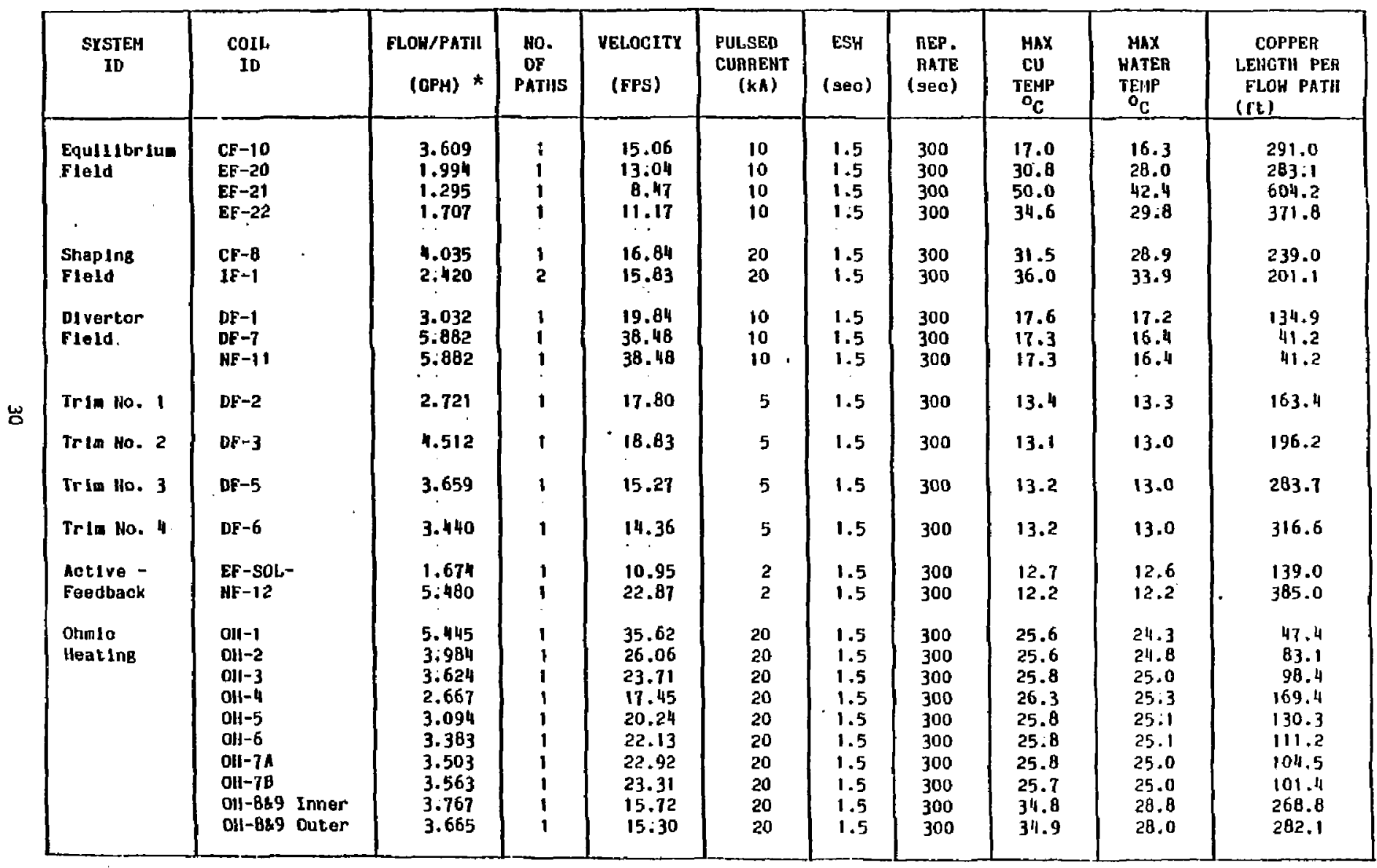

*Based on 400 psi $\Delta P$, Inlet Temp $=12{ }^{\circ} \mathrm{C}$

Table 4.3.1-1 (cont'd.) 
There are a total of five pairs of passive coils in the vacuum vessel surrounding the plasma.

These coils are fabricated from a composite of aluminum and stainless steel. A layer of nominal $1 / 8$ " thick stainless steel is explosionbonded to the plasma side of the aluminum to protect it from the plasma.

Each coil is manufactured as either 5 or 10 segments, which are fastened together with hardware, after they are brought inside the vacuum vessel.

The upper and lowei matching coils are then bussed together to form a complete circult. The "hockey-stick" coll differs from the other coils in that it has upper-lower bus connections at eleven places around the vacuum vessel. The coil parameters are indicated in Table $4.3 .1-2$.

A. Bus Runs

Most of the bus runs are water cooled and fabricated in sections which are mechanically fastened together with stainless steel hardware.

Each bus connection has been inspected using "PBX-M Pre-Power Test Joint Inspection Procedure" number CS-PBX-07. (See Appendix C.)

The outlet water temperature of each bus run is monitored for thernul protection and feed back to the main controls.

B. Polarity Reversal Panel

The "Polarity Reversal Panel" (Fig. 4.3.12) is located in the basement planking room which is secured.with a Kirk key interlock. It is on the machine side of the disconnect switches and links the bus runs from both the colls and the switches. Using removal copper planks, it allows each P.F. system to be aperated in elther the positive or negative modes.

A failsafe system has been ingtalled which indicates to the control room, that the proper planks are in position on the panel. 


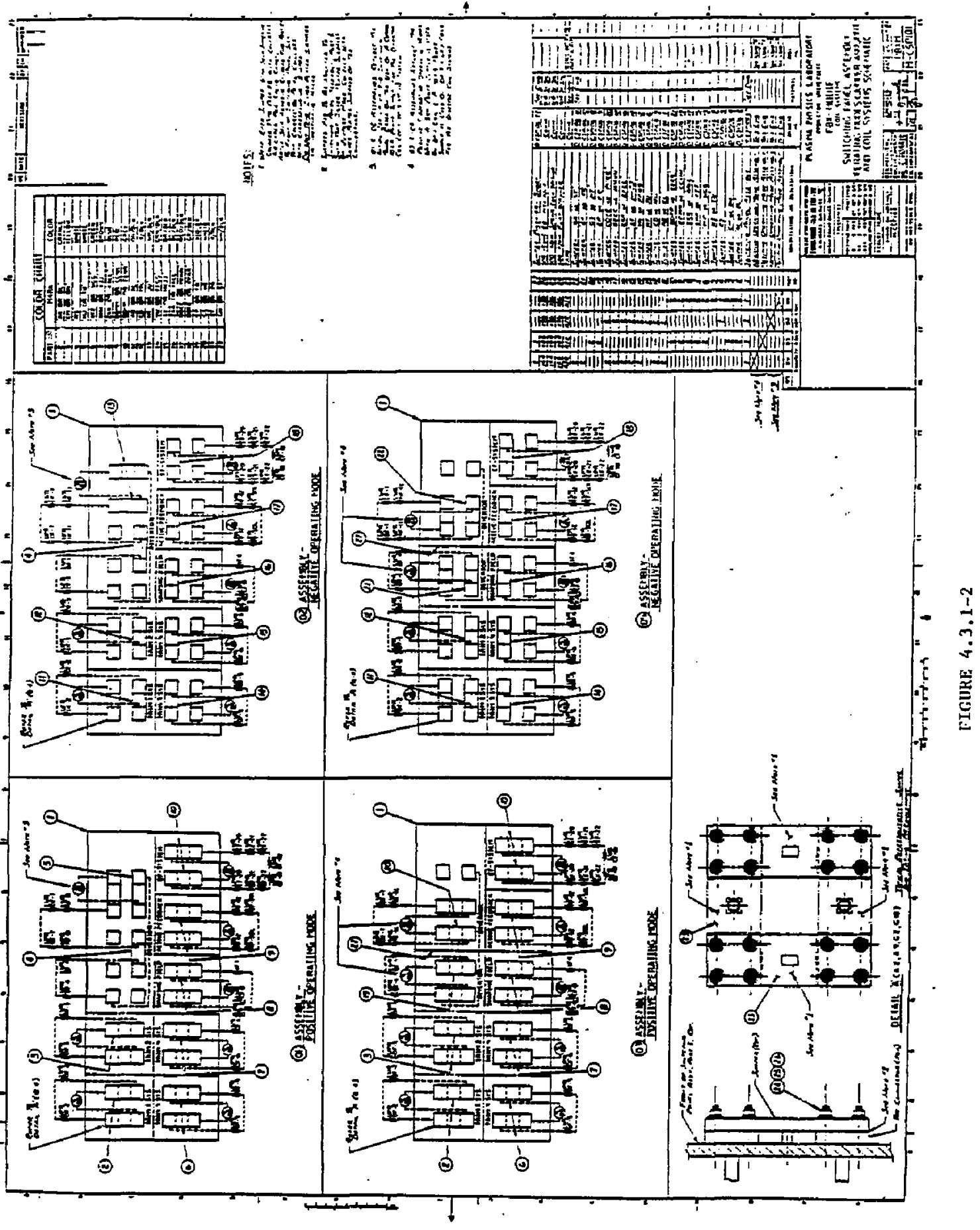


Grounding terminals have been installed on the panel which allows a coil system to be grounded before removing the copper planks.

Additional precautions such as color-coded silhouettes have been added to ensure that all planks are in their proper position.

TABLE $4.3 .1-2$

PASSIVE COIL PARAMETERS

Passive Coil

Inner Cone

Cylinder

hing

Outer Cone

Hockey-Stick $\operatorname{tax}$ Design Induced Current (KA)

138.0

24.0

123.0

60.0

10.0
Segments per coil

5

5

5

10

10

\subsubsection{Poloidal Field Coil Bus System}

There are a total of nine individual poloidal fie'd coil bus systems on the PBX-H device. They connect the P.F. coils at the wachine with the polarity reversed panel and power disconnect switches located in the basement areas.

For purposes of safety and ease of identification, eight of the new systems have been color and letter coded as noted in Table 4.3.1-3. 
TABLE $4.3 .1-3$

\begin{tabular}{|c|c|c|c|}
\hline System & Coils & $\begin{array}{l}\text { Letter } \\
\text { Code } \\
\end{array}$ & $\begin{array}{l}\text { Color } \\
\text { Code } \\
\end{array}$ \\
\hline $\begin{array}{l}\text { E.F. } \\
\text { I.F. } \\
\text { D.F. (A) } \\
\text { D.E. (B) } \\
\text { Trim } 1 \\
\text { Trim } 2 \\
\text { Trim } 3 \\
\text { Trim } 4 \\
\text { A.F. }\end{array}$ & $\begin{array}{l}E F-20,21,22, \mathrm{CF}-10 \\
\mathrm{CF}-8, \mathrm{IE} \\
\mathrm{DF}-7, \mathrm{NF}-11 \\
\mathrm{DF}-1 \\
\mathrm{DF}-2 \\
\mathrm{DE}-3 \\
\mathrm{DE}-5 \\
\mathrm{DE}-6 \\
\mathrm{EF}-\mathrm{Sol} . \mathrm{NE}-12\end{array}$ & $\begin{array}{l}\text { A } \\
\text { B } \\
\text { C } \\
\text { D } \\
\text { E } \\
\text { E } \\
\text { G } \\
\text { H } \\
\text { J }\end{array}$ & $\begin{array}{l}\text { Gray } \\
\text { Blue } \\
\text { White } \\
\text { White } \\
\text { Orange } \\
\text { Yellow } \\
\text { Green } \\
\text { Brown } \\
\text { Red }\end{array}$ \\
\hline
\end{tabular}

\subsubsection{Vaculm System}

The vacuum vessel is formed from two concentric vertical axis cylinders $60^{\prime \prime}$ in axial length with radif of approximately $28^{\prime \prime}$ and $88 "$ ", respectively; the volume between them is enclosed top and bottom by a pair of hemi toroidal spinnings of 30" minor radius and 58" major radius each. The wall of this vessel is formed from 1/2n 304 stainless steel. The toroidal vessel geonetry thus formed is broken electrically in two locations on a major diameter at the torus; forming two hemitori. The resulting vacuum vessel is thus composed of 8 flanged segments bolted together with elastower "O" rings forming the vacuum seals. Twenty toroidzl field coils located every $18^{\circ}$ surround the vacuum vessel. At every other toroidal field location a structural "I" beam is mounted inside the toroidal spinnings top and bottom. These supports carry both active and passive coils. The reinforced inner-cylinder also supports active and passive coils. A number of vacuum diagnostic ports have been provided in the gaps between the toroidal and poloidal field cofls. Man access to the vacuum vessel interior is possible through certain ports on the equatorial plane and certain dome flanges. The vessel interior is defined as a "confined space" so that work inside the vessel must be conducted according to the safety rules and regulations for "confined spaces," per HSD 5008 , section 8 (HSD8). Breathable atmosphere is maintainable by continuous ventilation of the vessel.

\subsubsection{Vacuum Pumping System}

The vacuum vessel is pumped by four $15001 / \mathrm{sec}$ turbo pumps backed by a $50 \mathrm{cfm}$ mechanical pump. The system is roughed down from atwospheric pressure by means of a 500 efm mechanical purp. Several Ti Ball sublimation getters provide active metal surface pumping during plasma operations. The vacuum system "aimic" control panel is in the room below the PBX control room. Only trained, qualified personnel are permitted to operate the system. 


\subsection{PBX-M Operating Controls (P.Mathe, R.Mica)}

\subsubsection{Control System Architecture}

\subsubsection{Introduction}

The supervisory and control functions on the previous machine (PBX) were provided by an IBM-1800 process controller. This computer became obsolete and was replaced by a modern distributed control system (Eig. 4.4-1). The system consists of four EROGRAMMABLE LOGIC CONTROLLERS (PLC's) connected via an industrial local area network, a CRT CONSOLE which accesses the PLC's memory through its own data acquisition links, OPERATOR CONTROL PANELS which utilize serial communication to the PLC's, and a PROGRAM LOADER/MONITOR which permits on-line monitoring of the PLC logic and status.

\subsubsection{Programable Logic Controllers (PLC's)}

PLC's are reliable control equipment, since they are made to operate in industrial environments and use solid state components. They offer flexibility both is the area of software and hardware, because of their modular architecture. Sof tware development is simplified by powerful program development tools that also permit quick debugging and troubleshooting of the system. The distributed I/ 0 architecture reduces the cost of wiring by placing remote $I / 0$ racks at the controlled equipment and communicating-back to the CPU via high-speed serial links with CRC error detection and correction for error-free coumunication. PLC's are not new to the laboratory, they have been used on all major projects- TFTR, PBX, PLT, S-1- and the experience has been very favorable.

\subsubsection{Distributed Architecture}

One of the benefits of distributed architecture is that each PLC is responsible for controlling a fewer number of subsystens resulting in simplified sof tware management effort. Each PLC is independent, allowing different individuals to work in parallel on several subsystems. Logic execution speed is increased since several processors operate similtaneously. A new requirement, however, is a communication path that allows sharing information among the PLC's. This requirement is met by industrial local area networks. Several interlocks are shared on a periodic basis, and the rellability of this communication is expected to be similar to requirements imposed on remote $I / O$ communication. The network also provides expansion for future subsystems on PBX-M, a few of which are 




DEF DUGS

C4CC-A-HED4O0-DL MAIH DRAWHV MDEX C4CC-A-HED4O1-DL MAN DRAWIWO MDEX CACC-A-HED402-DL MAIN DRAWING MDEX CACC-A-KP 1-100-DL PLC-1 DRAWHG MDEX CACC-A-HP2-100-DL PLC-2 DRAWHG HDEX CACC-A-HP3-100-DL PLC-3 DRAWWO IDEXX C4CC-A-HP4-TOO-DL PLC-4 DRAWHG INDEX

\begin{tabular}{|c|c|c|}
\hline P. Máthé & mate & $\begin{array}{l}\text { PRINCETON UNINERSITY } \\
\text { PLASMA PHYSICS LABOARTORY }\end{array}$ \\
\hline CMKL: & & $\begin{array}{l}\text { IITL: } \\
\text { COXX M } \\
\text { CONTROL SYSTEM BLOCK DIA }\end{array}$ \\
\hline$m+n:$ & & DHE. W\%. CACC-A-HED 405-BL \\
\hline
\end{tabular}

Figure 4.4-1 
already undar consideration, such as pellet injection, RF heating, and current drive. This expansion can be accommodated in a way that will have minimum impact on existing systems, since new software will reside in new PLC's.

\subsubsection{Operator Interface}

Intelligent Panel System

The operator control panels are based on CTC's Intel11gent Panel System (IPS) which utilizes serial communication to the PLC's $\left(E_{1 \mathrm{~g}} \cdot 4 \cdot 4-2\right)$. The system contains Illuminated push-button panels, key-pads, vacuum fluorescent and plasma displays. The control board which supports up to four of these modules provides the transtation of parallel signals to serial format.

\section{Pushbutton Panels}

The lighted pushbutton panels contain 32 illuminated buttons and were chosen to provide a similar control environment to the previous hardwired console. The PUSH-TO philosophy is maintained, that is, the lights behind the command buttons are used as prompts for operator acticrs. When the buttons are not lit and pushed, the associated display modules provide messages that explain the reason why the system cannot accept the command.

Plasma Displays *

The plasma display features 4 lines of 16 characters for primitive operator prompts, error messages, or display of parameters. The main annunciator system implemented with the CRT Console provides detailed alarm display and logging capabilities.

Vacuum Eluorescent Display, Real-time Clock

The vacuum fluorescent display module features two lines of 24 character alphanumeric displays. It also contalns a real-time clock, settable and readable by the PLC. The clock information will be used with the Annunciator System for logging the date and time information with the alarn messages.

\section{Numer 1c Keypad}

The numeric keypad module contains two rows of 8 digit display, and a telephone style keypad for entry of numerical values to the PLC's. 


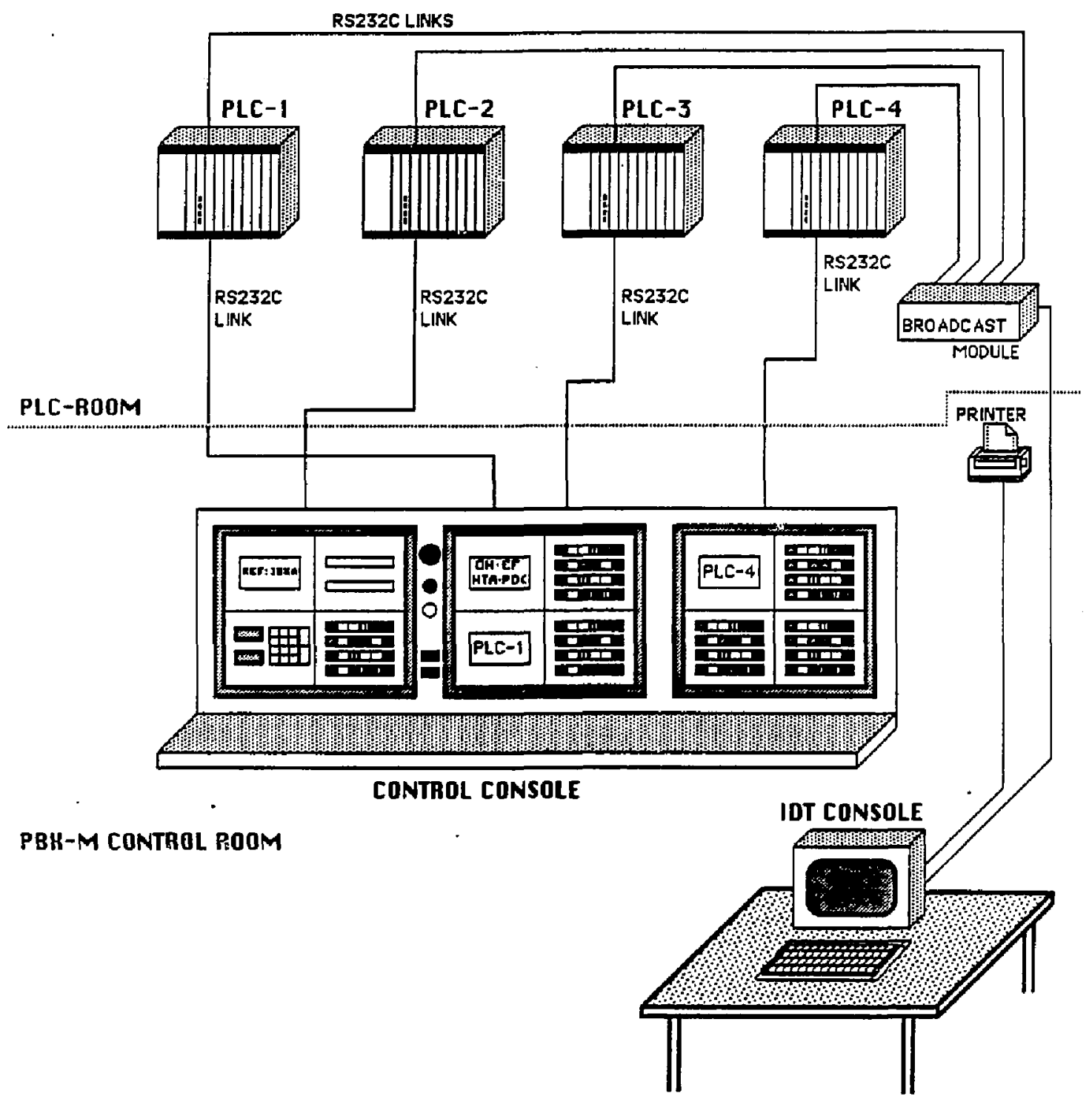

MEF BHES

C4CC-A-HED400-DL MAWN DRAWING RDEX C4CC-A-HED4OI-DL MAN DRAWWNG WOEX C4CC-A-HEDAO2-DL MAN DRAWIHG ADDEX C4CC-A-HP1-100-DL PLC-1 DRAWHG NOEX C4CC-A-HP2-100-DL PLC-2 DRAWIING 5 DEX C4CC-A-+P3-100-DL PLC-3 DRAWIHI MDEX C4CC-A-HP4-100-DL PLC-4 DRAWHIG INDEX

\begin{tabular}{|c|c|c|c|c|}
\hline P. Máthé & inte & \multicolumn{3}{|c|}{$\begin{array}{l}\text { PAINCEION UNIUERSITY } \\
\text { PLASMA PUYSICS LABOAATORY }\end{array}$} \\
\hline cant: & & \multicolumn{3}{|c|}{ PBX-M OPERATOR INTERFACE } \\
\hline wro: & & DWe. $\mathrm{N}$ & CACC-A-HED $412-L O$ & AEY \\
\hline
\end{tabular}

Figure 4.4-2 


\subsubsection{Mimic Panels}

The mimic panels will be mastly the ones inherited from PBX with an additional mimic for the new shaping field power supplies that will occupy the space freed up by the NF/CF mimic panel.

\subsubsection{CRT Console}

The CRT console is used primarily as a system annunciator to annunciate approximately 500 messages on various alarm conditions, but also provides several status pages on flow and area interlock conditions, and a system summary page . The terminal has its own data acquisition link via a serlal multidrop connection to read the data from the PLC's and has a printer port for hard copy generation. The CRT console permits the creation of these displays and the message system without programing.

\subsubsection{Hardwired Personnel Safety System}

\subsubsection{Introduction}

The most significant change with the new PLC-based control system is the Hardwired Personnel Safety System (Eig. 4.4-1.). As opposed with the IBM-1800based control system all Area access interlocks, such as K1rk interlock switches, door interlocks, and the Emergency Shutdown switches are summed up by a relay system. The resulting commands such as disable or shutdown are sent directly to the power supplies, or breakers bypassing the PLC system. Annunciation for all of the personnel safety devices is provided by the PLC system.

\subsubsection{Area Access Inter locks}

\section{Exclusion Areas}

In addition to the test cell there are other interlocked areas, l.e., bus and water tunnels, disconnect switch enclosures, planking room for polarity swltching panel, which are located in the CS basement and together with the test cell constitute exclusion areas for PBX-M. The access to these areas and the interlocks used are according to the PPPL Safety Manual, and their operation is described below.

Safety Lock-out Switch (SLS)

The Safety Lock-out Swltch prevents application of control power to the motor drives of coil disconnect switches until the area lock-up is completed. The 
hard-wired limit switches of the same disconnects are summed up into a key release solenold which allows operation of the SLS to free access.

\section{KIRK Interlocks}

Under the normal operating conditions the experimental area is evacuated and locked. The KIRK interlock system of uniquely registered keys is implemented preventing operation of power sources if the area is not secured ( $\mathrm{E} 1 \mathrm{~g} 4.4-3$ ). If an emergency entry into the exclusion area is required, a secondary key under glass enclosure is available for each door. Usage of the secondary key causes emergency shutdown.

\section{Door Inter locks}

Each door leading to the exclusion area is equipped with a microswitch which is summed into the hardwired master disable circuit.

Kick-out panels

Each door leading to the experimental area is equipped with a kick out panel allowing quick exit from the area under the emergency condition.

\subsubsection{Machine Safety Disconnect Switches}

The primary safety devices for assuring personnel safety in the test cell are the coil disconnect switches. Their control is interlocked with Safety lock-out switch. The disconnect switches can only be operated when the SLS is put Into RUN mode. When a disconnect switch is in the disabled position it grounds one side of the coil. Only when all the disconnect switches are grounded will access be allowed into the test cell. A maintenance mode is provided for all disconnects to perform maintenance work. This mode requires keys from all power supplies rendering them safe. This is an important safety improvement over the old system which required jumpering of the SLS contacts.

\subsubsection{Emergency Shutdown System}

At strategic locations manually operated emergency shutdown stations are provided. Activation of pushbuttons at these stations trips main breakers for each power subsystem, and closes the water valves to the inachine. Each station is equipped, in additicn to the pushbutton, with a light and reset button, and is hardwired into the Safety system. 


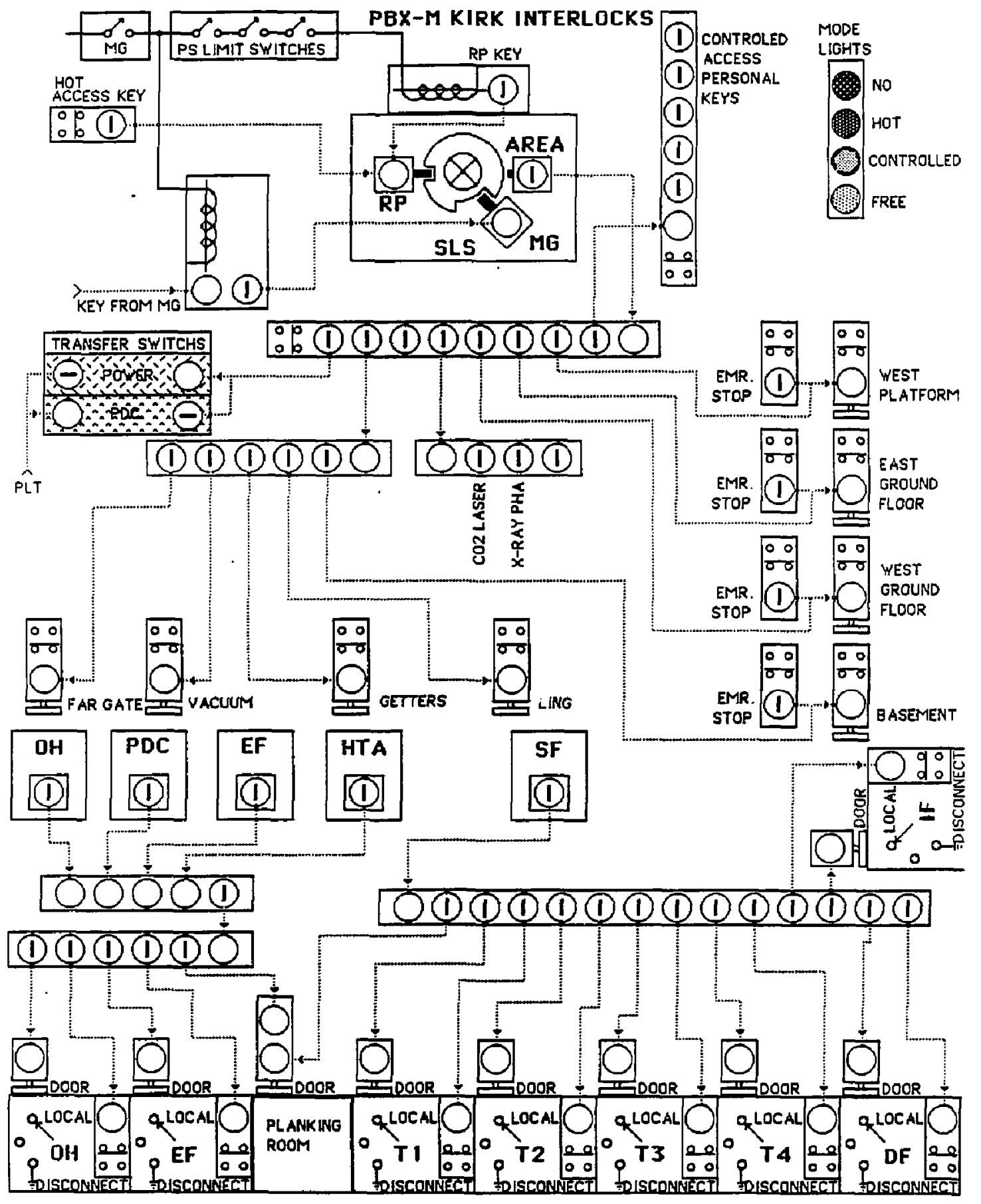

Figure 4.4-3 


\subsubsection{Master Disable}

The hardwired Master Disable is used to disable the output circuits of each PLC until the test cell is secured. It is also used as a disable interlock when

- Kirk switches or door interlocks open while the SLS is in the RUN mode. Another use of this function is when communication between the control console and PLC is lost: the operator can activate the master disable pushbutton located on the control console.

\subsubsection{Remote Control and Monitoring of Power Systems}

\subsubsection{General}

\section{A. Block Diagram}

A typical block diagram depicts the one line schematic of the given power subsystem; the physical arrangement; and the control interface to the power supply, the central controls, and any hardwired interlocks which are separate from the PLC controls. For illustration purposes the $\mathrm{TF}$ and $\mathrm{OH}$ subsystem block diagrams are included (Fig.'s 4.4-4 and 4.4-5). The remaining poloidal fleld subsystems closely resemble the $\mathrm{OH}$ subsystem.

\section{B. State Transition Diagram}

The control of each of the subsystems follows a structured sequence of events. Some of these events are operator commands which will perform state transitions. The operator can exercise both upward and downward transitions. The upward transitions, which put the subsystem in a progressively more unsafe state (or closer to current pulsing) require that all the permissive conditions be satisfled. The operator and the control system can perform downward transitions, which bring the subsystem down into a safer level. The major states and the corresponding transitions for the $T F$ and $O H$ subsystems are shown on state transition diagrams, Fig's. 4.4-6 and $4.4-7$. 


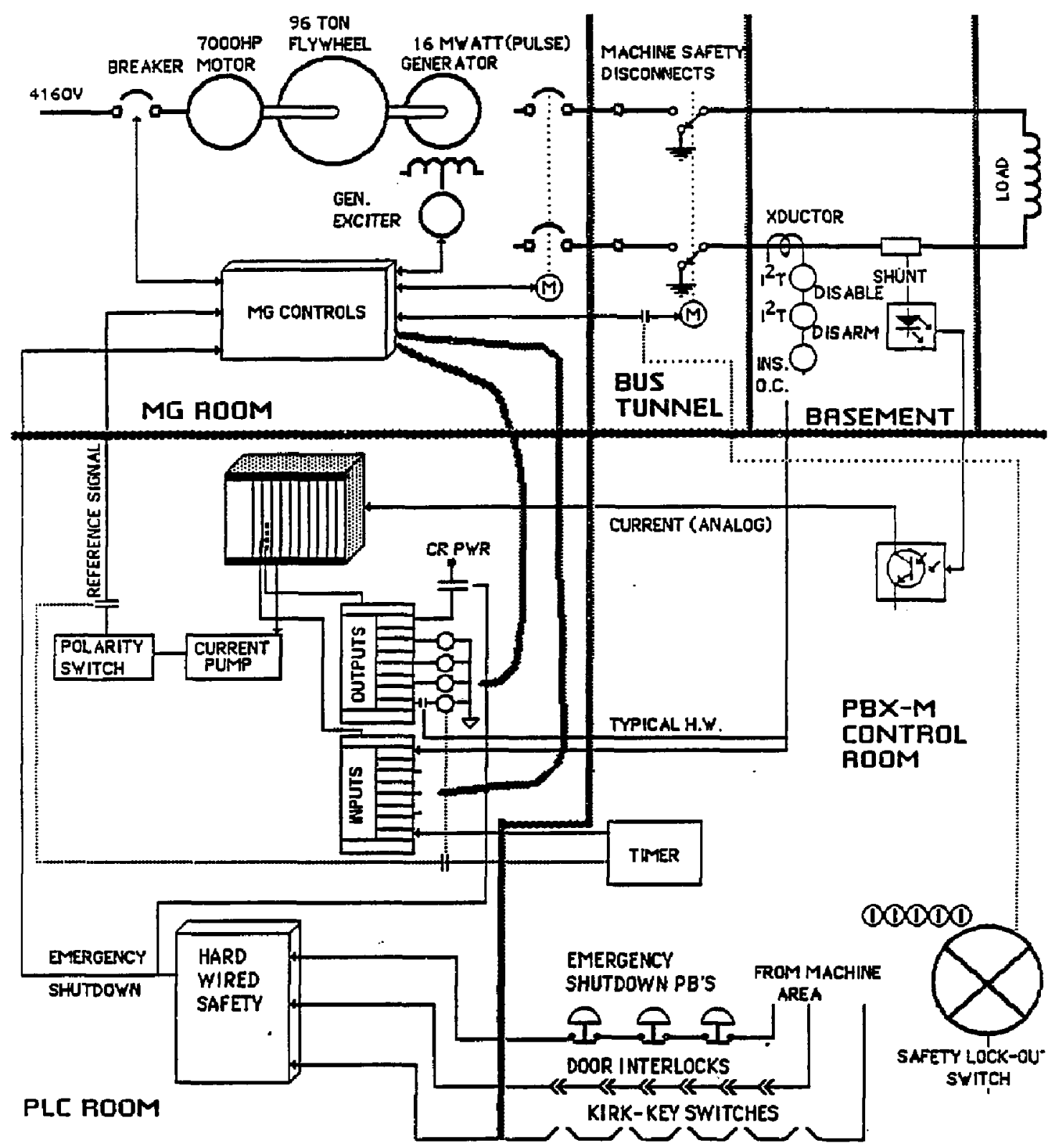

- TF CONTROLS BLOCK DIAGRAM

Figure 4.4-4 


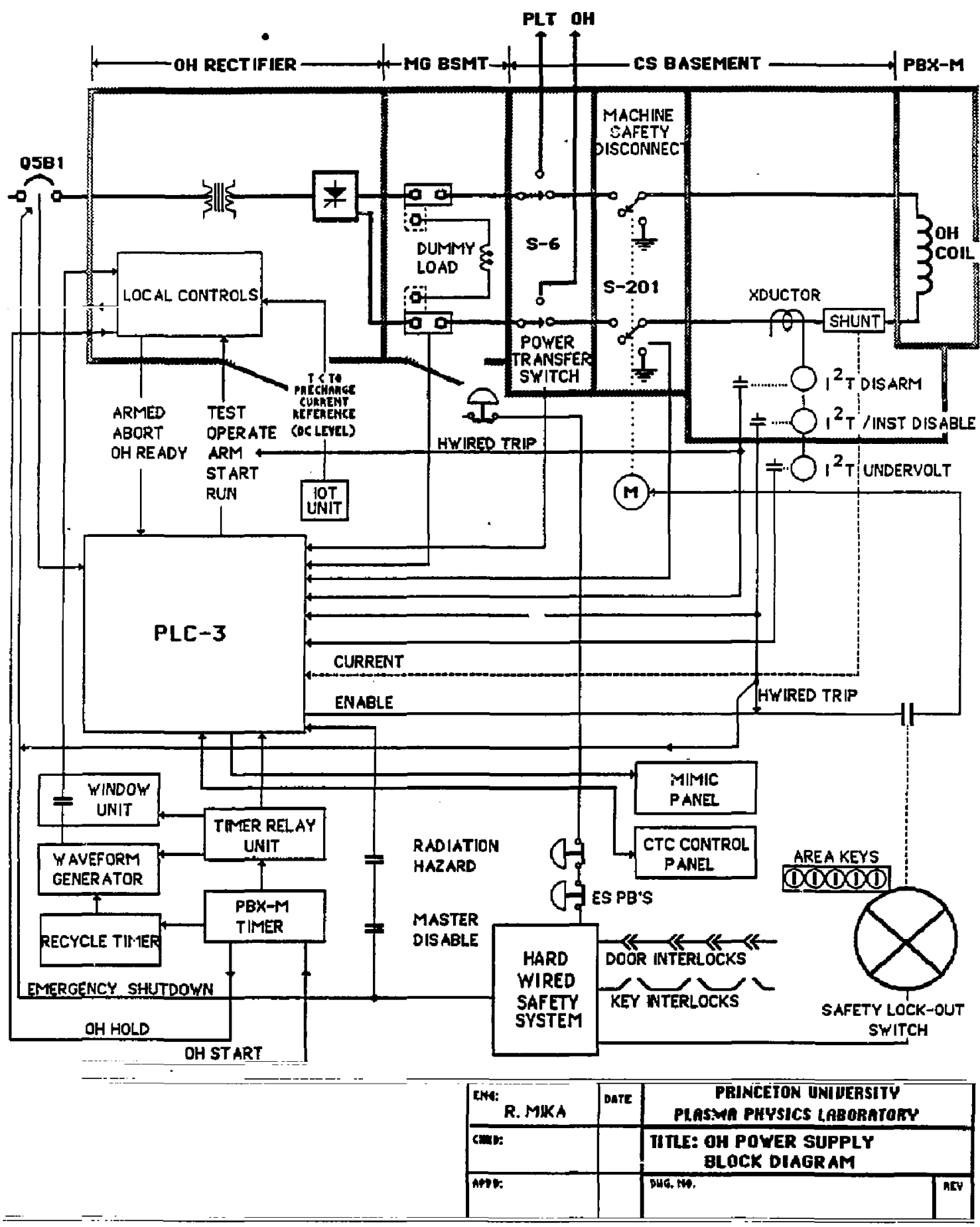

Figure 4,4-5 


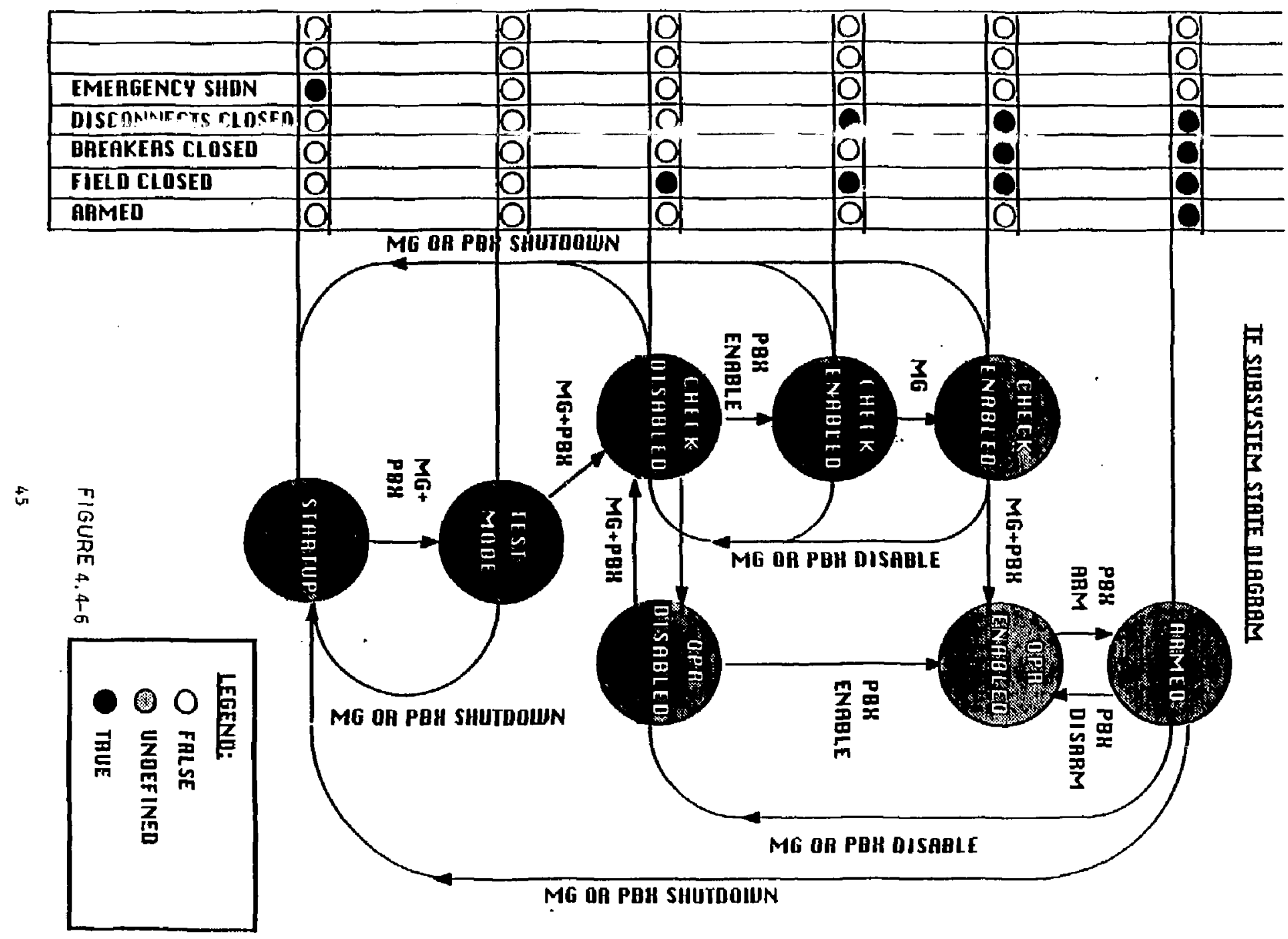




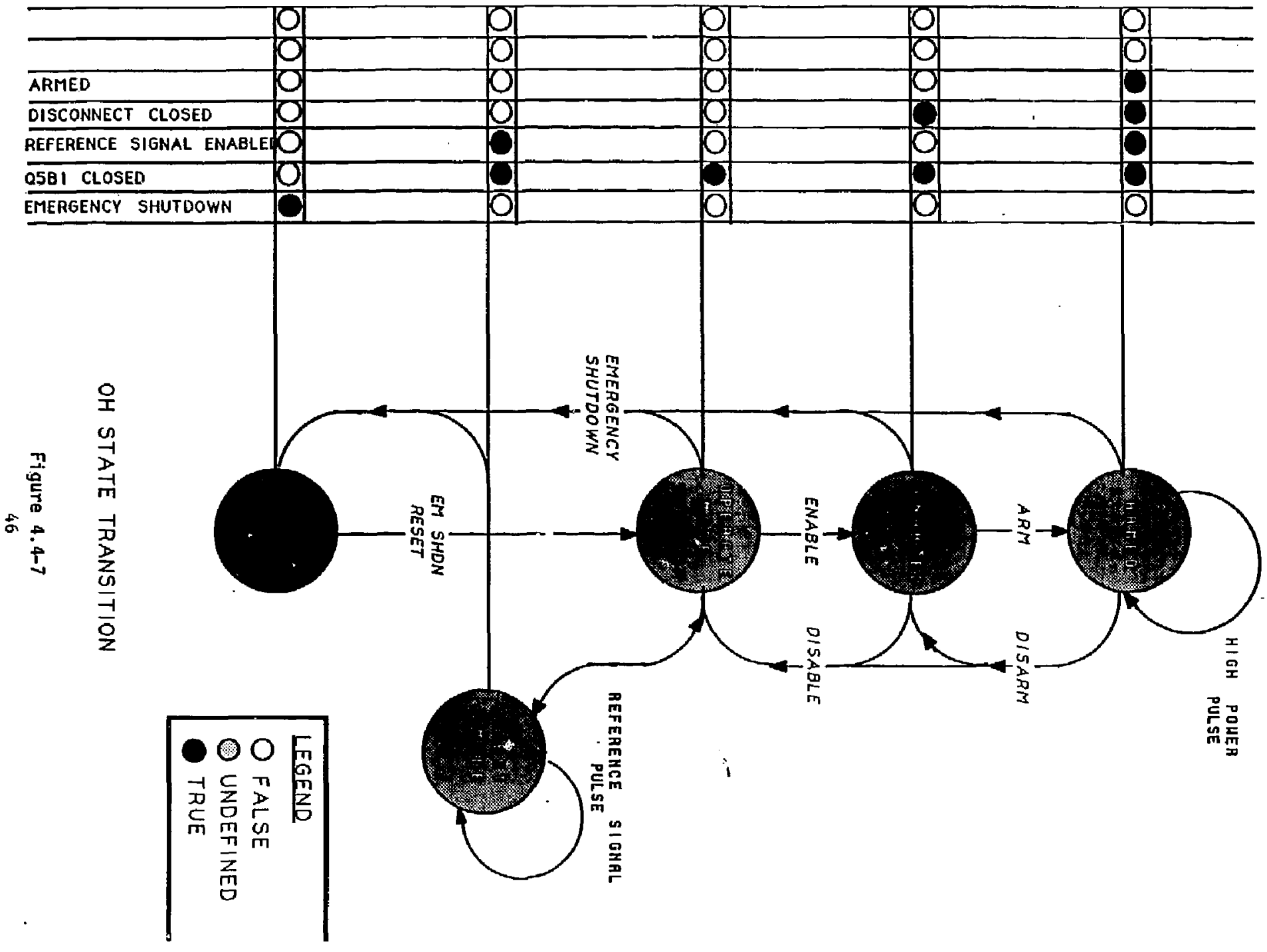


4.4.3.2 Toroidal Field Subsystem (HG)

A. Definition of functions (state transitions)

ENABLE IN OPERATE WODE

This function closes the disconnect switches, then the resistor breakers, and finally the high speed breakers.

ENABLE IN CHECK MODE

This function closes the disconnect switches only, permitting manual closing of the generator breakers by the $M G$ operator.

ARM

This function connects the reference signal path to the generator field controls.

DISARM

This function disconnects and shorts the reference signal path to the generator field controls.

\section{DISABLE}

This function disarms the TF subsystem and trips the generator high-speed breakers, resistor breakers, and after a time delay opens the disconnect stitches.

\section{ERERGEHCY SHUTDOLN}

This function disables the TF subsystem and trips the generator field circuits. It will also force the TEST wode in the C4 controls.

\subsubsection{Poloidal Field Subsysteas}

B. Definition of functions (state transitions)

ENABLE

The primary function of enable is to close the disconnect switch. For the SF subsystems this function also closes the AC contactor. 
ARM

This function applies a control signal to the control rail of the reference signal relay allowing it to be operated by the PBX-M timer.

RUN

The run signal is timer generated; and if the subsystem is armed, it connects firing pulses to the SCR's allowing them to gererate current.

DISARM

This Function disconnects and shorts the reference signal path to the power supply.

\section{DISABLE}

This function disarms ine subsystem and after $a$ time delay opens the disconnect switches, For $S F$ power supplies it also opens the $\mathrm{d}$ C contactors.

\section{EMERGENCY SHUTDOWN}

This function disables the subsystem and trips the main AC breakers. It will also force the TEST mode in the controls.

4.4.4. Machine Protection Eunctions

\subsubsection{PLC System Protection}

Since the PLC system is based on complicated computerized control equipment, there is potential for failure. The manufacturer (Reliance Electric) incorporated a number of safeguards which will detect any single point failure and shut down the process in a safe manner. In addition, at PPL we have designed both hardware and software features that will further enhance the integrity of the control system. Among them are watchdog timers that monitor the communication, through the $I / 0$ interface, the serial link to the control console, and the R-Net local area network. Upon detecting loss of communication, the system wlll selectively shut down.

\subsubsection{Reference Signal Protection}

The protective features for the reference circuit were designed to minimize the chance of producing excessive ourrent due to failures in the reference signal axplitude or pulse length. Problems with amplitude are reported to the operator. Since PaX-M 
is operated in a pulse mode, the reference signal is only allowed in a window of time around $T(0)$. At other times the reference cireuit is disconnected from the power sources and grounded.

\subsubsection{Overcurrent Protection}

Each of the TF, OH, EF, IF, DF, T1, T2, T3, and T4 coils are equipped with a transductor that drives two integrating type oyercurrent relays used for I ${ }^{2} t$ protection. The two units are set for selective tripping, the lower set unit disarms, the other disables the respective power subsystem. The instantaneous overcurrent trip also causes disable. The new implementation of these protective functions incorporates direct hardwired trips for both the disarm and disable signals. In the case of the $O H$ and $E F$ power supplies the hardwired disable opens the $4160 \mathrm{~V}$ breaker, since these power supplies are not equipoed with vacuum contactors.

\subsubsection{Coil Cooling System}

Each of the coils are cooled by deionized chilled water. There are approximately 100 inputs to the PBX$M$ controls system monitoring the status of over 500 flow and temperature switches. Any of these switches can disarm all operating systems by a global interlock. Some coils experience a larger temperature excurstion after each pulse than others. In order to prevent temperature ratcheting, additional temperature switches ( set to trip after each pulse) were installed on the $\mathrm{OH}, E F$, and IF coils and are interlocked with the PBX-M Timer. The Timer is placed on hold until all these suitches are reset.

\subsubsection{Hydraulic Clamp}

The unique dewountable construction of the TF coils resulted in two joints in each coil. These foints are equipped with floating hydraulic clamps to impose a 2000 psi contact pressure on the joint and to allow relative notion of one coil with respect to another. The hydraulic system is operated at 8000 psi pressure and 40 pressure switches are used to monitor the pressure of each line. A pressure drop in the system would cause an increase in the electrical resistance at the joint which could result in thermal damage. The control system does not allow machine operation unless the pressure is normal. 
4.4.5. Eailur: Mode and Effect Analysis

Critical failures for PBX-M operations, their effects, and both primary and secondary protection against those failures are shown in Table 5.14 .

\subsection{Radiation (J.R. Stencel)}

\subsubsection{Ionizing Radiation}

The exposure history of the occupied areas having the greatest potential for personnel exposure is as follows:

In 1981 and again in 1982, the accumulative exposure doses to the PDX Control Roam relative to PLT and PDX operation, did not exceed 200 mrem (St82, St83). In the first six months of 1983, these levels reached approximately 600 mrem (St.84a, St84t) as PDX operations went into a perlod of extensive $D-D$ runs before the PDX was sthut down to become the PBX. In 1984, the levels were at 100 mrem (St85a, St85b) and in 1985, the levels were 365 mrem (G.86). Because no individual spends his entire time in these areas, actual personnel exposures are much lower.

Occupational exposures are presently governed by $\mathrm{Ch}$. XI of DOE Order 5480.1A (DOE81) and PPPL HSD-5008, Ch. 10. (HSD 10). Draft Order 5480.11 is expected to be implemented by DOE within the next year.

Exposure control follows the as-low-as-reasonably-achievable (ALARA) philosophy. It. is Laboratory Policy, that if an exposure is expected to exceed $1000 \mathrm{mrem} / \mathrm{year}$, the Project Manager wust petition the Executive Safety Board (ESB). If it appears that this level will be exceeded, the Project Manager will have to convince the Executive Safety Board that all reasonable measures have been taken to remain below this level. In no case will the dose be permitted to exceed the legal whole body exposure dose limits of $3 \mathrm{rem} / q u a r t e r$ and 5 rem/year.

Fadiation fluxes from the PBX-M are expected to be similar to the PBX, and at most, a factor of 2 higher (Ok86). The radiations involved are primarily neutrons (during D-D runs) and hard $X$-rays (Eremsstrahlung). Activation of vessel parts, as on PAX, are expected to be insignificant. Calculation of activation levels were done for PBX in 1980 (Sc80). This report postulated a 400 mrem/hour exposure rate at 1 minute after 500 pulses. Actual operations were such that measured levels were never weasured to be over a few mrem/hour at the earliest occupancy after a run perlod. In any case, standard health physies procedures of radiation survey checks and wipe tests, when appropriate, have been, and will continue to be made before any maintenance or modification procedures begin. 
Personnel will be monitored with radiation dosimeters supplied by an outside vendor. Personnel Dosimetry requirements for PBX-M will be established by the P\&OS Health Physics Branch in accordance with the established criteria of HSD-5008 Supplement 10-1. Records on exposure are kept by the PPPL Safety office. Health Physics will continue, as in the past, to do area monitoring which will consist of passive devices (film, track etch, Thermoluminescent Dosimeters (TLD)) supplied by an outside vendor and in-house TLD for radiation profile stulies. Real tIme monitors our exposure rate at 1 minute after 500 pulses. Actual operations were such that measured levels were never measured to be over a few mrem/hour at the earliest occupancy after a run period. In any case, standard health physics procedures of radiation survey checks and wipe tests, when appropriate, have been, and will continue to be made before any maintenance or modification procedures begin.

The PBX-M will retain the same thick shield wall $(32$ inches of high density concrete) as was used for the PBX. There is no overhead shield on this facility so skyshine radiation will continue to contribute its share of the total exposure dose to occupied areas. Consideration was given to an overhead shield in 1979 ( $\mathrm{Gr} 79$ ). However, because of the cost involved versus the small reduction in potential exposure, along with the knowledge of the operational history of this device, it was decided not to proceed with this task.

The PBX-M will also retain the KIrk interlock system, which prevents access to machine areas, that is, areas of greatest hazards which may include radiation during operation.

With the in-place shielding, interlocks, monitoring, and prior history of the $\mathrm{PDX}$ and $\mathrm{PBX}$, no unusual or unique radiation problems are anticipated for the PBX-M.

4.5.2 Non-Ion1zing Radiation

\subsubsection{Lasers}

The PBX-M, like Its predecessors PDX and PBX, will use some lasers for dlagnostics. These devices are regulated by HSD- 5008 (HSD3) which follows ANSI 2136.1-1986 (ANSI86). Because these laser areas are interlocked during operations, the potential hazards are related to individuals involved in standard aligment and calibration procedures. These individuals by Laboratory Policy must be knowledgeable in the use of lasers, and where supervisors request, they wlll take part in laser training programs. Also all high powered class IV and most class IIIb lasers require written safe operating procedures. 


\subsubsection{RF/Microwave}

RF/microwave heating is being considered for the PBX$M$. The BPPL has had extensive experience with rf/microwave applications on the Princeton Large Torus (PLT) and are installing similar appljications on TFTR.

Any such systems will have rigorous design reviews before Implementation and all applications must meet with the requirements of the PPPL Health and Safety Directive on this topic (HSC4) and ANSI C95.1 (ANSI82). Surveys will be conducted in accordance with ANSI C95.5 (ANSI81) to ensure compliance with the present regulations. Interlocks would be used where appropriate and real time monitors (sniffers) would be installed for some specific frequency applications.

\subsection{Fire Protection and Emergency Services}

\subsubsection{Fire Protection System}

Fire damage is the principal property damage risk. The facility occupies parts of two floors of a multistory building. Both stories are protected by preaction, dry pipe automatic sprinkler systems with the second floor region designed for ordinary hazard accupancy. Fire alarm boxes and sprinkler annunciator alarms are connected through the fire alarm system to the fire and security headquarters which are manned at all times.

All fire alarns are also monitored by the plant monitoring system that provides information in a matter of seconds on the exact location of an alarm and on planned procedures. The system is computerized and Includes the flre alarm boxes and sprinkler annunciator alarms for all PPPL occupied buildings. A Halon fire protection system is installed in the energy storage vault adjacent to the machine area. Smoke detectors that are located in the energy storage enclostre initiate the Halon release sequence, close the vents in the energy storage area, and shut off the ventilation fan.

The control room is protected by a Halon system. When the control room smoke detectors are triggered, dampers in the air conditioning ducts are automatically closed. 
4.6.2 Fire Eighting Personnel and Equipment

The PPPL Emergency Squad, responds to all alarms with a pumper, a fully equipped emergency truck, and an ambulance, according to need. At least five full time fire fighters are available for each shift, 24 hours per day, seven days per week. (Another pumper truck serves as backup.) Under mutual aid agreements additional personnel and equipment from ather plants and Plainsboro Township will respond and provide backup in the event of larger emergencies.

Any new power supplies that present an additional fire hazard will be installed in canformance with existing strict fire protection codes governing the bullding in which this experiment is housed. The capacitor-igritron enclosure as well as the control room have Halon protection. 


\subsection{HAZARD ANALYSIS (Kees Bol/wES Coordinators)}

Accidents of sufficient severity to endanger continuation of program funding and their mitigation or risk acceptance are indicated in section 5.1 below. Other fallure modes are listed in section 5.2 .

\subsection{High Consequence Accidents To Equipment}

\subsubsection{Machine Accidents}

\subsubsection{Mechanical Failures}

A. Vacuum vessel buckling under combined electromechanical, gravitational, and atmospheric loading.

Analysis: The vacuun vessel, reinforced as per design, can withstand worst case loading under realistic dynamie conditions without stress linits being exceeded in either the vacuum vessel or its supports. The analysis is documented in Engineering Report (EAD R37 Rev. 1).

B. Failure of TF coils, especially the joints, under electromechanical stress (overturning moment).

Analysis: The TF cotl points were a critical item in the original PDX design and are even more so in PBX-M. In the absence of a complete stress analysis, an operating limit has been established for the product of toroidal and poloidal field strength such that the TF joint stresses in PBX-M do not exceed those obtaining in PDX when it was operated at design conditions. By that criterion all PF supplies can be run at rated current for any TF current to $30 \mathrm{kA}$; however, the margin of safety in the PDX design does not appear to have been documented.

Excessive coll currents would constitute a fault condition. Redundant overcurrent protection is provided for all power supplies as shown in Table 5-1. Except for the IF and TF it is a plausible assumption that the intrinsic current limits give adequate stress protection when the $\mathrm{TF}$ is held to $30 \mathrm{kA}$.

Operation of the TF at full rating (43.7kA) is not covered by this document and will require further analysis as well as detailed operating procedures. 


\section{Table 5-1}

\begin{tabular}{|c|c|c|c|c|}
\hline & $I^{(1)}$ & $I^{(2)}$ & $I^{(4)}$ & $I_{2}^{(5)}$ \\
\hline System & op & $\max$ & 1 & 2 \\
\hline$I F$ & 20 & 38 & 22 & 22 \\
\hline DF & 10 & 15 & 11 & 11 \\
\hline T1 & 5 & 16 & 6 & 6 \\
\hline$T 2$ & 5 & 17 & 6 & 6 \\
\hline T3 & 5 & 15 & 6 & 6 \\
\hline T4 & 5 & 14 & 6 & 6 \\
\hline$E F$ & 10 & 10 & $?$ & 11 \\
\hline $\mathrm{OH}$ & 20 & 25 & 22 & 22 \\
\hline$T F$ & 30 & $41^{(3)}$ & $?$ & 33 \\
\hline
\end{tabular}

\section{Table 5-2}

$\begin{array}{ccccc} & \text { Max } & \text { Normal } & \text { High } & \text { Low } \\ \text { Fault } & \operatorname{Max} & \text { Setting } & \text { Setting } \\ \text { Coil } & T\left({ }^{\circ} \mathrm{C}\right) & T\left({ }^{\circ} \mathrm{C}\right) & \left({ }^{\circ} \mathrm{C}\right) & \left({ }^{\circ} \mathrm{C}\right)\end{array}$

$\begin{array}{llllc}\text { OH } 8 / 9, \text { T\&B } & 35 & 22 & 48-52 & 19-21 \\ \text { OH } 7 \text { T } & 24 & 15 & 40-44 & 19-21 \\ \text { EF 21, T\&B } & 20 & 12.3 & 40-44 & 19-21 \\ \text { IF 1 } & 39 & 16 & 40-44 & 19-21 \\ \text { All other colls } & - & - & 40-44 & -\end{array}$
(1) Design ratings
(2) Maximum currents power supplies can produce, given the primary reactance and the load resistance. (ER 1)
(3) Under-speed trip ( 2 shafts, $4 \times 2$ generators)
(4) Instantaneous trip relay, power supplies
(5) Instantaneoug trip relay, machine side 
c. Eailure of inaccessible buswork

Analysis: Buswork supports are presumed designed for operation at full parameters, but a comparison of design with "as built" status is not possible for the critical buswork to inner stack coils, nor were the original design oriteria documented. - The "as built" completely unsupported bus pair to $\mathrm{OH} 8-9 \mathrm{~L}$ was braced in 1983 through windows cut in the inner wall of the vacum vessel and the matching upper pair does have some support. Fortunately, the PBX-M design currents in the remaining inner stack colls are reduced to half or less EF solenoid of the uriginal values, so that even at full TF operation there will be a margin for those colls. Furthermore, the changed mode of operation of the $\mathrm{OH}$, by allowing a much better balance of the $+/$-current swing, will reduce the maximum stress in those busleads for equivalent volt-second applications. The administrative application of signal level clamps will enforce the operating procedures to ensure this result.

D. Stressing EF colls by increasing rating from original design value of 7.2 to lokA.

Analysis: A previous analysis showed operation at 10kA to be acceptable. Operation at $15 \mathrm{kA}$, also contemplated at one time, would have required additional bracing of the coils themselves.

\subsubsection{Electrical Failures}

A. High resistance joint, leading to pitting, arcing and ultimate destruction, also to ignition of insulation by molten metal or the are itself. Widespread soot can hamper machine operation though probably not force a permanent stop. 
Analysis: Joints in TF buswork are monitored regularly. However, many bus joints in other systens are accessible only with difficulty, and the beneflt of preventing an accident has to be balanced against the increased $r$ isk of causing one when reinsulation of the joint is carried out under very cramped and difficult conditions. In those cases the defense will be ex post facto, and will consist of much better fire and smoke detection for the Halon system than existed for PDX-PBX.

\subsubsection{Overtemperature Failures}

A. Deterloration or destruction of coll insulation and subsequent turn-to-turn shorts.

Analysis: To protect against insulation damage from overheated coils $\left(\mathrm{T}^{2} 0^{\circ} \mathrm{C}\right.$, CH87) PBX-M uses the following system: the shot timer is inhibited from beginning a new cycle until the water temperature in certain critical goils has dropped to a preset low temperature; $I^{2} t$ relays limit the temperature rise from a credible fault current; and all systems are disarmed if any coil system exceeds a preset high temperature. The first two protect against damage from excessively high currents, from which the temperature rise of the copper far outruns the thermal measurement, and the third is protection against $a$ steady ourrent that exceeds the permitted level but which may fall in the "dead" zone of the I $\mathrm{C}_{t}$ relay.

Table 5-2 shows the coils that have been selected for special protection. AlI other coil systems have a fault temperature so low $\left({ }^{<} 7^{\circ} \mathrm{C}\right)$ that an initial temperature just below the high temperature trip point will not result in damage from a subsequent fault. For the selected coils the opposite is true. Hence, it is necessary to ensure against insulation damage by starting a shot at a low enough coll temperature so a subsequent fault will not cause damage.

B. Fatigue failure of coils under repeated and excessive thermo-mechanical stress.

Analysis: Eatigue due to thermal cycling has not been found to be a problem where it has been examined. 


\subsubsection{Accident Sources External to Machine}

\subsubsection{Seismic}

A. Collapse of shield wall.

Analygis: Unlike the remainder of the PBX-M shleld wall, the older segment dividing PLT from PBX-M consists of stacked smooth rectangular blocks having no keying feature. An analysis undertaken in 1989 by the PPPL Mechanical Engineering Division to investigate raising the height of the divider, concluded that this should not be done without relnforcing the structure. A calculation by E. Kaminsty and $E$. Nelson carried out in 1980 showed the block wall separating PLT and (then) PDX to be unstable in case of an mpe event (i.e., a once-in-a hundred year earthquake). A job has now been initiated to brace at least that section of the shield wall.

5.1.2.2 Fire

Analysis: The machine area is protected by a Halon system. The smoke detection system is in process of being upgraded.

\subsection{Failure Mode And Effects Analysis}

The following tables are the Faflure Mode and Effects Analysis for the reconfigured PBX-M Experimental Device. 
TABLE 5-3

VACUUM VESSEL ASSEMBLY

FAILURE MODES AND EFFECTS ANALYSIS

\section{Component}

1. Vacuum Vessel

Plate Sections

\section{Function}

Maintain vacuum condition

C) Leak in elastomer seal joining vacuum vessel components

A) Non-catastrophic air leaking

external

attachments

B) Catastrophic vacuum fail ure, as by

inplositon of

a WIndow

\section{Fault Detection \& Erfect/Corrective Action}

Torus interface values close; audible vacuum alarm warns operators. Stop operation, locate leak and repair.

Vacuum alarm is above. Damage to pumps probable, Preventive measures: minimize window gize; cover windows with plexiglass where compatible with diagnostic requirement; do careful checks for loose magnetic materials (tools, etc.) before each run.

Same as (A); however, many of the joints are inaccessible. Construction of the seal allows it to be pumped, providing some tolerance in seal quality. 
2. Vacuum Vessel insulating gap

3. Vacuum vessel coolling/heat ing tubes on walls

Cool vessel during multigetter operation;

heat during pumpdown

Leaks in coolling

tubes

4. Internal active

Shape plasma

gr
Avoid short-

circuiting OH voltage
A) Leak in vacuum

housing

through

defective weld

F) Leak due to particle impact
Low voltage observed on internal flux loops and consequent inability to initiate discharge. Prevention: shield gap from plasma, debris. Corrective action: short defective gap and remove shorting bars from second gap, $180^{\circ}$ away.

Loss of vacuum (see 1A). Cooling is not used; hot water heating only used during pumpdown. Corrective action: keep defective tubes under vacuum until next opening and then repair.

See 1A. Pump defective coll. If leak can be located, repair.

See above. Preventive measures: exposed cofls are shielded from neutral beams and plasma with graphite armor and with additional stainless steel shields. 
TABLE 5-II

NEUTRAL BEAM INJECPION SYSTEM

FAILURE MODES AND EFFECTS ANALYSIS

\section{Component}

1. Neutral BeamTorus Duct

$\$$

2. Main Valve

\section{Function}

Conneots Neutral Beam to torus vacuum vessel; provides adequate clearance for beam

Provides a seal between the torus and neutral beam vacuum enclosures when alther vessel is pressurlaed while the other is under vacuum

\section{Fallure Mode}

Missteering of Ion beam

A) Fallure to fully open on command

B) Fallure to fully close on command

c) Leakage through valve seals

\section{Fallure Erfect/Correctlve Action}

Potential Impingement of beamline onto duct walls or components. Posslble damage is prevented by duct scrapers whlch are positloned at the smallest section of duct to "gcrape off" any beams diverging outside the defining aperture; and by water-cooled protcctive plates which prevent power deposition onto critical components of the maln value. Optical sensors at the duct scraper detect beam dif ift to provide for its correction.

i) Beam pathway to torus is partlally or totally blocked preventing neitral beam injection. Beami ine calopimeter remaing In position blocking the neutral beam unt 11 the maln valve is fully open.

B) Inabillty to seal NB vacuum vessel from torus vacuum vessel when one vessel is pressurlzed, as required, unt 11 repalrs are made.

C) Fallure effect and corrective action as in I tem 2, fallue mode B). Removal of undesirable gas flow into evacuated vessel can be accomplished by the vacuum pumplng systems or the Nil cryopanels (if cold). 
3. Ion Source

Generates a low-volgage, hIgh-current discharge to produce a plasma from which deuterium lons are extracted and accelerated

4. Ion Deflection Magnet

\section{Cryopumping} System
Deflect tons from the mixed beam leaving the neutralizer, onto the ton duimp

Maintain proper vacuum conditions in the NBL from the deflection magnet to the torus end of the NB torus duct during normal operations
Filament or electrode (arc) short elrcult

A) Fallure of magnet power supply

B) Break in electrlcal supply line to magnet, or break in magnet wind Ing

A) Cryogenic. I the rupture
Greatly reduced generation of qui escent uniform plasma and deuterium lons in af fected NBI's. Af'fected power supply (are or fllament) is automatically shut cown and energy is safely disslpated without damage to affected NBI's or Neutral Beam Power Supply. NB aperation can continue with the affected source shut down unt ll repairs are made.

A) Ions are not deflected onto the lon dump but are sprayed onto the NB-torus duct. Duct scrapers and protective plates prevent damage to duct and duct components, as per I tem 1. Ion source Is shut down by NB Power Supply. NB operation can continue in degraded mode until repalrs are made.

B) See (tem 5, fallure mode A).

A) Release of cryogente flutd(s), boll-off of of condensed gases on NB cryopanels, and pressure increase in Cryogente Supply System (CSS). NB operation will cease and gate valve wlll close. Burst discs in the CSS will relleve any high pressure surge In the eryoplanels and CSS. Gases bolled off from the cryopanels can be removed by the Neutral Beam Vacuurm System. Absence of personnel in Test Cell during operations, as well as use of special procedures during maintenance will prevent hazards to personnel from released cryogens. 
B) Loss or degradation of cryogenic supply to cryopanels

6. Neutral Beam Vacuum Vessel

Provide main vacuum envelope for NBL

Provides cooling water to remove heat generated in ion sources, ion dumps, calorimeters, beam scrapers neutral1zers, deflection magnets, and NB duct pro-

Major leakage ar rupture

A) Loss or degradation of cooling water supply nents
B) Effective pumping by cryopane ls is degraded resulting in eventual shutdown of affected NBL. If fast warmup of cryopanels is involved, burst discs in CSS will prevent damage to cryopanels. Bolled of gases can be removed by NBUS to NBL compo-

B) Leakage or rupture of cooling water line inside NB vacuum Vessel
Pressure rise in the vessel Hill automatically shut down the NBL and close the absolute valves. Fast warmup of the cryopanels will cause burst discs in the cSs to relieve excess pressure and prevent damage to cryopanels.

A) Low water rate flow to and/or high water exit temperature from water-cooled components w1ll cause interlocks in the NB Control System to shutdown the affected NB Power Supply(s) thus inhibiting NB operation. At least $10 \%$ of design water flow must be maintained in NBLCWS to prevent water freezing in components and piping subject to $\mathrm{LN}_{2}$ temperatures, until temperature in the affected NBL components reach above-freezing levels.

B) Loss of coolant would cause shutdown of of affected NBIS, as in 1 tem 8 , failure A); cause pressure $r$ ise in NB vessel (detected by vacuum gauge readout in Main Control Room); and would result in vaporlzation of leaking water and subsequent (initial) condensation on cryopanels. Cryogenlc supply to cryopanels wlll be shut down, and pressure rise in panels and CSS could cause burst discs in CSS to vent and relleve pressure. Gate valve will close and NBVS will be (remain) isolated from affected NBL. Water supply flow will be shut of $f$ as soon as possible, consistent with prevention of line freezing, and heatup of cryopanels. Hith increase in temperature of the cryopanels, condensed 
8. Neutral Beam Injection System
Injection of Neutral ized lons into the plasma

providing auxilary heat ing
Loss of electrical power at the bottom of the NB Vessel.

All Ion sources are automat leally shut down and gate valve closes. Cryogen flow to NB cryopanels is stopped and any pressure surges In the CSS or cryopanels are relleved by CSS burst discs and relief valves. Gases bolled off from cryopanels are released to NB vessel. 
TABLE 5-5

VACUUM PUMPING SYSTEMS FAILURE MODES AND EFFECTS ANALYSIS

\section{Component}

1. Duct, Torus to High Vacuum Pump

\section{Function}

2. Flange, Torus to High Vacuum Duct

3. Bellows, Joint Assembly; Torus to High Vacuum Duct

4. Ceramic Joint

5. Duct Bellows, Joint Assembly, High Vacuum Duct to TMP $(41 \mathrm{~cm})$

6. Valve, Assembly TwP Inlet - High Vacuum Isolation TVPS
Torus gas transmission, vacuun access to torus

\section{Failure Mode}

Leakage

Facilitate installation and structural joining. two flanges.

Torus motion isolation from hlgh vacuum pumn for each duct, two bellows.

Electrical Insulation

Motion isolation for each TMP in the TUPS

Isolation of TMP from torus vacuum vessel
Leakage

Leakage

Leakage

Leakage

A) Failure to close on command

B) Fallure to close on command

c) Internal

\section{Fault Detection \& Effect/Corrective Action}

Pressure rise in torus and vacuum system detected by pressure instrumentation. Machine (PBX) operation and experiment interruptedpotential deuterium or hydrogen release to test cell area. Hepair as soon as possible.

Same as Item 1.

Same as I tem 1.

Same as Item 1

Same as I tem 1

A) Detected by valve position switch. If "Close" command is due to railed TMP, machine operation and experiment will be interrupted Bring torus up to atmosphere with $\mathrm{N}_{2}$ gas. Repair as soon as possible.

B) Detected by valve position switch. Machine operation continues in degraded mode. Repair at next scheduled maintenance period.

c) Detected by pressure instrumentation. 
6a. Valve Assembly, TMP Inlet - High Vacuum I solation

Isolation of TMP from NBL

High vacuum pumpling of torus

Regeneration of Neutral Beam and initial pumpdown from $10^{-1}$ torr
TMP Assembly/TUPS (8)

8. TMP AssemblyNBVS (4)

9. Duct, TVPS-TMP Discharge Vacuum leakage

(across value seat)

D) External leakage

A) Fallure to close on command

B) Fallure to open on command

A) Fallure to start on stops running

B) External leakage

A) Failure to start on command or stops running

B) External leakage

Leakage command or

PBX-M operation will be interrupted. Bring torus up to atmosphere and repair as soon as possible.

D) Same as I tem 1 ,

A) Detected by valve position switch. Failure of valve to close will preclude NB operation due to excessive TMP pressure during Regeneration or ofl back-migration if TMP failed. Vent $\mathrm{NB}$ with dry $\mathrm{N}_{2}$ and repair as soon as possible.

B) Detected by valve position switch. Machine (PBX-M) operation continues in degraded mode whereby the main roughing pumps regenerate NB cryopanels. Repair at next scheduled maintenance period.

A) Detected by pressure instrumentation. isolation valve automatically closes. Machine operation continues in degraded mode. Repair at next scheduled maintenance perlod.

B) Same as Item 1.

A) Detected by pressure instrumentation. Isolation valve automatically closes. Machine continues in degraded mode. Repair at next scheduled maintenance period. Can regenerate using roughing system.

B) Same as 1 .

Access for gases from TMP to backing valve
Same as I tem 1. Isolate TMP assembly. 
10. Duct, NBVS-THP Discharge Vacumn

11. Valve, TMP Backing TMP(TVPS)

Evacuate gases from NB

Isolate THP discharge from backing manifold

12. Valve, TMP Backing (NBVS)

Isolate TMP discharge

13. Pressure Gages for (8) TVPS-TMP's (3) NBVS-TMP's

14. Valve, Torus Roughing Duct
Leakage

A) Failure to close on command

B) Fallure to open on command

c) External leakage

Failure to close on command

\section{Erroneous}

indication

Isolate torus from me-

chanical roughing/backing pumps. The duct in which this value is located is also used to take suction on the torus (by the tritium cleanup system) when a leak occurs in the torus or vacuum system.

\section{A) Eailure to open on command}

Same as Item 1; unable to regenerate NB. lsolate TMP assembly.

A) Detected by value position switch. Shut down all THP's and stop PBX-H operation, Repair or replace as soon as possible.

B) Detected by valve position switch. Affected TMP is automatically shut down. Machlne operation continues in degraded mode. Repair at the next scheduled maintenance period.

C. Same as Item 1 .

Detected by valve position switch.

Redundancy provided by additional instruments. Machine operation may safely continue.

A) Detected by value position switch. Rough pumping of torus is precluded.

B) Failure to close on command
B) Detected by valve position switch. Torus is exposed to roughing manifold pressure and $\mathrm{PBX}-\mathrm{M}$ operation is impossible (cannot achieve high vacuum). Repair as soon as possible. 
15. Valve, Forel ine Trap Vacuum Inlet (TVPS)
Isolate foreline trap/ backing pump from remainder of system
A) Fallure to open on command

B) Failure to close on command

Provide for rough pumping of the torus and neutral beams

\section{Provide backing for} TMP's Assembly Backing (2 for TVPS)

18. 011 Demisters

19. Backing/Roughing Pumps Exhaust Line

20. Solenoid Valve, TMP water inlet phere or tritium cleanup

Pumping ceases
Isolate coolant

Capture exhaust of contamination from mechanical pumps

Transfer gas to atmosunit

B) Fallure to close
A) Failure to open
A) Detected by valve position switch. Can use redundant pump for TMP backing (will take longer for pumpdown). Repair at next scheduled maintenance.

B) Detected by valve position switch. If "close" command is due to backing pump fallure, vacuum system(s), $P B X-N$ and/or neutral beam operations are shut down. Repair as soon as possible.

Detected by pressure instrumentation. Rough pumping can proceed over a longer time interval using redundant pump. Isolate affected pump and repair at next scheduled maintenance.

Detected by pressure instrumentation. Redundant pump is capable of providing backing for all TMP's with full gas load. lsolate and repair at next scheduled maintenance.

Some oll contamination of exhaust line occurs, however, maintenance schedule will preclude this failure made.

Detected by pressure instrumentation. Patential leakage of trace amounts of tritium, area monitors will detect the low levels released and exhausted via the HVAC system. Shut down system (and $\mathrm{PBX}-\mathrm{M}$ ) and repalr as soon as possible.

A) Detected by cooling water flow switches. Coolant unavailable to TMP. TMP WIll automatically stop or be prevented from starting. Repair or replace at next scheduled maintenance period. Can continue to operate in degraded mode.

13) Detected by cooling water flow switches. close hand isolation valve and shut down TMP. Repair or replace at next scheduled maintenance period. 
21. Valve, TMP Nitrogen Supply

Isolate vent gas

8:

\section{Valve, TMP} oll Drain c) Leakage

Leakage
C) Loss of cooling water detected by flow and/or temperature switches. Potential impact on electrical equipment. Clase hand isolation value and shut down TMP. Can continue operating in degraded mode. Repair at next scheduled maintenance perlod.

Detected by nitrogen supply pressure switch. Potential oll backstreaming upon TMP shutdown. Rebake of TMP plus valve repair or replacement required at next scheduleḍ maintenance perlod.

Fallure to close Detected by nitrogen supply pressure sultch. Nitrogen delivery continues to TMP. Close TMP inlet and discharge isolation valves. Repair or replace at next scheduled ma intenance perlod. Continue machine operation with remaining active TMP's.

Detected by oll level switch. Low all level will result in automatic shutdown of TMP and closure of inlet and discharge valves. Continue operation with remaining active TMP's. Repair at next scheduled maintenance period. 
TABLE 5-6

NITROGEN SUPPLY SYSTEM FAILURE MODES AND EFFECTS ANALYSIS

Component

1. Liquid Nitrogen Storage Tank

ฮั

2. $\mathrm{LN}_{2}$ Storage Tank outlet Valve

3. Vacuum Jacketed Supply Lines

\section{Function}

Stores the $\mathrm{LN}_{2}$ supply

on-site

Isolate storage tank from supply system and loads

Transmission of $\mathrm{LN}_{2}$ supply to service

loads
Fallure Mode

A) Leakage

B) Overpressurization

c) Underpressurization

A) Fails to close on command or falls closed

B) Falls to close on command

Thermal/leakage

\section{Fault Detection \& Effect/Corrective Action}

A) Loss of LN detected by tank pressure ind 1cator or level indicator (local). Isolate tank from supply system, and temporarily provide $\mathrm{LN}_{2}$ from tank truck. Repair as soon as possible.

B) Detected by tank pressure instrumentation Excessive pressure precludes nominal service to loads. Pressure is relieved handoperated valve relief value (75 psig) or burst disc ( $90 \mathrm{psig}$ ). Repair as soon as possible.

c) Detected by valve position indicator. $L_{2}$ cannot be transferred from tank to service loads. Shut down system and loads and repair as soon as possible.

A) Detected by valve position indicator. $\mathrm{LN}_{2}$ cannot be supplied to loads and will result in eventual shutdown of NBL's. Repair as soon as possible.

B) Detected by valve position indicator. $\mathrm{LN}_{2}$ storage tank can be isolated via closing of individaul service load supply valves (and later by hand operated valve). Repair as soon as possible.

Contamination of the $\mathrm{LN}_{2}$ in the system with oxygen due to inleakage could cause a potential explosion hazard (if the leak is not repalred). Shut down Nitrogen. System and affected load(s) until repairs are made. 
4. LN Supply Valves to Loads

5. Pressure Relief Valves without Redundant Paths
Isolate $\mathrm{LN}_{2}$ supply to individual service loads

A) Fails to open on command or falls closed

B) Falls to close on command

\section{Overpressure} protection
A) Premature rellef

B) No relief
A) Detected by valve position indicator(s). Supply of $L_{2}$ to affected service load is prevented or interrupted. Shut down affected load unt 11 repairs are made.

B) Detected by valve position indicator(s). When required, $\mathrm{LN}_{2}$ supply can be isolated by closure of storage tank outlet valve which interrupts $\mathrm{LN}_{2}$ supply to all service loads. Shut down system (and loads) and repair as soon as possible.

A) Uncontrolled rellef of $\mathrm{LN}_{2}$ or $\mathrm{GN}_{2}$ causes reduced system pressure and results in precluded supply service detected by pressure instrumentation. $\mathrm{LN}_{2}$ supply is isolated by closure of storage tank outlet valve and system is shutdown until repairs are made.

B) Detected by pressure instrumentation. Attempt to depressurize faulty leg. Effect repair as soon as possible. 
TABLE 5-7

POLOIDAL FIELD COIL AND NEUTRAL BEAM POHER DISTRIBUTION SYSTEM FAILURE MODES \& EFFECT ANALYSIS

Component

1. Power Main Leads

\section{Function}

Transfer energy feeding power convertors buses

\section{Fallure Mode}

A) Fallure to start on command (Breaker fails to close)

B) Breaker fails to open

C) Overvol tage operation

D) Oyercurrent operalior

E) Short to ground

F) Loss of control power
Failure Effect/Corrective Action

A) Failure will prohibit transfer of power No PBX-M operation. Facilitate repair as soon as possible.

B) Power flow contlnues to distribution system. Stored energy in the coils will be dissipated by intrinsic resistance with-in the colls and Pulsed Energy Con version System circuit. $4.5 \mathrm{kV}$ distribution breakers will be tripped, and system and PBX-M Hill be shutdown. Facilitate repair as soon as possible.

c) Will result in $5 \mathrm{kV}$ overvol tage for 60 milliseconds. System is designed for this operation mode. Breaker(s) open.

D) Thermal stress $\left(I^{2} T\right)$ on system occurs during pulsing operation. System is designed not to exceed predicted ( $\left.{ }^{2} T\right)$ theral stress. Relays detect situation and open breaker(s).

E) Protectlve relaying will cause breaker to trip removing power. PBX-M operation ceases. Facilitate repairs as soon as possible.

F) Breakers have stored energy mechanism which will enable manual operation to isulate the distribution system. PBX-M operation ceases. Facilitate repair as soon as possible. 
2. $5 \mathrm{kV}$ Switohgear and Current Limiting Reactors

\section{istribute power to Individual energy conversion systems}

A) Failure to start on command

(Switchgear breaker fails to close)

B) Failure to stop on command (Switchgear breaker fails to open)

C) Overvol tage operation

D) Overcurrent operation

E) Short to ground

F) Loss of control

G) Inadvertent swi tching

Facilitate power transmission from switchgear to Field Coll and Neutral

A) Overvol tage operation

Beam power supplies. under load

A) Faifure will prohibit transfer of power to affected energy conversion system, and related sub-system operation cannot take place. Facilitate repair as soon as possible.

B) Power clow continues to subsystem. Upstream breaker can be manually operated as a backup trip. PBX-M shutdown; facilitate repairs as soon as possible.

c) See 1 tem 1, faliure mode C),

D) See item 1, fallure mode D).

E) Feeder reactors sized to limit fault to effective breaker rating.

F) See item 1 , fallure mode F). Individual feeder breakers can be manualiy operated.

G) Lass of power to feeder circuit. No power transferred to affected systems. These systems are shut down untli power is restored.

A) Feeder cables designed to $133 \%$ insulation level to permit $60 \mathrm{millisecond,} 8 \mathrm{kV}$ operation. System operation can continue after overvoltage is cleared.

B) Short to ground
B) Feeder breaker fround fault relaying will trip breaker. Affected Field coil or Neutral Beam is prevented rrom operating. Facllitate repair as soon as possible. 
4. Fleld Coil and Neutral Beam

Distribution

System
See Section 7.2.3.1
Fire System will be shut down by protective devices.
Fire detection in the MG Building, East Bullding, or Experimental Area will preclude the existence of an undetected rire of destructive magnitude. Automatic sprinkler and Halon systems in these areas will suppress and contral any fires. 
TABLE 5-8

AUXILIAAY SYSTEMS POWER DISTRIBUTION

FAILUAE MODES AND EFFECTS ANALYSIS

\section{Component}

1. 480 V Feeder clicutt Breakers, $480 \mathrm{~V}$ switahgear bus.

Feeder Cable

3. $4.16 \mathrm{kV} / 480 \mathrm{~V}$ Transformers

4. 4BOV Substation circuit Breakers

5. $4.16 \mathrm{kV}$ Motor Control Center

6. 480 V Feeder Cable
Connects $4.16 \mathrm{kV}$ Feeder to

Connects $4.16 \mathrm{kV}$ subsysten to feeder circult breakers

\section{Fallure Mode}

A) Fallure to close

B) Overheating poor contacts

c) Explosion

\section{Energlzes $480 \mathrm{~V}$ bus}

Connects transformer to $480 \mathrm{~V}$ bus

Starts and stops motors for chillers; provides motor running protection

Connects 480 V subsystem to feeder circust breakers
Short eircuit; grounded

Internal short circuit

Fallure to close, overheating, or poor contacts

Contacts whll not close, or $\mathrm{MCC}$ trips off

Short clrcujt ; Braunded

\section{Fallure Effect/Corrective Action}

A) No power to Feeder. Supply auxillary power with an alternative feeder and circult breaker. Check and repair breaker or control clrcuit.

B) No power to Feeder. Supply auxillary power Hith alternate feeder and clroult breaker. Check load on circult. Preventive maintenance will minimize oceurrence.

c) No power to Feeder, damage to swltchgear, and potential fire. Extinguigh fire. Check overcurrent relays and load on circuit. Preventive maintenance will minimize accurrence.

Trips circult breaker. Supply power with alternate feeder. Prevent through perlodic inspection.

Primary fuse blows; no power supplied to $480 \mathrm{~V}$ bus by affected transformer. Supply loads through alternate transformer.

No power to load through affected substation breaker. Sufply loads through al ternate transformer and its substation breaker.

No power to chlller motors; losy of HVAC system chllled water. Shutdown PBX-M. Repair as soon as possible.

See 1 tem 2 
7. $4160 \mathrm{~V} / 480 \mathrm{~V}$ Transformers

8. 480 V Automatic Transformers Circuit Breakers

9. 480 V Motor Control Centers

10. $4.16 \mathrm{kV} / 480 \mathrm{~V}$ Standby Power Transformer and Network Protector

11. Diesel Generator "Substat ion" Circult Breaker
Energizes $480 \mathrm{~V}$

switchboards

\section{Connects transformers}

to $480 \mathrm{~V}$ bus

Starts and stops motors

for varlous auxillary sys-

tem equipment; provides

motor running protection.

Energizes 480 V switchboards by connection to dlesel generator during loss of off-gite power.

Connects diesel generator to $4.16 \mathrm{kV}$ bus dur Ing loss of off-site power.
Internal short circuit

Failure to close, overheating, or poor contacts

Contacts will not close or trips of $\mathrm{f}^{\circ}$

Internal short circult (transformer); fallure to close, overheating or poor contacts (network protectors)

Fallure to close, overheating, or poor contact.s
Prinary fuse blows; no power supplied to $480 \mathrm{~V}$ bus by affected transformer. Supply loads through alternate transformers by closing their disconnect switches and interconnecting bus manual circuit breakers.

No power supplied to bus through affected substation protector. Supply loads through alternate transformer and substation protectors by closing their disconnect switches and interconnecting bus manual clrcult breakers.

No power to affected auxiliary system motor(s). Cessation of PBX-M operation may bn necessary. Repair as soon as fossible.

No power to $480 \mathrm{~V}$ loads during loss of of site power. Shut down PBX-M. Repair as soon as possible.

No power to all auxiliary loads during loss of of offsite power. Shut down PBX-M. Repair as soon as possible. 
TABLE 5-9

TOROIDAL. FIELD PUL.SED EMERGY CONVERSION SYSTEM (MG SETS)

\section{FAILURE MODES AND EFFECTS ANALYSIS}

Component

1. Traisforaer

$y$

\section{Functlon}

Supplies AC power

to drive $M G$ sets

\section{Fallure Mode}

A) Turn to Turn Short.

B) Overheated

c) Loss of Coollng oll

D) Ground Fault

E) Fire

Converts $\mathrm{AC}$ to $\mathrm{DC}$; supplles and controls the DC current in the colls.

A) DC terminals section

shorted.

\section{Failure Effect/Corrective Actlon}

A) The ac breaker trips in 5 cycles $(60 \mathrm{~Hz}$ ) and the de output voltage is reduced by $41 \mathrm{kV}$. Detected by oil pressure detection and Hinding temperature sensing; generates fault signal. The experiment is terminated. Shut down PBX-K.

B) See 1tem 1, Fallure Mode A)

C) Detected by oll level gauge, oll flow indicator, and oll temperature detection. Fallure effect and corrective action are the same as for iten 1, Fallure Mode A)

D) Detected by AC ground fault detection, and equipment. Failure effect and corrective action are the same as for item 1, Fallure Hode A)

E) Detected by oil pressure and ofl temperature detection. Effect is limited by outdoor installation, and provision of crushed stone and drainage to prevent ofl accumulation outside of transformer. Fire would be extinguished manually by use of outdoor apparatus. PBX-M is shut down. of a generator

B) Fire
A) No output vol tage across generator output. betected by relaying. Shut down PBX-M.

B) Detected by MG housing heat detectors. Fire is suppressed by $\mathrm{CO}_{2}$ discharge within the housing. PBX-H is shut down. 
3. Metal Enclosed DC Equipment
Coil overvoltage protection and personnel safety.
A) Disconnected ground cable.

B) Fire

Connect converter transformer to the power supplies and colls to the power supplies, respectively.
4. $A C$ and $D C$ Cables
A) Loose connection

B) Ground Fault

c) Fire

D) Excessive Cable Movement
A) Ground protection exists in ground protection system which shut down PBX-M.

B) Smoke emitted would be detected by MG Buildlng smoke detectors. Damage to equipment could cause loss of function and consequent shutdown of PBX-M. Fire spread would be limited by metal enclosure, with extinguishment by $\mathrm{CO}_{2}$, Halon, or by manual means.

A) Can result in overheating and damage to insulation, and possible loss of one or more cables. Experiment is terminated. Periadle inspection of high current terminations corrects loose connections.

B) Detected by ground fault relay trip. May cause large fault currents and unbalance ground potentials. Experiment is terminated.

c) Detected by ground fault relay or by bullding smoke detector. Fires inside MG Building would be extinguished by $\mathrm{CO}_{2}$ and $\mathrm{Hal}$ on systems; fires outside the buifding would be extinguished by manual means.

D) Power testing has shown that movement of nigh current pulsed cables and bus during normal and postulated fault conditions is prevented by the restraints that have been installed. 
TABLE $5-10$

OHMIC HEATING PULSED ENERGY CONUEASION SYSTEM

\section{FAILURE HODES AND EFFECTS ANALYSIS}

Component

1. Transformer(s)

2. Power Supply

ขั)

3. Ignitron Reversing Switch.

Reverses the direction of the OH Coil current.

\begin{abstract}
Converts ac to de; supplies and controls the do current in the colls.
\end{abstract}

4. The Energy Dissipation System

\section{Metal Enclosed DC Equipment} (D1sconnects)

\section{6. $A C$ and $B C$} Cables

See Table 5.9 item 4

\section{Failure Mode}

See $7.3 .1-1$

A) DC terminals of a power supply section shorted.

B) Loss of one module

c) Commutation fallure

D) Loss of cool Ing water

A) Switch stays closed in reresponse to an open command.

B) Switch closes.

Dissipation resistance opens.

\section{Failure Effect/Corrective Action}

Item 1

A) No output voltage. Detected by power supply internal (hard-wired) Power supply trips off. Shuts down PEX-M unt 11 bypassed or repal red.

B) See Table 5.2-7, item 2, Fallure Mode B).

C) Experiment talls. Power supply trips off. Check for operator misadjustment, if not repair.

D Power supply trips of $f$. Investigate cause, repair or adjust as necessary.

A) Shorts out supply causing overcurrent trip. Investigate cause, repair or ad just as necessary.

B) See 5.2-8, 3.A.

High voltage across the $O H$ power supply and coil. Overvoltage protection system will prevent equipment damage. The experiment is terminated. 
TABLE 5-11

EQUILIBRIUM EIELD PULSED ENERGY CONVERS ION SYSTEM

FAILURE MODES AND EFFECTS ANALYSIS

Component

1. Transformer

2. Ронеr Supply

3. Metal Enclosed DC Equipment

4. AC and DC Cables

\section{Function}

See Table 5.10 item 1

See Table 5.10 1tem 2.

See Table 5.10 item 5

See Table 5.10 item 6
Fallure Mode

\section{Failure Effect/Corrective Action}


TABLE $5-12$

NBPSS FAILURE MODES AND EFFECTS ANALYSIS

\section{Component}

1. PPS HV Transformer

\section{Function}

Converts 3 phase $A C$ power to DC power

\section{PPS HV \\ Rect if ler}

\section{Fallure Mode Failure Effect/Corrective Action}

A) Grounded or trans former winding.

B) Open transformer winding.

A) Open rectifier stack

B) Shorted rectifier stack

C) Combustible gases in transformer
A) Breaker trips on closing. Af fected power supply cannot be operated but NB operation can continue in degraded mode. Replace and/or repair transformer. Check condition of rectifier stacks.

B) Reduced power avallable from Primary Power Subsystem. Affected NBIS operation is degraded. Replace and/or repair transformer.

A Reduced DC current output or no power. Affected ion source is degraded or inoperable. Replace and/or repair rectifier stack.

B) If one or more series rectifiers are shorted, each of the remaining rectiffers will be subjected to a higher voltage and may eventually fall into a line to line short. Affected ion source may become inoperable (breaker will trip on closing). NB operation can contlnue in degraded mode. Replace shorted rectifiers.

c) Possible internal explosion and damage to transformer with resultant inoperabllity of affected ion source. Potential damage to adjacent equipment is mitigated by the physical separation of adjacent equipment in the swltchyard and by the enclosure of the transformers in steel jackets which would prevent equipment damage from any small missiles which may result from an internal explosion in a transformer. This failure mode and effect will be prevented 
3. PPS capacitor bank (rilter)

4. Modulator' Regulator

Provides control and regulation of accel voltage pulses.

Provides local energy storage for Modulator Regulator, as well as transient compensation.

B) Open capacitor

A) Fails to turn on

B) Falls to turn off

c) Loss of cooling water

Provides arc, filament and decel power to the Neutral Beam I on Source.
A) Failure to turn on by running a dissolved gas analysis on a continuing basis, using built-in gas detection equipment; if arcing is indicated, preventative maintenance procedures will be followed.

A) Higher stress level on the remaining units. Affected ion source operatiori can continue. Determine the location of the shorted capacitor and replace at next scheduled maintenance period.

B) Increased ripple to Modulator/Regulator. Afrected ion source operation can continue. Determine the location of the open capacitor or blown fuse and replace at next scheduled maintenance per lod.

A) The power pulse is not delivered and delivered and affected ion source cannot be operated. NB operation can continue in degraded mode. Determine the location of the failed component and repair and/or replace.

B) Power to Ion Source could be extended with possible damage to Ion Source and/or Modulator/Regulator. Time-out of are and filament will prevent such damage. Affected NBIS cannot be operated but degraded NB operation can continue. Determine the location of the failed component and repair and/or replace.

c) Power pulse to af fected $M / A$ is prevented or terminated automatically. Operation of affected ion source is precluded but NB operation can continue in degraded mode. Repair and/or replace affected equipment.

A) Affected auxiliary power pulse for one Ion source is not delivered. Operation of affected NBIS is degraded or precluded; NB
System Pow 
B) Failure to turn of
C) Decel voltage goes off while the accel supply is on

E) Loss of cooling water
Provides control and mont toring of the NBPS.
A) Loss or control power

operation can continue in degraded mode. Determine the location of the failed component and repair and/or replace.

B) Extended power pulse to element (s) of the Neutral Beam Ion Source with possible damage to the Ion Source. Protection against catastrophe afforded by AC breakers and rectifier fuses. Affected lon source cannot be operated but NB operation can continue in degraded mode. Determine the location of the failed component and repair and/or replace.

C) Current on all grids goes up with resulting overheating and posilble damage: Inter lock removes accel voltage. Other corrective action as in 1tem 5, Fallure Mode $B$.

E) Operation of affected power supply(s) is automatically prevented or terminated and affected ion source is shut down. Operation of affected ion source is precluded but NB operation can continue in degraded mode. Repair and/ or replace affected

\section{NB Contral} Subsystem

\section{.}

\begin{abstract}
equipment.
\end{abstract}
A) Ion Source power pulse will be terminated and the affected Ion source will be safely shut down. NB operation can continue in degraded mode, if a partial failure. Determine failed component and repair and/or replace.

8) Instrumentation B) Incomplete or Caulty process information malfunction: missing or deteoted by operator. Shutdown affected beam line. Locate source of error and make erroneous data 
TABLE 5-13

DIESEL GENERATOR SYSTEM FAILURE MODES AND EFFECTS ANALYSIS

Component

1. Diesel Generator Support Systems (Fuel 011, Lube 011 , Cooling Water, and starting Systems)

2. Diesel Generator Breaker

$\mathscr{2}$

3. 5 kV Cable Intertie

\section{Furiction}

To start the diesel engine and maintain the engine temperature, lubrication and fuel oll at optimum operating levels

Connects diesel generator with $4.16 \mathrm{kV}$ bus

Connects diesel generator breaker with $4.16 \mathrm{kV}$ bus

\section{Failure Mode \\ Failure to carry out required funct ior:}

Pailure to close on command, overheating, or poor contacts

Short or open circuit

\section{Failure Effect/Corrective Action}

Detected by affected support system parameter monitors, and/or by generator speed monitor. Diesel engine ralls to start or is shutdown automatically (see note (a) below).

Absence of current in $4.16 \mathrm{kV}$ and $480 \mathrm{~V}$ subsystems detected by $4,16 \mathrm{kV}$ load feeder ammeters, and $480 \mathrm{~V}$ switchboard bus feeder wat tmeters, voltmeters and/or ammeters. Diesel generator cannot supply power (see note (a) below).

Failure causes trip of generator breaker. Diesel generator cannot supply power (see note (a) below).

(a) In the event that PBX-M's primary power distribution falls and the Diesel Generator fails to start, operate or deliver power, the facility will go into a safe shutdown status. This means that by way of the hardwired interlocks required of each system the power supplies will shut down, energy will be dissipated safely, valves to vacuum systems will close. 
TABLE 5-14

\section{PBX-M CONTROL SYSTEM PROTECTIVE FUNCTIONS}

\begin{tabular}{ll}
\multicolumn{1}{c}{ Componen! } & Function \\
\cline { 2 - 2 } & \\
PLC Memory & $\begin{array}{l}\text { PLC System } \\
\text { Hardware }\end{array}$ \\
PLC Processor &
\end{tabular}

1/0 Communication

INO Rail

Output point stuck

Input module fails

R-NET Communication

心

Contṛol PNL comm.

\section{Scan stops}

Ref. hits amplitute limit

REF. Signal too long

REF. at wrong time

High current fault

Low current exceeds steady state rating

Inst. overcurrent

Flow problem

\section{Hardware}

\section{PLC system}

Software

Reference signal

Coil overcurrent

Coil cooling system
Failure Mode

Random output pattern

Random outpul pattern

J/O not being updated

Randiom I/O pactern

Loss of control

Loss of thtus

Loss interlocks

Loss of control

Loss of control

Coil damage

Coil overheating

Unwanted pulse

Thermal damage

Mechanical stress

Loss of cooling
Failure Effect/Corrective Action

Internal diagnostics - Disable/

External watchdog timer - Disable

Internal watchdog times - Disable

External watchdog timer - Disablc/

External watchdog timer - Disable/

Intemal diagnostics - Disable

Internal diagnostics - Disable/

External watchdog timer - Disable

H.W. Master disable (OPERATOR)

Emergency shutdown (OPERATOR)

Software check

Internal diagnostics - Disable/

R-NET watchdog timer - Disable

PLC - Disable/panel shut down--None

Internal diagnostics - Disable/

External watchdog timer - Disable

Warning message

Overcurrent RLYS - H.W. Disable

Window unit time-aul/ PLC - Disarm

Window unit blocks it / None

Overcument RLYS - H.W. disam

Overcurrent RLYS - H.W. Disable

Overcurrent RLYS - H.W. Disarm

Temperature switches - Disarm

Overcurren! RLYS - H.W. Disable

PLC disarm on flow PLC disarm

on temp. sw. 
TABLE 5-14

PBX-M CONTROL SYSTEM PROTECTIVE FUNCTIONS

\section{Component}

Temperture irip

Recycit 100 fast

Low preature
Funclian

Failure Mode

Coil overhealing

Temp ratcheting

Hydraulic clamps

TF joint overheating

Failure Effect/Corrective Action

PLC dissum - none

Timer recycle inhibit PLC disarm on iemp sw.

PLC2 disabłe - PLC1 global intlk disable 


\subsection{QUALITY ASSURANCE (R.E. Parsells)}

PBX-M has operated under the guidance of a specifically tailored version of NQA-1 titled PBX Modiflcation Plan of Conformance, PPPL Technical Operations Manual of Procedures, No. EP-PBX-M-001, February 11, 1986 (see Appendix A). Th1s document has been supplemented with the PBX-M Design Review Pracedure, No. PPPL-EP-001, (see Appendix B).

6.1 The Project was audited against the Design Review Procedure in May of 1986 .

6.2 The Project was assigned a Hork Package Coordinator (WPC) for Quality Assurance by PPPL QA/R Department head. The QA HPC reports to the Project Manager and works with each of the other WPC's to plan and schedule QAVC activities.

6.3 Table 6-1 shows the assurance controls currently legislated for the safety aspects of the operational phase of PBX-M.

\subsection{CONDUCT OF OPERATIONS (K. BOL)}

7.1 Organization

The Laboratory has complled a set of Health and Safety Directives (HSD's) which describe safety organization and responsibllities. Safety at PPPL is considered to be a line responsibility extending throughout the line organization to all Laboratory employees. The Project and Operational Safety Office maintaing a close liaison with the PBX-M staff to provide Input to PBX-M on safety related issues. A project safety coordinator has been assigned to provide a single point of contact between the P\&OS and PBX-M organizations. Additionally, the PPPL Safety office provides an independent audit function of safety processes. Also area safety coordinators are assigned to all areas of the Laboratory in accordance with HSD-5002 (HSD5).

\subsection{Training}

Training is addressed in HSD-5028 (HSD6). The Laboratory has an actlye safety training program.

All devices at PPPL Including PBX-M require skilled and well-trained exployees. Specifically, in the area of safety training, sessions have been held on fire protection systeris, including talon. All training w1li weet the requirements and standards of the Laboratory. The PijX-M project managers will be responsible for identifylng employee deficiencies and ensuring their enroliment in required courses. 
TABLE 6-1

CONF IGURATION CONTROL

TOPIC

Functional Aequlrements

Spect I I cations

Design Approach

nellabI11ty

Fohrleaction Hethods

Procurements

scinctule

Cast

Verification

Inspection

$\infty$

Test

Qut liftcector

Ask

Integration \& Asoembly

safecy
CDNCEPT DESIGI REV TEW

Daseline, Approved

LIst

Sketchs \& Famlly Treo

Prellmlnaty Asuesament

Anticipated

L1si, preliminary

Prelinlery

Prollminary Estmate

\begin{tabular}{|c|c|}
\hline & Wist crlelcal \\
\hline Prellinlary Test PIan & Test Plan, Draft \\
\hline Proposed & Update \\
\hline Prel Im I naty & Crltical Areas \\
\hline Pre $1 \mathrm{mLnary}$ & $\begin{array}{l}\text { Prellininary Rlan } \\
\text { Update }\end{array}$ \\
\hline
\end{tabular}

Changes

Hadiflcation, Status

Layouts, Family Trae

Update

Upilate

LISt

Updace

Status

Upate
FLHAL DESIOM HEVIEU

Clianges

Approved speciflcaclon

Dranings, Complete

Upinte

Update, Spectal Tools

FInal List

upilate

statug

Spectal Instruction, Procedures, Toollug etc.

Test Plan/test Procedures/

Test Equipment

Qually Test Results

Final Assessinent

Plan \& Procodures

If pila te

- The above partal listing of toptes and doctirientation to be evaluated ac each Destgn Kevtew is tor guldance only, subject co áppropriate modificaton, expansion, or revision by the Design Reviaw Horking croul chatrperson. 


\subsection{Testing Program}

Preoperation and operational testing is conducted on all new equipment, components, or structures. Written procedures are used for new tests and are signed off by P\&OS. New operating paramecers which have a potential for radiation production are monitored by P\&OS and subsequently released for routine operation by written memo or radiation work permit (RWP).

\subsection{Configuration Control}

Formal configurar: in control was set up for the design phase of PBX$M$ and is described in PBX Modification Plan of Conformance, PPPL Technical Opecations Manual of Procedures, No. EP-P9M-M-001, Eebruary 11, 1986, (See Appendix A). This document has been supplemented with the PBX-M Design Review Frocedure, No. PPPL EP-001, (See Appendix B).

\subsection{Procedures}

HSD-5015 (HSD7) encourages written procedures for most operations and requires them for unusual hazards. The PSX-M projecr uses written procedures in accordance with this HSD.

\subsection{Safety Review System}

An independent safety review is provided by HSD-5014 (HSD8). New systems procedures will have safety review and signof:. In addition, the area safety coordinator will note deficiencies on a daily basis and management will schedule safety walk-throughs of the area.

\subsection{Emergency Planning}

Emergency plans follow the requirements of HSD-5007 (HSD9). Th1s is a Laboratory wide plan which addresses emergencies site-wide, and defines responsible individuals, training programs, and emergency drills and exercises.

\subsection{ACKNOWLEDGMENTS}

The editors wish to acknowledge the hard work of the authors which are listed for the various sections and on the title page of this report. In addition the work of H. Takahaski, M. Pelovitz, F. Lawn, S. Kaye, M. Okabayashi and $\mathrm{L}$. Gereg in providing inputs to the weekly meetings which bears on the safety of the project is gratefully acknowledged.

Project leadership was provided initially by D. Kungl and later by D. Huttar. K. Bols and M. Okabayashi provided the overall direction for the project. 


\subsection{REFERENCES}

ANSI81 (ANSI) C95.5 1981 Recommended Practice for the Measurement of Hazardous Electromagnetic Radiation at Microware Frequencies.

ANSI86 (ANSI) 2136.1-1986, "Laser Safety," American National Standards Inst itute.

ANSI82 (ANSI) C95.2 1982 Safety Levels With Respect to Human Exposi ? to Radio Frequency Electromagnetic Fields, 300kHz to $100 \mathrm{GHz}$.

CH87 Chryzanowski, J., February 1987, PPPL Internal Comannication.

DOE81 DOE Order 5480.1A, Chapter XI, Requirements for Radiation Protection.

DOEB2 DOE Order CH5481.1A, March 26, 1982, "Safety Documentation Guide For Safety Analysis; Aeports of Non-nuclear Facilities."

DOE86 DOE Order 5481.1B, September 23, 1986, "Safety Analysis and Revie: Sy: zem."

EAD R37 Revision 1, Engineering Report.

FR1 Fron, N., January 16,1987 PPPL Internal Communication.

Gi86 Gilbert, J., 1986 "1985 Annual Ionizing Radiation Report," JG-15, Princeton Plasma Physics Laboratory Internal Report.

Gr79 Grimesey, R.A., et al, April 1979, "Preliminary Studies for the PDX Tokamak Radiation Shield Design." INEL Report.

HSD2a Health and Safety Manual, Section 2, Electrical Safety, Princeton Plasma Physics Laboratory Health and Safety Directive (HSD) 5008.

HSD2b Health and Safety Manual, Section 2, Electrical Safety Supplement 2-1, Part V, Table 1, Princeton Plasma Physics Laboratory Health and Safety Directive (HSD) 5008.

HSD3 Health and Safety Manual, Section 3, Laser Sarety, Princeton Plasma Physics Laboratory Health and Safety Directive (HSD) 5008.

HSD4 Health and Safety Manual, Section 4, RF and Microwave Safety, Princeton Plasma Physias Laboratory Health and Safety Directive (HSD) 5008 .

HSD5 PPPL Health and Safety Directive, HSD-5002, Safety Organization.

HSD6 PPPL Health and Safety Directive, HSD-5028, Training.

HSD7 PPPL Health and Safety Directive, USD 5015, Written Operating Procedures.

HSD8 PPPC Health and Safety Directive, HSD 5014, NJ Worker Right to Know Compliance Program. 
HSD8 Health and Safety Manual HSD 5008, Section 8, "Industrial Hygiene."

HSD9 PPPL Health and Safety Directive, HSD 5007, Emergency Preparedness Plan.

HSD 10 Health and Safety Manual, Chapter 10, Radiation Safety, Princeton Plasma Physics Laboratory Health and Safety Directive (HSD) 5008.

Ok86 Okabayashi, M., 1986; "The Neutron Elux in PBX-M," Princeton Plasma Physics Laboratory Memo.

PBX83 June 1, 1983, "A Proposal for Department of Energy, Division of Fusion Energy," Princeton Beta Experiment, Princeton Plasma Physies Laboratory, Princeton University.

Ro84 Rossi, R.A., February 15, 1984, "Working Alone Laboratory Policy," Princeton Plasma Physics Laboratory Meroo.

Se80 Scott, A.J., et al., October 1980, "Preliminary Activation Calculations for the PDX Tokamak," EGG-PHYS-5278.

St60 C-Stellarator Safety Comittee, Apri1 11, 1960, To Insure Safety to Personnel and Equipment Safety during Installation, Operation and Service of the C-Stellarator Facility.

St82 Stencel, J.R., January 13, 1982, "Estimates of Radiation Exposure to Occupied Areas for Calendar Year 1982 from PLT/PDX Operations," Princeton Plasma Physics Laboratory correspondence.

St83 Stencel, J.R., April 1983, "Environmental Monitoring Report for Calendar Year 1982," Princeton Plasma Physics Laboratory Report No. 1977.

St84a Stencel, J.A., Eebruary 13, 1984, "Estimates of Radiation Exposure to Occupied Areas for Calendar Year 83," from Princeton Plasma Laboratory correspondence.

St84b Stencel, J.R., May 1984, "Environmental Monitoring Report for Calendar Year 1983," Princeton Plasma Physics Report No. PPPL-2105.

St85a Stencel, J.R., March 20, 1985, "Estimates of Radiation Exposures to Occupled Areas for Calendar Year 1984 from Princeton Plasma Physics Laboratory Research Activitles," Princeton Plasma Physics Laboratory internal report, JRS-291.

StB5b Stencel, J.R., May 1985, "Envirunmental Monitoring Report for Calendar Year 1984," Princeton Plasma Physics Laboratory Report No. PPPL 2220. 
SUBECT PROCEDLRE EP-PBX-M-001
PRX Modification Plan of Conformance

Please review the atrached procedure, and retain for reference.

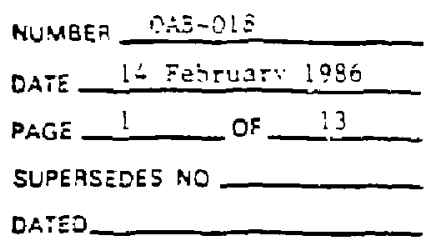
H. Allen
J. Alton
D. Barnes
K. Bol
J. Clark
S. Davis
H. Eubank
E. Eredd
C. Gegịck
R. Gould
D. Grove
P. Heitzentoeder
D. Huttas
D. Asheroít
S. Hand
P. Mathe
P. Murray
M. Pelovitz
J. Joyce
D. knueson
H. Rauch
R. Littie
R. Reny
L. Lontai
R. Rossi
D. Meade
D. Mullaney
N. Sauthoef
J. Murray
G. Sheffield
4. Nortis
E. Simon
J. Sinnis
G. Oliaro
R. Saart
H. Osborne,
C. Staloźf
R. Parsells
E. Perry
G. Rappe
J. R. Thonpsor
K. Young

H.P. HOWiñ

MANAGER OF QURLITY ASSURAMCE

RETAIN THIS BULLETIN UNTIL FURTHER NOTICE. DISCARO THIS BULLETIN AFTER NOTING CONTENTS. THIS BULLETIN WILL UE INVALID AFTER (DATE) THIS BULLETIN WILL EE INCORPORATED INTO OUALTT PROCEDURE NO BY (DATE) 


\section{PRINCETON UNIVERSITY PL ASMA PHYSICS LABORATORY}

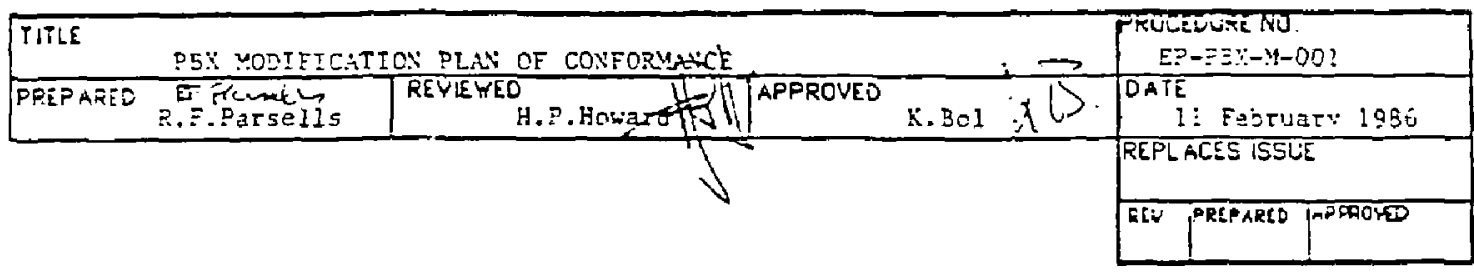

\subsection{IYTZODUCTION}

\subsection{Purpose}

This plan describes those PBX-M policies, practices, procedures, and protocols that are (or will be) in place to:

a) Provide the project framework for achieving the specified project goals.

b) Provide and control the documentation to suppozt system design, building, and commissioning requirements, and to baseline operation and maintenance.

c) Provide for problan vistbil ty so that the systes periorunance can be optimized by appropriate inprovecense.

\subsection{Applicability}

This plan is applicable to all hardware, software, and fasilities associated with the design, modification, combissioning, operation, and maintenance of the $P B X-H$.

\subsection{Heritage}

This document complies with the fintent of ANSI/ASME NQA-1, Chapter II, and PPPL-QAP-001.

\subsection{REFERENCED DOCUMENTS}

The following referenced documents are applicable to the extent specif ied:

ANSI/ASME NQSA L (i983)

PPPL QAP-0̣OL (June 1984)

PPRL QAP-009 (January 1985)

PPPL

EP-001
(TBD)
Quality Assurance Progran Requirements Eor Vuclear Facilities

Quallty Assurance Program

Nonconfarming Material Control

Design Review 


\section{PRINCETON UNIVERSITY PLASMA PHYSICS LABDRATORY}

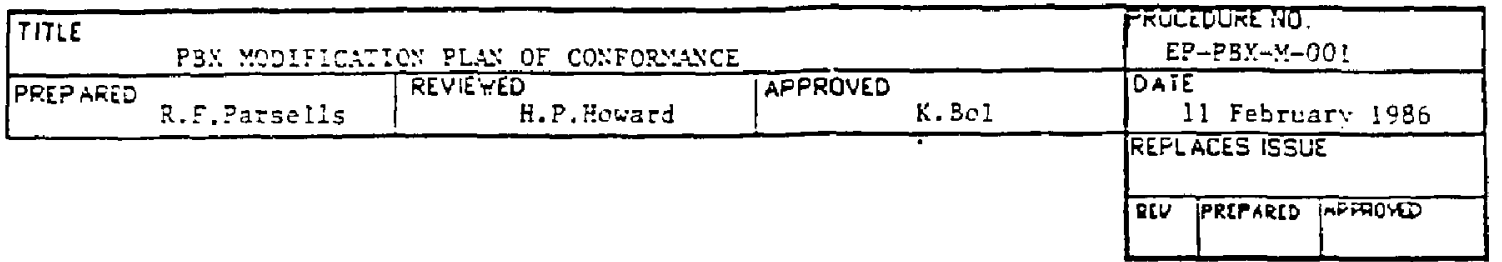

\subsection{REOUTEEYE:TE}

The following generally follows the paragraphing of NQA-l and PPPL QAP001 .

\subsection{Organization}

3.1.l Project Organization

The organiastion chare for the PSX-Y and the PPPt Quality Assurance sroup is shom on Appendix 1 .

3.1.: PPPL Quality issurance scope

Ppol Quality issurance is responsible for assuring that a Qualicy Assurance Program (QAP) is established and that activities afecting qualilty have been accomplished fa accordance with prescribed plans. Quality Assurance has sufficient authoricy, access and organizational freedom to identify quality problens; intiate, reconmend, or provide solutions to such problems; and to verify impleaentation of solutions.

3.1.2.1 Quality Assurance Persontel

Quality Assurance personnel assigned to the project have the following duties in meeting the above objectives:

- Identify procedures and other documents needed to support the PBX-M Quality Assurance Progran.

- Develop, approve, maintain, and inplement quality assurance procedures and ocher documents.

- Determine the need and scope of qualilty assurance Inspections and audits.

- Support and approve the selection of quality assurance requifements. 
TECHMICAL DPERATIOHS - MAHUAL OF PROCEDURES

PAGE 3 OR : :

\section{PRINCE TON UNIYERSITY PL ASMA PHYSICS LABORATORY}

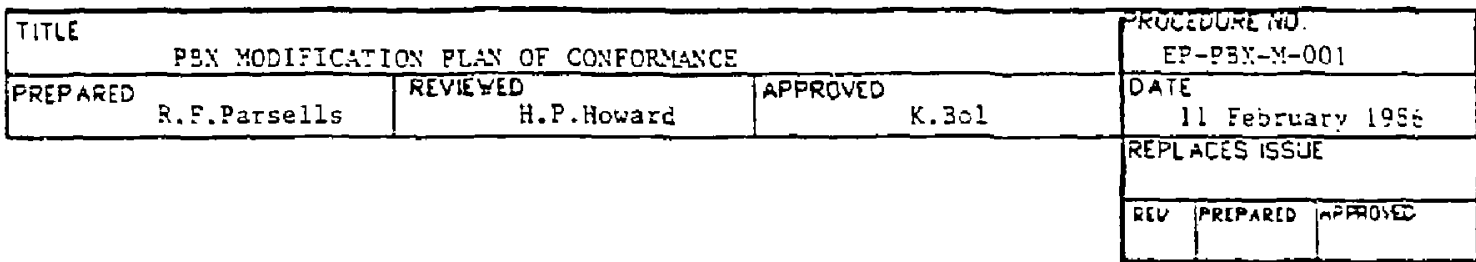

- Review all procedures, instructions, and policies which make up the Quality Assurance Progtam.

$\circ$

Particlpate in decisions concerning the qualifications of supporting suppliers and subcontractors.

o

Establish requirements for quality assurance training and indoctrination.

$\circ$

Report periodically to manajement on the stacus of the ?rostam, its accomplishrents, and fts problems.

0 Approve the disposicion of ronconformances and corrective actions. (See PQPL QAP-009, Nonconformance Concrol)

0

Provide a permanent member to project boards associated with change control, desizn review, test procedure, test acceptance, system and subsysten readiness, etc.

3.1.2.2 Project Review Boards

The following boards have or will be established to control the approval, release, and change of various critical project elements.

Design Review--per PPPL EP-001 (TBD)

Configuration Concrol--per the FPPL Draiting Manual, but taflored to specteic EBX-M requi rements.

Material Revien--per PPPL QAP-009, tallored for PBX-H conditions. 


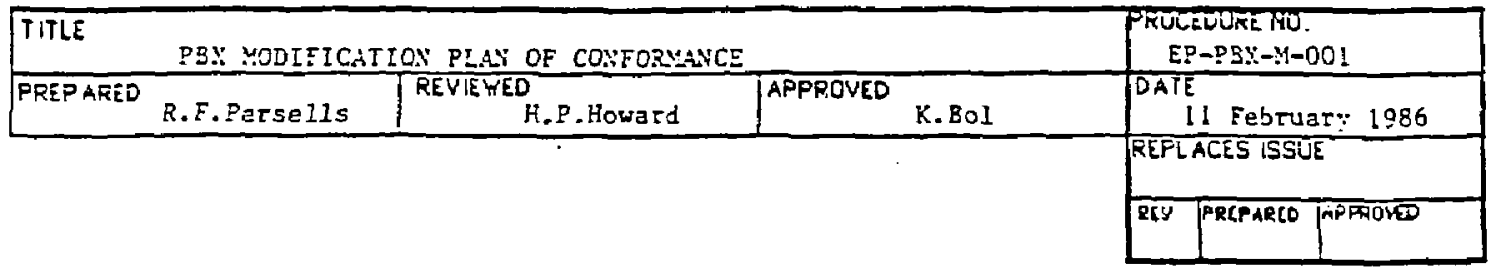

3.2 PBX-M Quality Assurance Program

3.2 .1 objec:ive

The primary objectives of the $B B X-M$ are defined in $A$ Proposal for an Upgrade of PBX (PBX-U) 3 July 1985.1 The scope of work co implement these objective is defined in the PBX-U Offical P lanning Document June $14,1985.1$ The Eramework for atructurigg this efsort is defined in this document. Project success will be achieved by PBX-M Management providing she notivation and support for assuring that this frampwork for project activities is deined, communicated, and inplace thraughout the design, build, comissioning, and operational phases. The focus of this program is the early detection of problens, timeiy fixes and subsequent correction action.

3.2.2 Relationship to PPDI Quality Assurance Program

QAP-001 (and its supporting procedures) is supplemented by chis document. Both shall be used to baseline design, installation, comissioning, operations, and maintenance, of the PBX-H. This Quality Assurance-Program Plan aay be. godified to weet changed requirements. firs.

3.2.3 codes and standards

Hationally recogaized codes and standards, such as ANSI, ASME, or IEEE shall be used in the degign, fabrication, testing, Lastallation, operation, and malntenance of the pBX-M, When a recognized scandard is not available but the reed is obvious, a suitable project scandard shall be formulaced. its $s$ Pionen

3.2.4 Training of Personnel

Technical and craft personnel who perform special process or who require unique system knowledge shall be given appropriate training. The extent and status of this tratuing shall be documented.

1. Project name revised to PBX-M (modification) 


\begin{tabular}{|c|c|c|c|}
\hline TITLE & \multicolumn{2}{|l|}{ PEX MODIFICATION PLAI OF CONFORYANCE } & $\begin{array}{r}\text { FULEUUKE MO } \\
\text { EP-PYX-M-001 } \\
\text { DATE }\end{array}$ \\
\hline \multirow[t]{3}{*}{ PREP ARED } & \begin{tabular}{|l|l} 
R.F.Parse11s & REVIEYED \\
H.P.Howard
\end{tabular} & APPROVEO K. Bol & 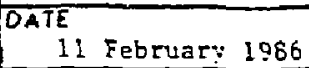 \\
\hline & & & REPL ACES ISSUE \\
\hline & & & REV PREFARLD FPDAOLE \\
\hline
\end{tabular}

\subsubsection{Responsibflity}

Managenent of the organizations using project resources shall verify the validity of this framework for their activity and shall assure lics effective implementacion.

3.3 Design Control

3.3.1 Procedures and Polictes

PPPL established procedures and policies shall be used in deviloping design disclosure docunents (specifications, drawings, procedures, danuals, etc.). These procedures and policies may be supplentented by equivalents that estabilsh project unique policy for design, build, and operational documentation requirements.

\subsubsection{Design Reviews}

All desizn packages shall be verified by design geviews compliant with the intert of PQPL-EP-001. The design reviews shall be aided by alternate calculations or qualification testing programs, if needed. Personnel performing design reviews shall have the knowledge, experience, and skills appropiate to the subject design, but shall not have direct design responsibllity.

\subsubsection{Change Control}

Design changes subsequent to FDR shall be approved at the weekly meeting of the PBX-M Project coordinators. Design changes shall be controlled and performed according ta approved project procedures. (TBD). Subsequent to achleviog full operational readiness all change control shall be incorporated into the PBX-H ERB/MCCB. (TBD)

\subsection{Procurement Document Control}

\subsubsection{Procurement Practice}

PPPL Procurement Manual procedures (specifically the "Requisitioner's Hanual") describe the system that shall be used for procurement of project items. 


\begin{tabular}{|c|c|c|c|c|}
\hline \multicolumn{4}{|c|}{ PBX YODIETCSTION PLAY OF CONEORYANCE } & 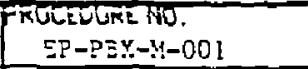 \\
\hline \multirow[t]{3}{*}{ PREP ARED } & R.E.Parse1ls & $\begin{array}{r}\text { REVIEWED } \\
\text { H.P.Howard }\end{array}$ & APPROVEO $\mathrm{K} . \mathrm{BOI}$ & $\begin{array}{r}\text { PATE } \\
11 \text { February } 1986\end{array}$ \\
\hline & & & & REPL ACES ISSUE \\
\hline & & & & REU PRLPARCD APAFOH \\
\hline
\end{tabular}

$3 .+.2$ Quality Requitenents

Cognizant technical personnel, (subject to Qualicy Assurance review and approval per Technical operations Directive 002, ) have che responsibility to deternine quality requirements of purchased items.

All basic technical requirements such as drawings, specifications, codes, and standards shall be a part of the procurement docunents. Procurenent docunents shall sepatacely define all deliverable docutantation.

3.-.3 Post Award Controls

The applicability of a preaward suryey, source inspection, and site audits shall be jointly determined by Quality Assurance and the conzaizant engineer. Access to supplier's plant facilities and inspection tecords shall be specified in procurement documents when determined to be necessary.

3.4.4 Subtier Supplier Requirements Passdown

When a PPPL supplier uses a subtier supplier for an itart or secvice, the requirenents of the PPPL contract shall apply.

3.5 Instructions, Procedures, and Drawings

3.5.1 Critical Fabrication, Test, Inspectlon, or operacional Procedures

PBX-M technical management and project Quality Assurance will determine the applicability of formal procedures based upon the cxitlcallity of the event, its ability to be rectieved when improperly performed, and the value in assuring system or component readiness. Activities affecting quality thall be prescribed and accomplished in accordance with Instructions, procedures, or drawings which have been prepared, reviewet, and approved by boch technical and quality assurance personnel. When applicable, Instructions, procedures, and drawings shall include appropriate quantl cative or qualicative acceptance criteria. 


\section{PRINCETON UNIVERSITY PL ASMA PHYSICS LABORATORY}

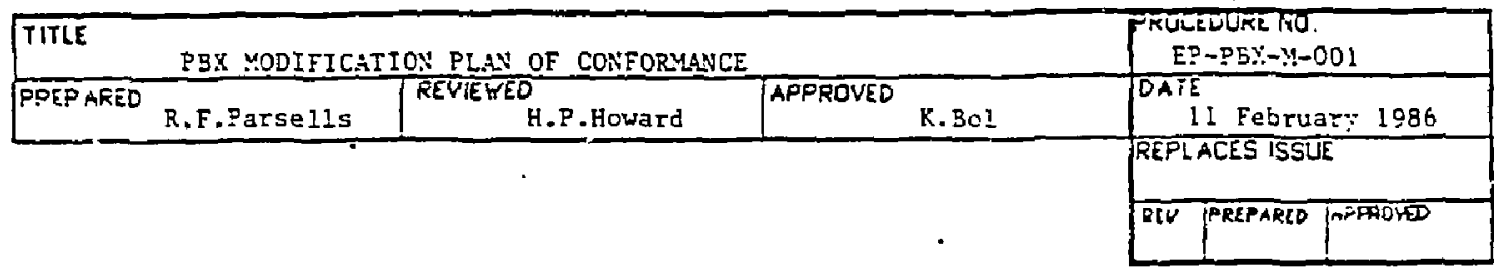

3.6 Docunent Control

3.6.L Procedure/Instruction Concrol

Procedures and instructions shall be controlled in accordance with the PBX-it Document concrol Procedure, (TBD) including preparation, review, approval, discribution, s tarage, and revision.

3.6.2 Change Control

Released docunents shall be subject to change concrol. changes must be approved prior to implementation. Revisions shall be approved by the sane Eunctional zroups involved in the approval of the origimal reloase.

3.5.3 Distribution

Controls shall be established to ensure that documents are curreat and are available at locations where activities are performed. These controls shall ensure that superseded documents cannot be inadvertencly used. An identiEication systen shall be established that is compatible with progran abjectives.

3.6.4 Project Quality Assurance Responsibilicy

PPPL Quality Assurante has the responsibility for assurfig the use of curcent and ralid procedures, drawiags, and working documents. This will be accomplished by maintalnIng transmittal records of documents released and issued for project use.

\subsection{Control of Purchased Material, Equipment, and Services}

Control of the quality of instruments, equipment, parts, materials and services purchased for use in the PBX-M shall be accomplished through reviews of purchase documents prepared in accordance with Section 3.4 of this plan. Items which do not conform to contract requirements are subject to the controls defined in PPPL-QAP-009. 


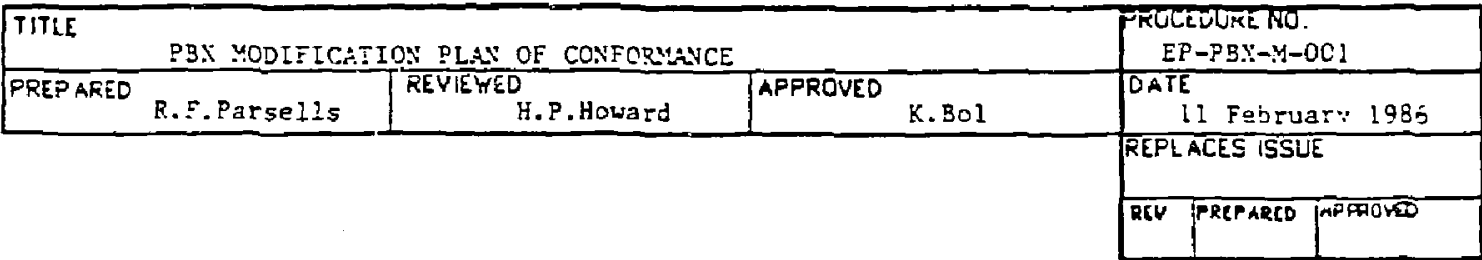

3.8 Identification and Control of Materials, Parts, and Components

Where applicable, prncedures, drawings, and speciflcations shall provide for the identiflcation and control of materials, parcs, and componencs. These documents shal? rrovide for integral identification markings, or records traceable to the iten. This requiremenc includes troubleshootigg, repair, and the prevention of incorrect or defective materials being used. Markings shall be cleat, legible, and indelible, shall not affect the overall function or performance of the iten, and stall be visible when installed in the system. The identification of materials shall be verified and documenzed by Quality Assurance on a surveillance basis.

3.9 Control of Special Processes

Weldiag, heat treating, brazing, nondegtructive testing, or other activities which are dependent on operator skill or where quality cannot be deterinined by post processing inspection or test are special processes. Verification is obcained through process controls including, procedures, equipmeat, and persannel qualification. Special processes shall be accomplished in accordance with applicable codes, standards, speciflcations, criceria, or other special requirements. When applicable, procedures will be prepared, approved, and wade available to the personnel pezforming the process vork before the wark is actually performed.

\subsection{Inspection}

Inspectlons required for structures, systems, and components shall be identifled and performed in accordance with approved procedures. Inspection procedures shall provide for:

- Characteristics and activicles to be inspected.

- Function responglole for the Iaspection operatian.

o hccept-reject criteria.

- Inspection methods and tooling required.

- Records and reporting. 
TECHNICAL OPERATIONS-MAHUAL OF PROCEDURES

\section{PREWCTON UNMERSITY PL ASMA PHYSICS LABORATORY}

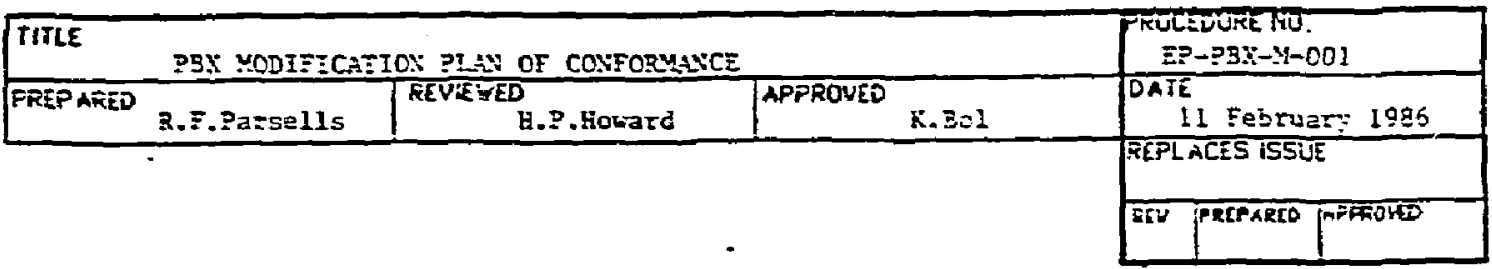

Individuals who perform the inspection operations shall not tave been zesponsible for the work being exacined and, should be qualiFied in accordance with applicable procedures, codes, or standaris.

\subsection{Test Control}

3.11.1 Test ?lans and Procedures

Test plans shall be prepared that relace specilied recuivenents to test(s) and to integrate all sest activities. Test procedures shall be prepared wing shoin secup, interfaces, environent, cooling, calitratior, tnstricenlation, data collection, tolerances etc.

Test plans and test procedures shall be prepazad, teviewed, and approved per par 3.5 and 3.6 .

\subsubsection{Test Evaluation}

The rest resulcs shall be docunenced and evaluated by a qualified individual. The docunented and approved tes: data shall be recaiged in project records.

\subsection{Control of Measuring and Test Equipaent}

3.12.1 Acceptance Heasuring Equipaents, Calilbration

Iools, gages, Instrunents, and other measuring and cest equipwent (HSTE) used in the neasurenent, inspection, acceptance, or evaluacion shatl be included in the PQP! calibration progran( $\$$ ). (Electrical/Hechanical)

The PPP: calibration systens provide for the identificacion and labeling of aeasuring and test equipment which shows that the itea has been callibrated, provides traceabillty, and the date recalibration is due.

\subsubsection{Tracenbility}

Reference standards used to callorate the measuring and rest equipment shall be cracenble to the National Bufeau of Standards (NBS) or equivalent. 


\section{PRINCETON UNIVERSITY PL ASMA PHYSICS LABCRATORY}

\begin{tabular}{|c|c|c|c|c|}
\hline TITLE & P3X YODIFIC: & ON PLAY OF CONEORY & & $\begin{array}{r}\text { RutevUr.t } \\
\text { E?-PBX-Y-001 }\end{array}$ \\
\hline PREPAFED & R.E.Parsells & $\begin{array}{r}\text { REVIEWEO } \\
\text { H. D .Ho:ard }\end{array}$ & APPROVED & $\begin{aligned} \text { DATE } & \\
& 11 \text { February } 1986\end{aligned}$ \\
\hline
\end{tabular}

3.12.3 Systen Integrated Jevices, Calibration

Moasuring or control devices incorporated into the PBX-L shall be subject to periodic calibration and/or preventacive malntenance. PPPL Qualicy Assurance will be responsible for coordinacion and records for this systel. The PBX-Y calibration and maintenance Progras (TDD) baselines this activity.

3.13 Handigng, Storage, and Stipping,

3.23 .1 General

Cleaning, handling, processing, packaging, shipping, anc storage of naterials, parts, and componencs shall be controlled in accorcance with standard laboratory practice. Where there exists special concern for contarination environmencal exposure, age sensitivity, etc. special project procedures will be viriter.

3.14 Inspection, Test, and Operating stacus

To assure that critical items wich have not passed the required inspections and cescs are not installed, used, or operated the status of such items shall be maintained chrough an appropriate indicator, such as cags, warkings, stanps, records, or opetating Logs.

3.15 Monconforming hacertals, Parts, or Components

3.15.1 Nonconforming Haterials Contrul System

Heterials, equipment, Items, or processes shall be considered to be nonconforming when they do not neet established requirements or their qualicy has been tendered Indeteruinate. Such nonconforming conditions shall be processed in accordance vith PPPL-QAP-009. 
TECHMICAL OPERATIONS-MAHUAL OF PROCEDURES

PRINCE TON UNIVERSITY PLASMA PHYSICS LABOR ATORY

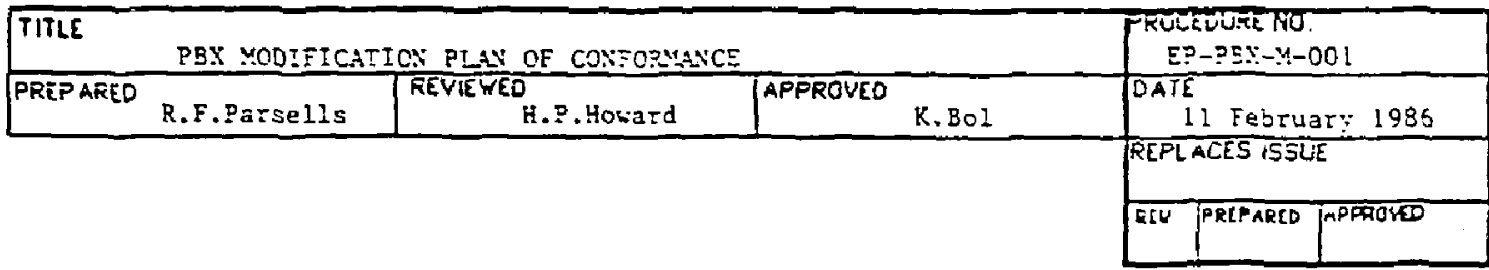

3.15.2 Trouble Reporting System

During operation, problens encountered will be documented and processed per the PBX-M Trouble Reporting Systea which will be adopted for the present PBX systens.

3.15.3 General

Significanc conditions adverse to quality identified eithet fornably by cesc, inspection, of audit, or insoraally by technical or quality assurasce personnel are subject to project evaluation using the siCR, Irouble Report, Audit Report, or Procurement QA Trip Report to docunent disposition.

3.16 Corrective Action

All sources of problen documentation will be analyzed by Quality Assurance for trends, the effectiveness of corrective action, and the identification of other areas capable of improvenent.

3.17 Qualtiy Assurance Records

Project Qualicy Assurance records shall be controlled per PBX-M Document Control Procedure (TBD) which identifies specific documents retention period, location, and responsibilities. Records alay be designated for permaneat or noupermaneat $s$ torage and shall be so ariked. Records to be maintained in permanent starage shall be identified and retrievable.

Quality Assurance records include, but are not limited to;

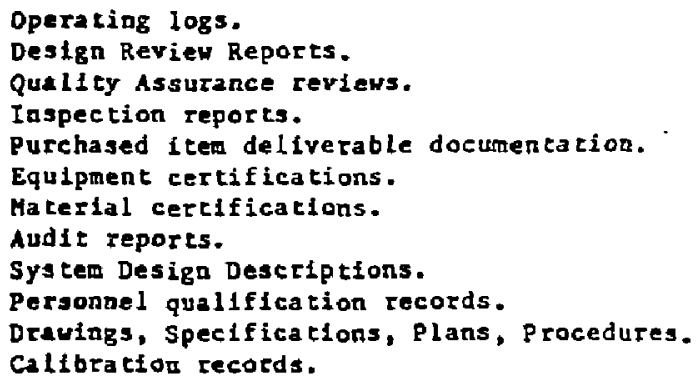


PRINCETON UNIVERSITY PL ASMA PHYSICS LABORATORY

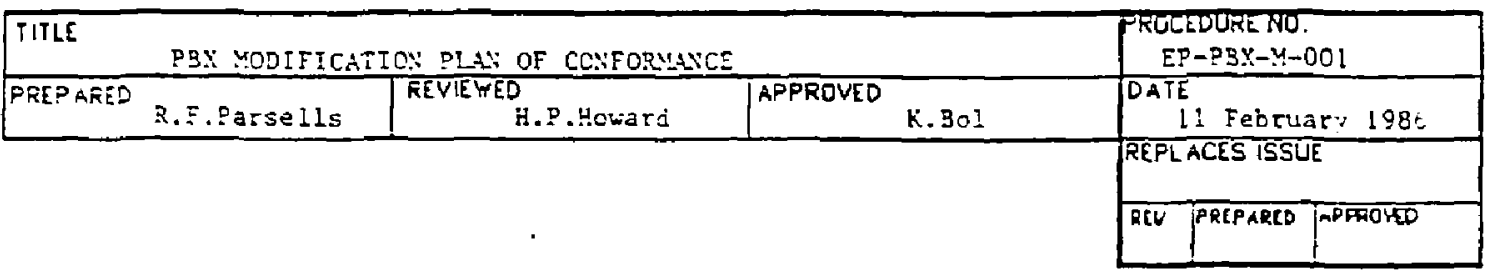

\subsection{Audits}

Quality Assurance shall perform audits per PPPL-QAP-OLL of selected PBX-H acrivicies to determine the degree of compliance and the effectiveness. 


\section{PBX-M DESIGN REYIEW PADCEDURE}

\subsection{DESIEN REYIEYS}

The Designs will be reviewed for:
a) Functional requirements.
b) Design documentation.
c) Cost of the design and ils implementation.
d) Inter foces, monufacturability, safety, quality, and maintenance considerations.
e) Approval to relese the of awings to the next phese.
1) "Chits" (by reviewers) documenting issues not copeble of on-the-5pot- resolution.

\subsection{DESION REYIEY PHASES}

Design Reviews will be held at three steges of design.
a) Conceptual (CDR)
b) Preliminery (POR)
c) Final (FDR)

Documentation (PDR \& FDR) will be deliverad to the Design Review Working Oroup one (1) week prior to the scheduled review.

\subsection{Concentual Desion Review (CDR)}

The CDR is held afler the scoping study and before tha start of formal do afting The finctional requirements, design concept, preliminary analysis, sketches, end theumentation will be presented

\subsection{Preliminery Desiqu Reviear (PDR)}

The Preliminary Design Review is heid ofter the design loyout stage and before detailed design. The CDR will be updeted and extended

\subsection{Eingl_Desion Review (EDR)}

The Final Design Review is held after all drawings are complete and before release to menufecture.

\subsection{PROCESS}

The Tuesdoy weekly project meeting will atd to its egend, as required, the iunction of Design Review Manogement Baero (DRMB).

3.1 Design Review Menegement Review Board will consist of:
a) Chairparson - Den Kungl.
b) Project Heod - Kees Bol.
c) Engineering - work pectaye coordinotors.
d) Quality Assurenco - Bco Porseils
e) Safehy Orfice - Joe Stencel. 
and be responsible for:
a) Esteblighing the level of Design Review for each job.
b) Appointing the ad hoc Design Review Working Group Chalrperson (generally the work packsge coordinator).
c) Reviewing and approving the conclusion of the Design Review Working Oroup.
d) Resolving open issues.
e) Aulhor ize the implementation of all approved chits.
f) Maintein a file of all Design Review documentation.

\subsection{Design Review Working Group will consist of:}
a) Chairperson, who selects other group members from the following disciplines:
b) Engineers end Physicists to assess the lunctional needs end the proposed design.
c) User technical representotive.
d) Technical representative from design inter fece groups.
e) Sofety representative.
f) Quality Assurance representative.
g) Others as appropriate.

and the Chairpersan will be responsible for:
a) Orgonizing the composition of the Design Review Working Group defined in per. 3.2 .
b) Arrangements for the Design Review and Working Group meetings (scheduling time and plece).
c) Inviting other members of the professional and support steffs.
d) Assuring timeliness, atequacy, and availebility of thoumentation.
e) Control of the review meeting and porticipant focus an the issues involved
f) Secure DRMB epproval of chit dispositions (sample attechect).
g) Responding to all chits approved by the Dewign Review Warking Oroup in a tivively nianner.
h) Qeneration of summary stotement closing the Desion Review.
i) Resolution of issues ot eppropriate menagement or technical levels.
1) Distribution of all correspondence end reparts to participants, the DRMB, and the project designated conifguration control person.

and the Working Group will be responsible for:
b) Reviewing engineer ing documentation for adequacy and accur acy.
b) Evcluale the deaign features and charecteristics.
c) Review questions of reliability, maintainability and safety.
d) Review inter ferences end inter fece compatibility.
e) Qenerate chits (all inter ested perties moy generate chits, not only the working croup).
f) Review chits of the conclusion of the review and recommend disposition. 


\subsection{Presenter}

The presenter(s) are the responsible cognizont persen/group and are responsible for:

a) Prebirina the documentetion rev lew of the desian.

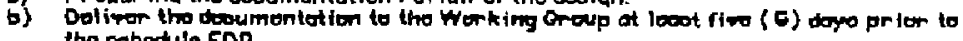
the chaditi FDA.

c) Presenting and terending the ceston end tesign options ot the Review

d) Complying with the racommendatione of the $Q D W Q$ and $/ 0$ DDMB

e) Secur ino Drdect aovroval for reouired chenes to existino controlled of ew inas. 


\section{APPEHDIX}

\section{Exceptions}

Exceptions to this procedure mey be euthor ized by the Design Review Management Board where the cost, criticality or schedule impect of a proposed cesign are judged to be relotively insignificont.

\section{Criteria}

In general a Design Review is nol required where the value of the design is less than \$10K, and failure would not signiflcantly impect the mechine schedule or affect the safety of equipment or personnel. This determination shall be made by the Design Review Management Board (par. 3.1), upon recommendation ol the cognizant project or engineering groups.

If the value of the design is in the range of \$10K to \$150K, or if the design impacts the mechine schedule or is critical to mechine safety (to the extent of the value range above), or concerns the safety of personnel, Design Review will be required Within this range, - CDR a d FDR are recommended. The Design Rey iew Management Boerd will make this determination besed on the recommendation of the project or engineer ing cognizant groups.

If the value of the design exceeds \$150X, or if the design impacts the machine schedule or is critical to machine performance to the value of $\$ 150 \mathrm{~K}$, a complete Deaign Review cycle is required 


\section{Functional Requlrements}

\section{Specifications}

Deslen Approach

Rellabllity

Fabrication Hethods

\section{Procurements}

Schailule

$\cos t$

Verifleation

Inspection

:

Test

Qualification

Ask

Integration \& Assembly

Safety

\section{Basallne, Approved, \\ LIst \\ Sketchs $\&$ Fanily Tree \\ Prellinlnary Assegsment \\ Anticipated \\ List, preilminary \\ Prel1mInary \\ PrelImInary Estimate \\ Changeg \\ Modiflcation, Status \\ Layouts, Family Trea \\ Update \\ upuate \\ LIst \\ Update \\ Status}

\section{List celtelcal}

PrellmInary Test Plan

$\begin{array}{ll}\text { Proposed } & \text { Update } \\ \text { Preliminary } & \text { Crltical Areas } \\ \text { Preliminary } & \text { Prelinlinary Pian } \\ & \text { Update }\end{array}$

\section{Changes}

Approved Speciflcation

Draulngs, Complete

Update

updace, Speclal Tools

Final List

Ij pila te

S tatus

\section{Spectal Instruetion,} Procadures, Tooling ecc.

Test Plan/Test

Procedures/

Test EquIpment

Qually Teat Results

Final tsassinent

Plan \& Procedures

Ilpdate

- The above partlal listing of coplcs and documentacion to be evaluated ac each Design Revien is for guldance only, subject co approptate mollfication, expansion, or revision by the Deslgn Reviow Horking liroup Cindrperson. 


\section{APPROVALS}

APPENDL: C

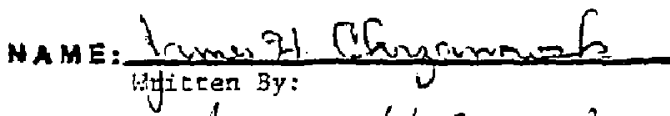

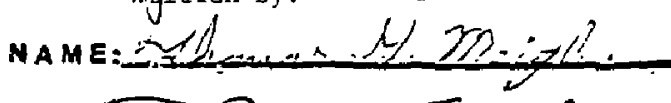

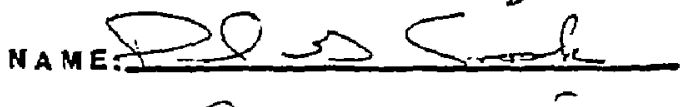

маме:

NAME:
DATE: $27-2 S-\varepsilon 6$

DATE: $U-\not L-S E$.

DATE: $11-11-E=5$

DАтE: $1 / / 20 / 86$

DATE:

\section{REVISIONS}

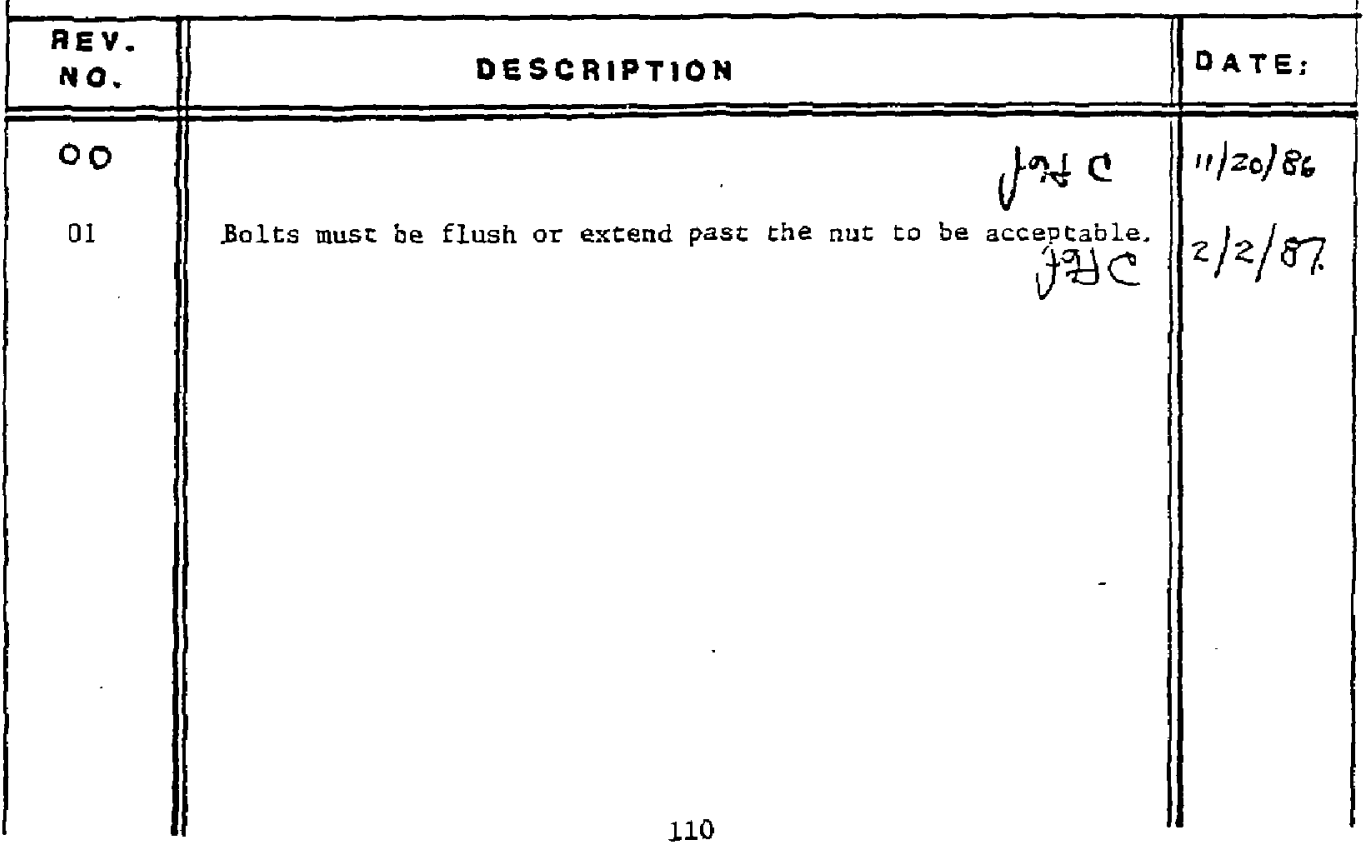




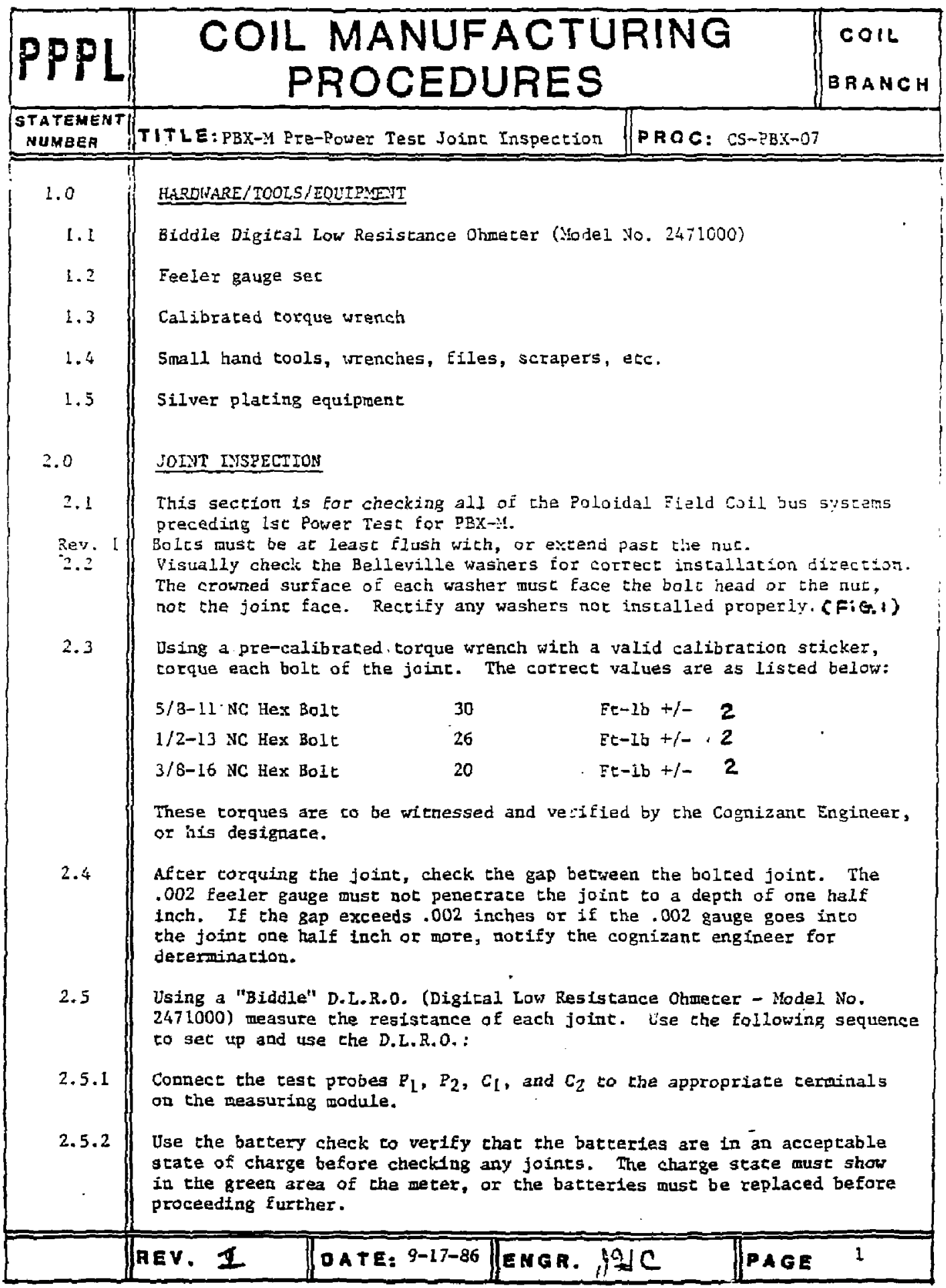




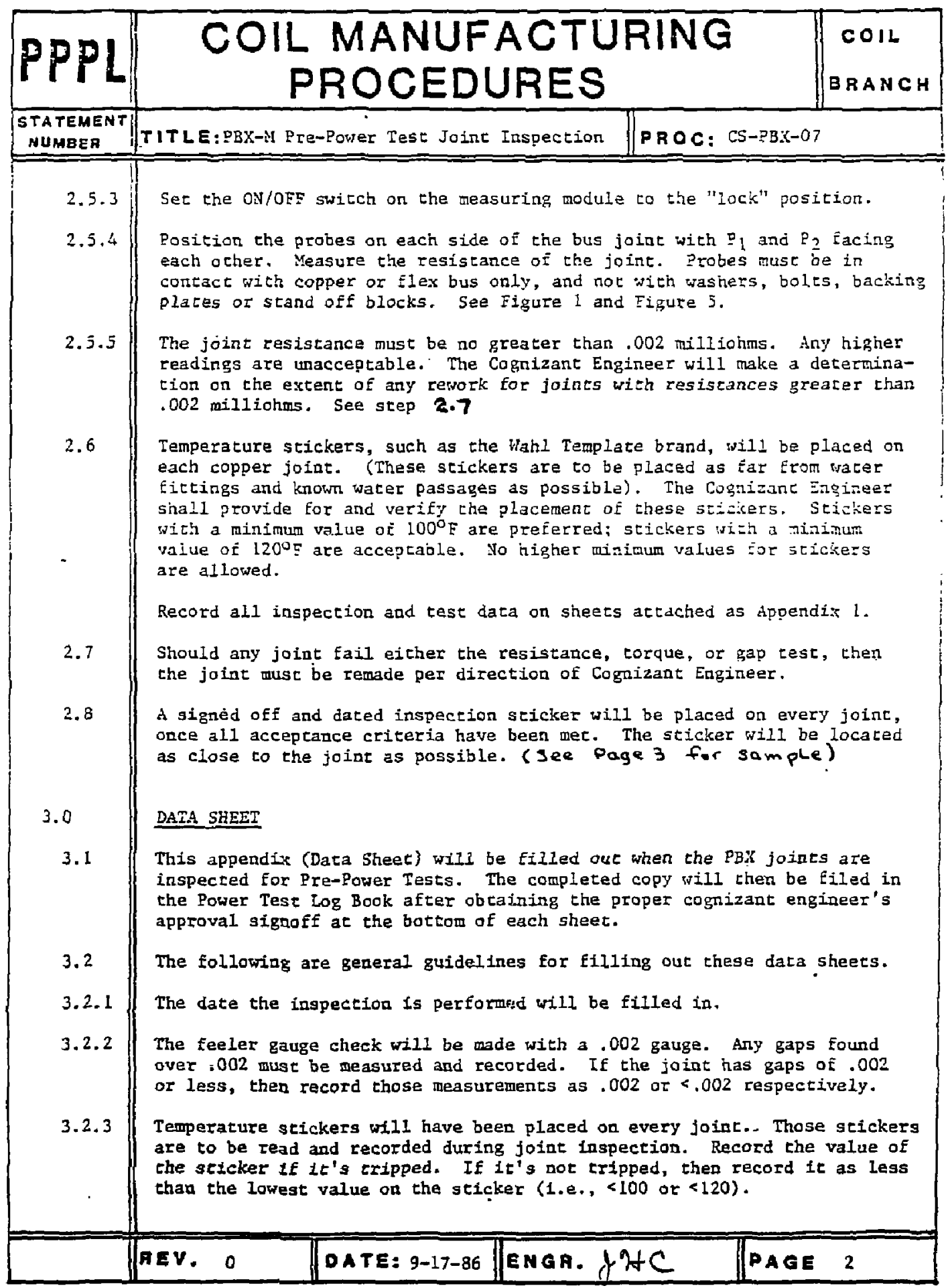




\section{PPPL \\ COIL MANUFACTURING PROCEDURES}

\section{STATEMENT \\ NUMBEF \\ TITLE: PBX-Y Pre-Power Test Joint Inspection \\ PAOC: $\quad$ CS-PBX-07}

3.2 .4

All resistance values will be recorded in millionms. Be sure that the scale is properly set before using the meter.

3.2 .5

Torques will be recorded in foor-pounds.

3.2 .6

When each joint inspection is complece, the cechrician inspecting the joint will sign off fin the space provided.

3.2 .7

The Cognizant Engineer or his designace will witness every joint inspection, verify all the recorded data then, if satisfied, will sign ot $\mathrm{t}$ al the data sheets.

QA $S I G I-O F F$

Cognizant Engineer will sign off on all daca sheecs. See Attachment 1. His signarure will verify the review of all cest data and che acceptabilicy of all bus joints for Eull power operation.

4.2 AII work has been perforged in accordance with this procedure.

COGNIZANT ENGINEER: DATE:

Cog. Designate $\because$. DATE:

\section{Imspection Stickeas}

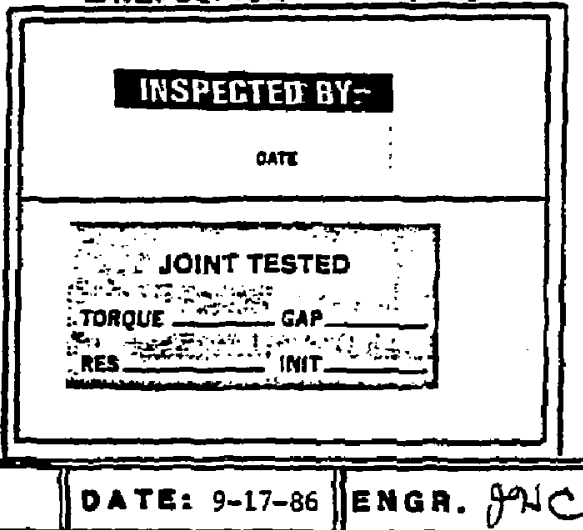

PAGE 


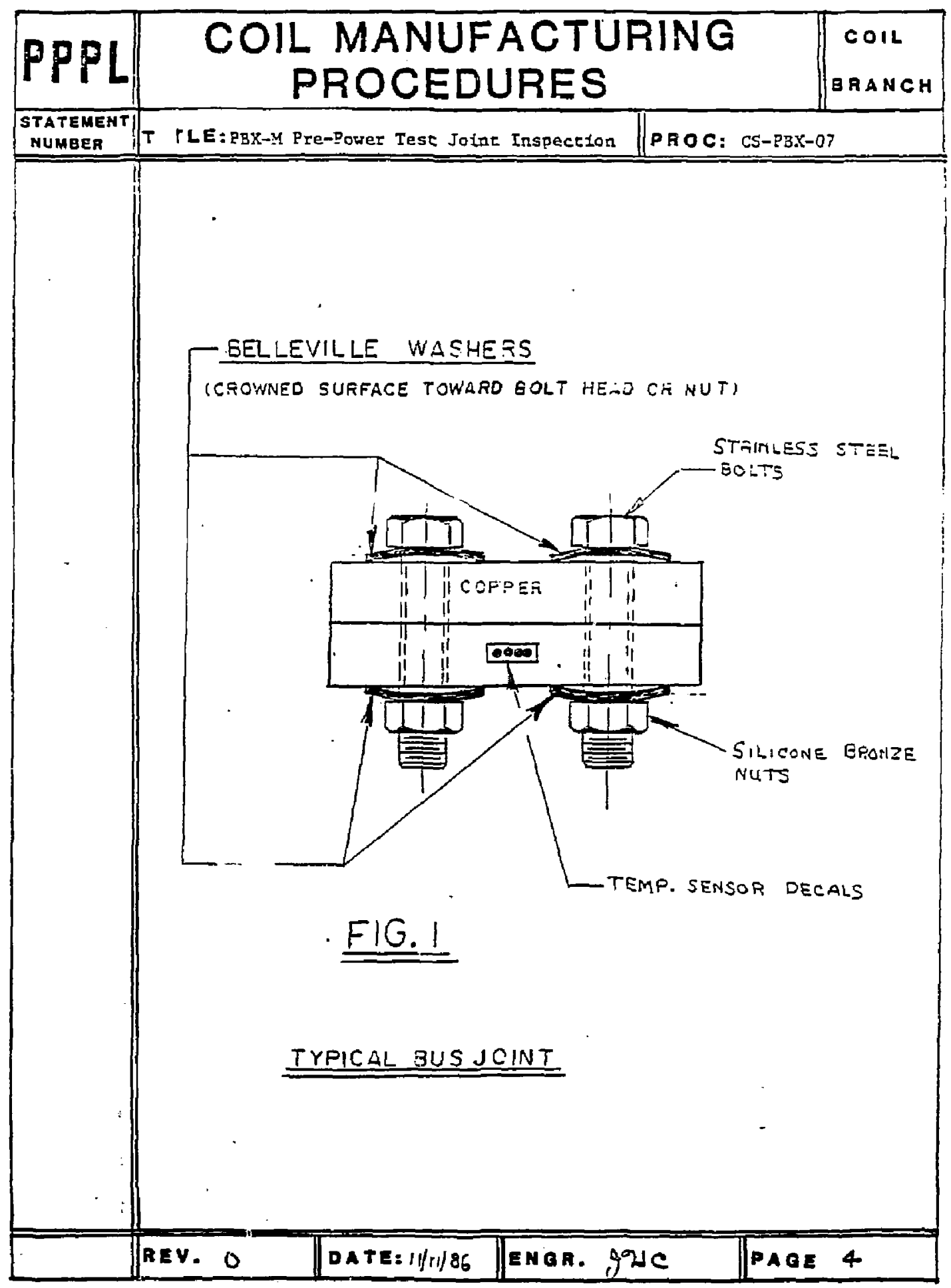




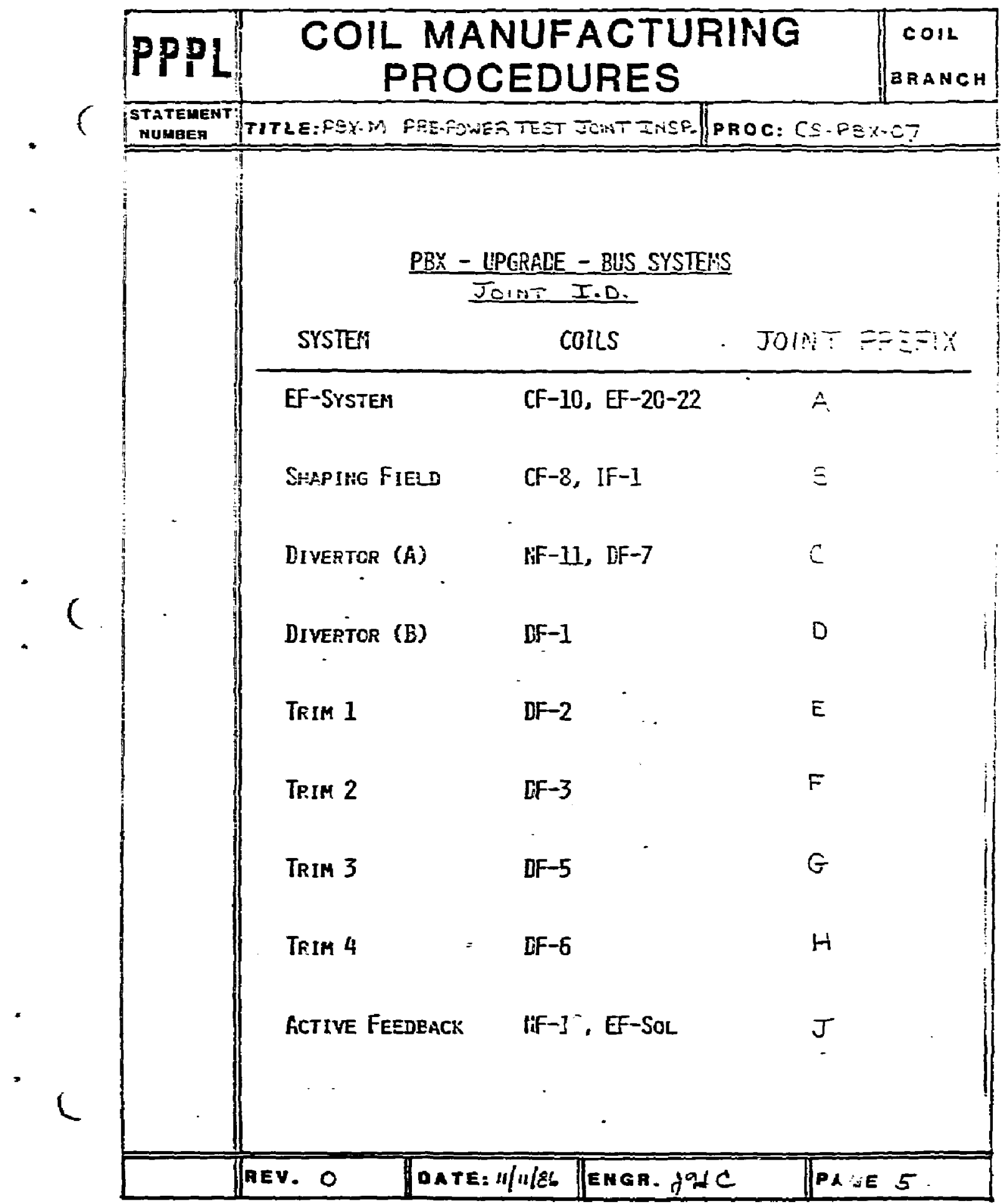


PBX BUS JOINT I IPECTION AND RETORK PROCEDURE

Systeg:

System Color:
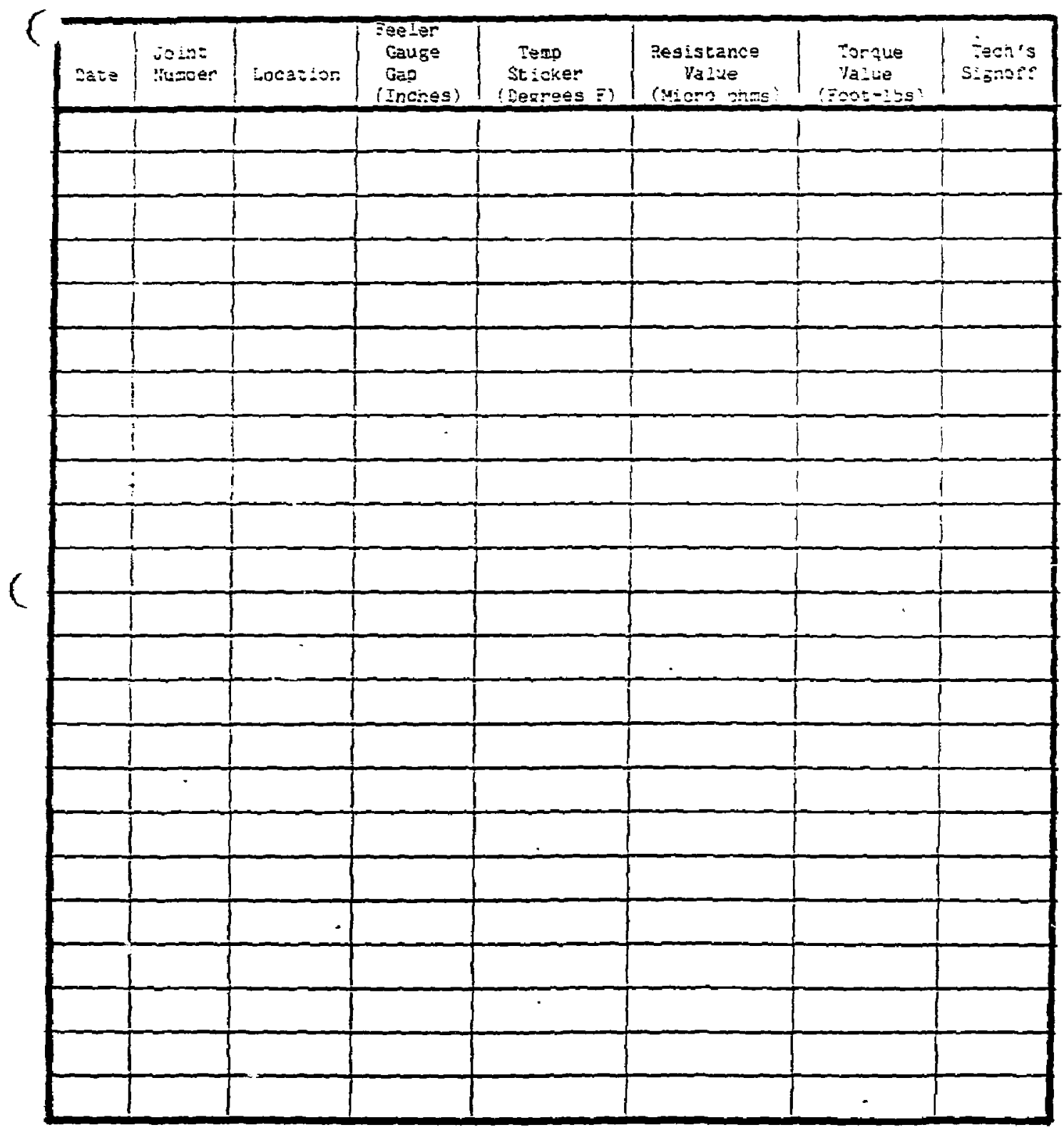

Cognizant Engineer Acceptance SIgnopt 
APPENDIX D

AEVIEW COMMITTEE ASSESSMENT AND PROJECT RESPONSE

i. Stress calculations for passive stabilizers.

P. Bonanos has checked the design conditions and talked with the designer, and is satisfied that reasonable standards were set.

2. Bracing of O.H. Leads.

After discovering in 1981 that it was unsupported, the $O H$ lead fair to the lower solenoid was braced with a stainless steel pillow inserted between the leads and the vacuum vessel. The pillow was then inflated with epoxy until it pressed the leads against the adjacent $O H$ coils. In 1982, we cut holes in the vacuum vessel wall, removed as much of the pillow as we could (unbeknownst, it had veered off to the side while being inserted) and used a glass bead/epoxy mix to accomplish what had been anticipated of the pillow. The upper lead pair was found to be braced and has not been touched.

On the same accasion in 1982 we drilled a hole to the foint where the leak had been found to be to insert a tube for catching the drip. This failed, but did have the subsequent benefit of reassuring us that we were dealing with a pinhole rather than the crack we had feared. That is, as long as all the insulation was there to impeds the water flow, it created enough back pressure to make the observable leak rate highly variable and sensitive to motion of the leads; with that impediment removed we found the leak rate to be quite constant. If the joint really were to have a crack in a loadbearing part, it is hard to see how it could have stayed so remarkably constant througt the ensuring years of operation.

In 1987 the solenoid lead was repaired by flowing epoxy through the water path. Subsequently we also reopened the leak in OH7U and repaired that as well.

3. Seismic analysis of PLT-PBX shield wall.

The wall does not meet current standards and we have submitted a job request to $f 1 x$ it. In 1980 E.I. Kaminsky and $E$. Nilsson analyzed the problem and presented their results and proposed solutions in two reports titled, respectively, "Design of PDX South Shielding Wall to Withstand Seismic Load" (August 1980) and "Revised Design of PDX South Shielding Hall etc." (October 1980). 
4. Minimizing exposure of personnel in PBX Control Room to radiation.

The basic safeguard is close monitoring of the i itegrated radiation dosage to the control room and djacent areas. When PBX was generating high radiation levels we kept a daily log and presenved the results in graphic form at the main control room entrance, and we will do this again. Awareness by the parties most directly concerned is the best way we know for minimizing exposure.

As is well known, the motivation for injecting $D^{\circ}$ into $D+$ is the higher beam power available and the better confinement typically ohserved with deuterium. Since these benefits will no doubt prove to be important or even essential for carrying out the PBX-M program, the associated radiation exposure will have to be taken as a given. But of course we will not exceed permitted exposure levels and either the mode of operation will be restricted or else more shielding w1ll have to be installed if these are approached. The Safety office will be kept fully aware of our operating schedule and will certainly continue to monitor the whole area as they have in the past.

5. Aceuracy of diagrams.

Peter Mathe generally agrees with specific oriticism John Murray has of the way the control systiem is presented in the SAD, but we do not believe the safety analysis to be at issue. Peter has a bookfull of documentation in varying levels of detail which we do not consider to belong in the SAD but which is available to anyone wishing to understand the full control system.

6. Single grounds on load disconnect switches.

Grounding only one side of the disconnect switches for the SF supplies allows an inactive coil system to be grounded without presenting an inductive short circuit to the remaining active coils. Having the switch go to an open circuit position leaves the coil floating electricaliy, which we consider to be a danger to coil insulation. The objection to grounding only one side is the potential personnel hazard it creates, should coupling to active circuits elsewhere result in dangerous voltages on the ungrounded terminals.

The PBX interlock system ensures that under normal operating conditions no coil is accessible wiless all systems are disabled Cause to violate the interlocks would of course be dealt with administrative'y, and partial grounding of any coil would not materially change the hazard level for someone in an area already deemed unsafe. Should PLT again be operated, or perhaps a successor machine, then this argument naturally fails. The most straight forward way to deal with the question would be to include in the procedure for transferring power supplies from one machine to the other a requirement to ground both sides of every coil in the inactive machine. Nevertheless, it should be realized that the problem is not a severe one, as the following rough calculations will show. 
Reducing the coupling problem to that between two coplanar rings separated by $R$, where $R$ is large compared to the ring size, one finds a mutual inductance given by:

$$
M_{12} \equiv N_{1} N_{2} A_{1} A_{2} R^{-3} \times 10^{-7} H . \quad \text { (mks) }
$$

where $A_{i}$ is the coil area.

The voltage appearing across coil (1) as a result of applying $v_{2}$ to coil (2) will be

$$
V_{1}=M_{12} / L_{2} V_{2}
$$

For PBX the coil systems with the highest NA are: EF $\left(1000 \mathrm{~m}^{2}\right)$, OH $(380$ $\mathrm{m}^{2}$ ) and $T_{4}\left(185 \mathrm{~m}^{2}\right)$. PLT has just the $\mathrm{OH}$ and $\mathrm{SF}$ coils, which have about the same $A$ as the corresponding PBX coils, but twice the turns. The PLT $\mathrm{OH}$ has the potential for inducing the highest voltages, its smaller NA product being more than of $f$ set by the higher voltage available (20 $k y$ is $5 \mathrm{kV})$. The results are as follows, where $R=15 \mathrm{~m}, \mathrm{NA}_{\mathrm{OH}}(P L T)=800 \mathrm{~m}^{2}$, $L_{\mathrm{OH}}=30 \mathrm{mth}$ and $V_{1}=20 \mathrm{kV}$.

$\begin{array}{ll}\mathrm{EF}(\mathrm{PBX}) & =16 \mathrm{v} \\ \mathrm{OH} & =6 \\ \mathrm{~T}_{4} & =3\end{array}$

Another voltage source would be plasma disruptions in PLT. A very unrealistic estimate can be easily made if one neglects the flux conserving properties of both the PLT OH and SF systems. For example, a 1MA plasma disappearing in $1 \mathrm{~ms}$ would induce $170 \mathrm{~V}$ in the PBX EF winding. However, it would also induce $150 \mathrm{kV}$ across the PLT OH coil, which could obviously not be sustained even if the coil weren't protected by spark gaps and a crowbar all set for (at present) $10 \mathrm{kV}$.

The conelusion is that having all PBX coils grounded on one side when they are in the disabled state wauld nat create life-threatening conditions even if PLT were to resume operation.

7. Emergency Stops.

A "qualified operator" should always be the one to make an emergency stop decision in the machine area, but since there are ES buttons in areas rewote from the machine, we agree to dropping that requirement.

8. Operating procedures.

Operating procedures developed for PDX and PEX will be expanded to cover PaX-M operations.

9. Laser power supply enclosures.

The enclosures are being constructed and will be protected in accordance with PPPL Safety Directives, and will be checked by the Safety office before being put into operation. 
10. TE hydraulic system.

The personnel hazard associated with a hydraulic system operated at 8000 psi is hard to assess. The amount of oil released from a line break would be small since the steel piping and the oil are relatively incompressible and the pump throughput is extremely low. (Also, the pump is automatically shut off when there is a sudden pressure drop in the system.) Furthermore, the only fallure modes we have encountered in the past 9 years are with leaky connections or split "mushrooms". The latter are completely inaccessible without dismantling the clamping structure; in the case of the former the oil emerges at atmospheric pressure. We suspect it would be difficult to create a break that would have oil emerging at high pressure, but not 1mpossible. We believe the hazard level to be sufficiently low so that no additional precautions are necessary.

11. Insulating breaks.

All control and monitoring devices in unsafe areas are carried into safe areas via either optical fibers or PPPL-approved safery breaks. 


\section{EXTERNAL DISTRIBUTION IN ADDITION TO, UC-20}

Or. Frgnk d. Pgolgni, Univ of wollongosg. AUSTRALIA Prot, M.\#. Brennon, Univ Sydney, Austral 1 A



Prot, I,R. Jones. Flindors Univ. AUSTRALIA

Prot, F. Cap, inst Theo Phys, AuSTRIA

Prot. M. Meindler, Institut tur Theoresisene Physik, Austria

M. Soossens, Astronomiseh Instituut, BELGILM

Ecole Royole Militaire, LaD de Phys Plasnas, BELGILA

Comission-Eurogean, Dg-XII Fusion Prog, BELGIUM

Drot, 7. Boueiqua, Laboratoriun voor Natuurkunda, BELGIUM

Dr, 2.H. Sakanaka, Instituto Fisica, BRAZli

Instituto De Pesouisas Espaciasi-tNPE, BRAZIL

Decuments office. Aromis Energy of Canada bimited, CAMADA

Jr. W,P. Bacnynsk, ipg Fechnologies, Inc., CANADA

Jr. H.M. Skarsgard, University of Saskatchewan, CANADA

jr. ᄀ. Barnars. University of Gritisn Columbia, CANADA



arar. 5.7. Sreen I vasan, University of Calgary, canada

s-ar, "aor 4 , jonnston, InRs-Energio, CANADA

Jr. C.R. James, Univ, ot Albarta, CANAOA

Jr. Sater Lukac. Komenskaho Unis. CZECHOSLOVAK1A

The : orarian, Cul ham Laberatory. ENGLAkD

the worarian, Ruthertord Aodeton Laboratory, ENGLAND

Mrs. 5.A. Huteninson, JET Library, ENGLAND

C. Wouttet, lab. de Physique das Miliaux lonises, GRANCE

1. Radet, CEN/CADARACHE - Bat 506, FRANCE

Univ, of loannina, Library of Physies Dapt. GAEECE

Dr. Tom Hual, Academy Bioliogranhic Sar.. Howg Kont

Preorint Liorary, Hungor i an Academy of Seiences, HavaRy

Dr. B. Dasgupta, Sana Inst af Nuel. Phys., INDIA

Jr. P. Kaw, Institure ror Plasma Researeh, INDIA

Dr. Philip Rosmau, Israel inst. Tech. ISRAEL

Liorjoian, Int'l Crr Theo Phys, ITALi

Prof, 5. Rostagni, Unis Oi Padova, ITALY

Miss Clelio De Palo, Assoc EURATOM-ENEA, ITALY

Biblioteca, Instituto di fisica del PIdsma, ITALY

Dr. H. Yangto, Toshipa Res a Dev, JAPAN

Prof, I, Kowakgai, Aronic Energy Ras. Instituto, JAPAN

Prof, Kyoji Nishikgwa, Univ of Hiroshima, JAPAN

Direc. Depr. Large Tokamak Res, JAERI, JAPAN

Prot. Satoshi Itoh, Kyushu Univarsity, JAPAN

Research Info Center, Negoyo University, JAPAN

Prof, S. Tonaka, Kyoto Inivarsity, JAPAN

Library. Kyoto University, JAPAN

Prof. Nobuyuki Inoue. University of Tokyo, JAPAN

S. MOrI, JAERI, JAPAN

Liorarian, Korea Advanced Energy Res, Institute, KCREA

Prof. D.t. Chai, Adv. Inst Sci \& Tech, KCREA

Prof. B.S. Liley, University of Haikato, NEW ZEALAND

I nstitute of Plasma Physics, PEOPLE'S REPUBLIC OF CHINA

Librorian, Instirute of Phys.. PEOPLE'S REPUBLIC OF OHINA

Library. Tsing Hus Uaivarsity. PEOPLE'S REPU⿴LIC OF CHINA
Z. Li, SOuthmest Inst. Physics, SEOPIE'S AEPJJLLIC OF CHINA Prot. J.A.C. Cagral, Inst Suder:or iecnico, PCRTUGal

Or. Oetavian Petrus, al I CU2A Univorsity, ZOMANIa Or. Jonan do Villiers, Fusion SPudies, AEC, SO AFRICA Prof. M.A. Melloorg, Universipy st Maral, SO AFRiCA

C.I.E.M.A.T., Fusion Div. B.orger, SPAIN

Or. Lennart Stentlo, Universicy of LMEA, SWEDEN

Library, Roya! Inst Tech, SHEDEN

Prof. Hons Wilhalmson, Cholmers Jniv Tech, SwEDEN

Centro Phys des Plasmas, Ecole Polytech Fad, 5wITZERLANO

Bibliotheek, Fom-last Voor PI Asma-fysica, THE NETHERLAtiOS

Dr. 0.0. Ryutou, Siborian Acad Sci. JSSR

Or. G.A. Eliseov, Kurshator institure, USSR

Or. V.A. Gluknikm, Inst Eloctropnysisul agoaratus, ISSR

Or. V.T. Tolak, nst, Phys. Tecn. JssR

Or, L.M. Kouriznnymm, inst tute jen. JnYsics, bSSR

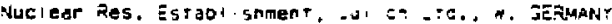

Biatiormex, Inst. Eur S usmatorschung, M. GeRMANY

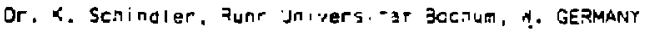

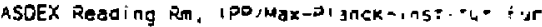

Plasmoonysuk, A. JETMANY

Librarian, Max-planex inst, rur. A. JëRMANY

Prot, R.K. Janey, Ins: Phys. ruGusidviz 